Andrews University

Digital Commons @ Andrews University

1995

\title{
An Analysis of the Relationship Between Nurturing Spousal Friendship and Marital Quality
}

Cherryl Anne Galley

Andrews University

Follow this and additional works at: https://digitalcommons.andrews.edu/dissertations

Part of the Family, Life Course, and Society Commons, and the Social Psychology Commons

\section{Recommended Citation}

Galley, Cherryl Anne, "An Analysis of the Relationship Between Nurturing Spousal Friendship and Marital Quality" (1995). Dissertations. 386.

https://digitalcommons.andrews.edu/dissertations/386

https://dx.doi.org/10.32597/dissertations/386

This Dissertation is brought to you for free and open access by the Graduate Research at Digital Commons @ Andrews University. It has been accepted for inclusion in Dissertations by an authorized administrator of Digital Commons@ Andrews University. For more information, please contact repository@andrews.edu. 


\section{Andrews \$university}

Seek Knowledge. Affirm Faith. Change the World.

Thank you for your interest in the

\section{Andrews University Digital Library of Dissertations and Theses.}

Please honor the copyright of this document by not duplicating or distributing additional copies in any form without the author's express written permission. Thanks for your cooperation. 


\section{INTORMATION TO USERS}

This mamuscript has been reprochuced from the microfilm master. UMI films the text directly from the original or copy submitted. Thus, some thesis and dissertation copies are in typewriter face, while others may be from any type of computer printer.

The quality of this reproduction is depeadent upon the quality of the cops subuitted. Broken or indistinct print, colored or poor quality illustrations and photographs, print bleedthrough, substandard margins, and improper aligment can adversely affect reproduction.

In the unlikely. event that the author did not send UMI a complete mamuscript and there are missing pages, these will be noted. Also, if unauthorized copyright material had to be removed, a note will indicate the deletion.

Oversize materials (e.gn, maps, drawings, charts) are reproduced by sectioning the original, beginning at the upper left-hand comer and contiming from left to right in equal sections with small overlaps. Each original is also photographed in one exposure and is included in reduced form at the back of the book.

Photographs inchuded in the original mamuseript bave been reproduced xerographically in this copy. Higher quality $6^{\prime \prime} \times 9^{\prime \prime}$ black and white photographic prints are available for any photographs or illustrations appearing in this copy for an additional charge. Contact UMI directly to order.

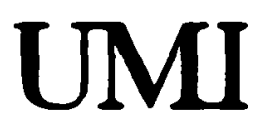

A Bell \& Howell intomation Company 300 North Zeeb Road. Ann Asbor. MI 48106-1346 USA

313:761-4700 800:521-0600 
Reproduced with permission of the copyright owner. Further reproduction prohibited without permission. 


\title{
Andrews University \\ School of Education
}

\section{AN ANALYSIS OF THE RELATIONSHIP BETWEEN NURTURING SPOUSAL FRIENDSHIP \\ AND MARITAL QUALITY}

\author{
A Dissertation \\ Presented in Partial Fulfillment \\ of the Requirements for the Degree \\ Doctor of Philosophy
}

by

Cherryl Anne Galley

September 1995 
UMI Number: 9613221

Copyright 1995 by

Galley. Cherryl Anne

all rights reserved.

UII Microform 9613221

Copyright 1996, by UII Company. All rights reserved.

This aicrofora edition is protected against unauthorized

copying under Title 17 . United states Code.

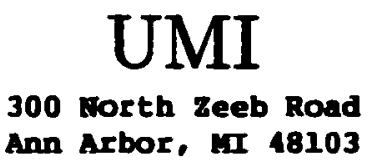

Reproduced with permission of the copyright owner. Further reproduction prohibited without permission. 
Copyright by Cherryl A. Galley 1995

All Rights Reserved

Reproduced with permission of the copyright owner. Further reproduction prohibited without permission. 


\section{AN ANALYSIS OF THE RELATIONSHIP BETWEEN \\ NURTURING SPOUSAI FRIENDSHIP \\ AND MARITAL QUALITY}

A dissertation

presented in partial fulfillment

of the requirements for the degree

Doctor of Philosophy

by

Cherryl Anne Galley

APPROVAL BY THE COMMITTEE :
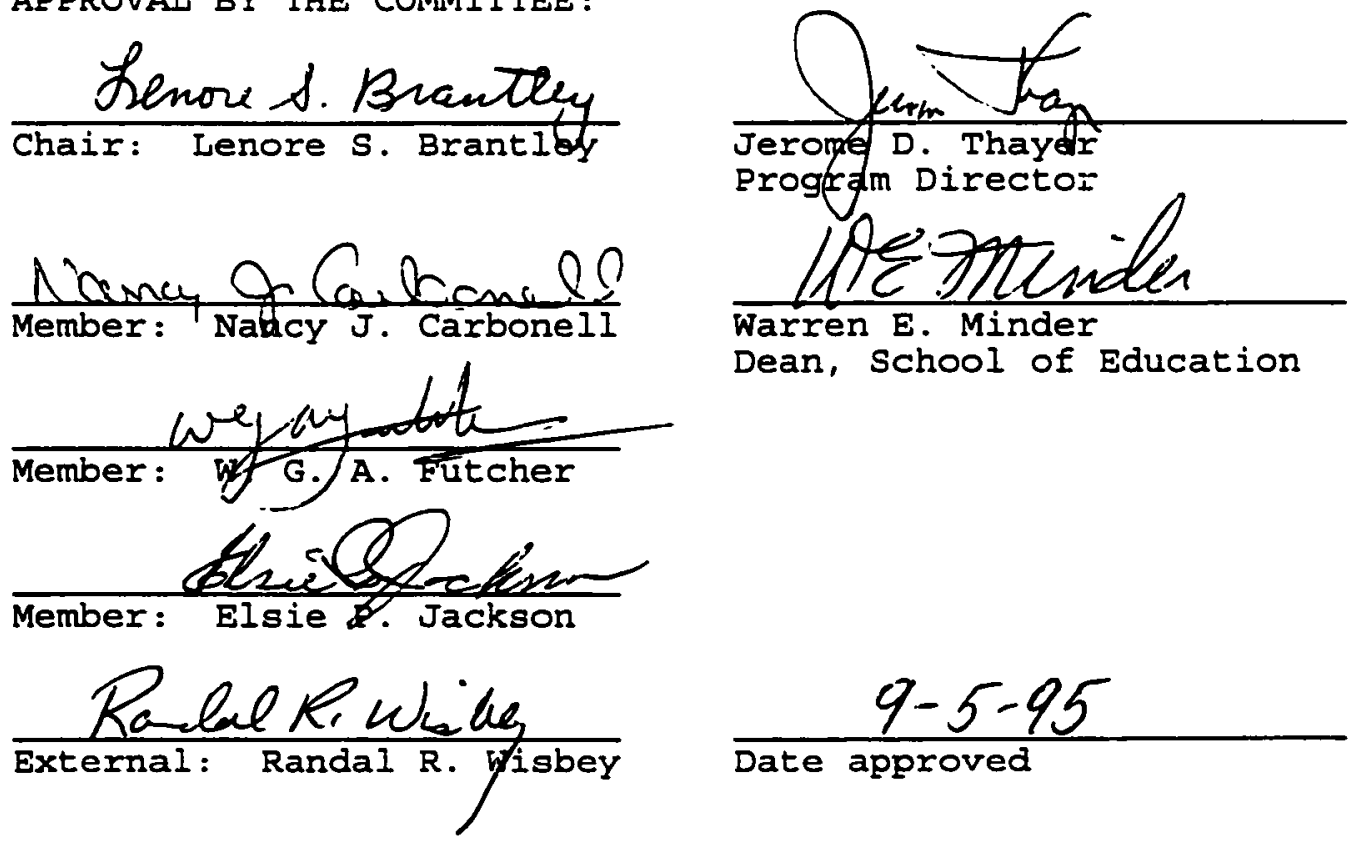
To my mother, Mrs. Anne Ebron Galley, who gave me an immeasurable supply of love, support, and inspiration

To my brother, Charles Eugene Galley, Jr., for his love and encouragement

In loving memory of my father, Charles Eugene Galley, Sr., and my brother.

Carleton John Galley 
TABLE OF CONTHITS

LIST OF TABLES . . . . . . . . . . . . . . . . . vii

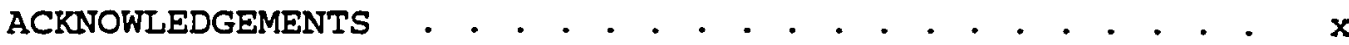

Chapter

I. INTRODUCTION . . . . . . . . . . . . . . . . . I

Statement of the Problem . . . . . . . . . . 4

Purpose of the Study . . . . . . . . . . . . . 6

Research Questions . . . . . . . . . . . . . . 6

Hypothesis to Be Examined . . . . . . . . . 6

Theoretical Frameworks . . . . . . . . . . . . 7

Alfred Adler. . . . . . . . . . . . . . . 7

Albert Bandura . . . . . . . . . . . . . . 8

Murray Bowen . . . . . . . . . . . . . . . . 9

Erik Erikson . . . . . . . . . . . . . . . 10

Abraham Maslow................ . . 11

Significance of the study . . . . . . . . . . . 12

Definition of Terms . . . . . . . . . . . . . . 14

Limitation of the study . . . . . . . . . . . . 15

Delimitations of the study . . . . . . . . . . 15

Organization of the study . . . . . . . . . . . 16

II. REVIEW OF RELATED LITERATURE . . . . . . . . . . . 18

Basic Need for Friends . . . . . . . . . . . 18

Development of Friendship . . . . . . . 20

Friendship in Childhood . . . . . . . . . . 23

Friendship in Adolescence . . . . . . . . . 27

Friendship in Young and Middle Adulthood . . 29

Gender-related friendship issues . . . . . 32

Friendship in Later Life . . . . . . . . . . 36

Self As Friend/Self Development . . . . . . . . 39

Value of Nurturing Spousal Friendship. . . . . 44

Parental Influence . . . . . . . . . . . . . 44

Positive Indications. . . . . . . . . . . . 47

Marital Quality . . . . . . . . . . . . . . 50

Summary . . . . . . . . . . . . . . . . . 54 
III. METHODOLOGY . . . . . . . . . . . . . . 56

Research Design . . . . . . . . . . . . . . . 56

Sample and Selection Procedures. . . . . . . . 57

Instrumentation . . . . . . . . . . . . . . . . 57

Demographic Questionnaire . . . . . . . . 58

Dyadic Adjustment Scale . . . . . . . . . . 58

Caring Relationship Inventory . . . . . . . 61

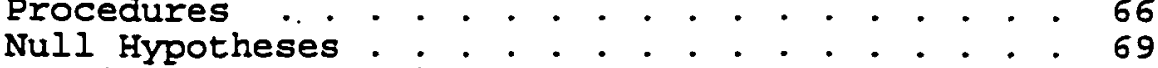

statistical Analysis . . . . . . . . . . . . 72

IV. RESULTS . . . . . . . . . . . . . . . . . 74

Introduction . . . . . . . . . . . . . . . . . 74

Demographic Data . . . . . . . . . . . . . 74

Basic Data . . . . . . . . . . . . . . . 77

Data Analysis. . . . . . . . . . . . . . . . . 81

Hypothesis 1. . . . . . . . . . . . . 81

hiyputhesis la . . . . . . . . . . . . . . . 83

Hypothesis $1 b$. . . . . . . . . . . . . . 84

Hypothesis 2. . . . . . . . . . . . . . . . 85

Hypothesis $2 a$. . . . . . . . . . . . . . . 86

Hypothesis $2 b$. . . . . . . . . . . . . . 87

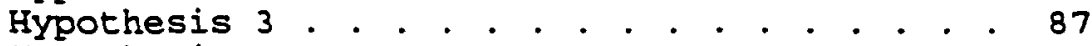

Hypothesis $3 a$. . . . . . . . . . . . . . . 88

Hypothesis 3b . . . . . . . . . . . . 89

Hypothesis 4 . . . . . . . . . . . . . . 90

Hypothesis 4 a . . . . . . . . . . . . . . . 92

Hypothesis $4 \mathrm{~b}$. . . . . . . . . . . . . . . 93

Hypothesis 5. . . . . . . . . . . . . . . . 94

Hypothesis $5 a$. . . . . . . . . . . . . 95

Hypothesis $5 b$. . . . . . . . . . . . 95

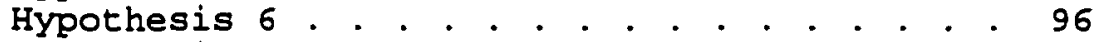

Hypothesis $6 a$. . . . . . . . . . . . . . . 97

Hypothesis $6 \mathrm{~b}$. . . . . . . . . . . . . . 98

Hypothesis 7 . . . . . . . . . . . . . 99

Hypothesis $7 a$. . . . . . . . . . . . . 100

Hypothesis $7 b$. . . . . . . . . . . . . 101

Hypothesis 8... . . . . . . . . . . . 101

Hypothesis 8a . . . . . . . . . . . . . . . 103

Hypothesis $8 b$. . . . . . . . . . . . 103

Hypothesis 9... . . . . . . . . . . . . 104

Hypothesis $9 a$. . . . . . . . . . . . . . . 105

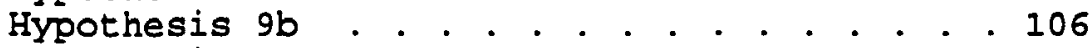

Hypothesis 10 . . . . . . . . . . . . . . . 107

Hypothesis 10a... . . . . . . . . . . 108

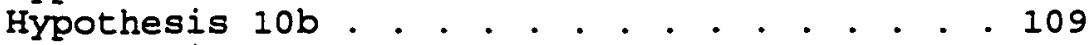

Hypothesis 11 . . . . . . . . . . . . . . . 109

Hypothesis 11 . . . . . . . . . . . . . 110

Hypothesis 11b. . . . . . . . . . . . . 112

$\mathbf{V}$ 


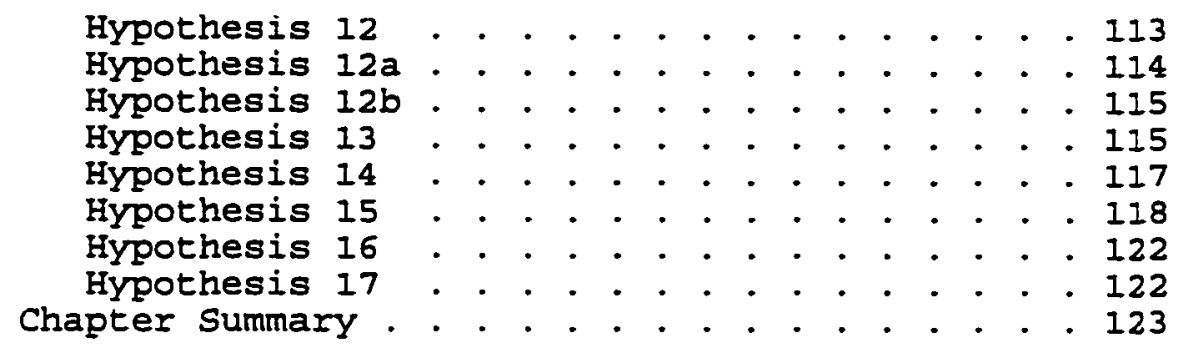

V. SUMMARY, IMPLICATIONS, CONCLUSIONS,

AND RECOMMENDATIONS . . . . . . . . . . . . . . . 125

Summary . . • . . . . . . . . . . . . . . . 125

Statement of the Problem . . . . . . . . . 125

Purpose of the study . . . . . . . . . . . 125

Methodology . . . . . . . . . . . . . . . 126

Subjects . . . . . . . . . . . . . . . . 126

Instrumentation . . . . . . . . . . . . . 127

Statistical Analysis . . . . . . . . . . . 128

Implications . . . . . . . . . . . . . . . . . 128

Conclusions . . . . . . . . . . . . . . . . . . 137

Recommendations . . . . . . . . . . . . . 139

Practice . . . . . . . . . . . . . . . 139

Research . . . . . . . . . . . . . . 140

APPENDIX . . . . . . . . . . . . . . . . . . . . . 143
A. CORRESPONDENCE
144
B. INSTRUMENTATION . . . . . . . . . . . . . . . . 156
C. DATA ..................... . . . 160

REFERENCE LIST . . . . . . . . . . . . . . . . . . . 166

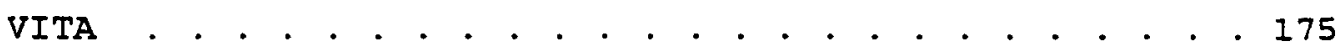

vi

Reproduced with permission of the copyright owner. Further reproduction prohibited without permission. 


\section{IIST OF TABLES}

1. Demographic Distribution of Sample . . . . . . 75

2. Means, Standard Deviations, and Score Ranges of Dyadic Adjustment Scale Variables. . . . . . . 78

3. Summary Scores for the DAS . . . . . . . . . . . 78

4. Means, Standard Deviations, and Score Ranges of Caring Relationship Inventory Variables... . 80

5. Means and Standard Deviations of Married, Troubled and Divorced Couples . . . . . . . . . 80

6. Correlation Matrix for CRI/Other on DAS . . . . . . 82

7. Correlation Matrix for CRI/Ideal on DAS . . . . . 82

8. Best Subset for Dyadic Consensus on CRI/Other . . . 83

9. Best Subset for Dyadic Consensus on CRI/Other for Husbands . . . . . . . . . . . . . . . . . . . 84

10. Best Subset for Dyadic Consensus on CRI/Other for Wives . . . . . . . . . . . . . . . . 85

11. Best Subset for Dyadic Satisfaction on CRI/Other . . . . . . . . . . . . . . . . . . 86

12. Best Subset for Dyadic Satisfaction on CRI/Other for Husbands . . . . . . . . . . . . 87

13. Best Subset for Dyadic Satisfaction on CRI/Other for Wives . . . . . . . . . . . . . . . 88

14. Best Subset for Affectional Expression on CRI/Other... . . . . . . . . . . . . . . . . 89

15. Best Subset for CRI/Other on Affectional Expression for Husbands . . . . . . . . . . . . 90

16. Best Subset for Affectional Expression on CRI/Other for Wives . . . . . . . . . . . . . 91

vii 
17. Best Subset for Dyadic Cohesion on CRI/Other . . . 91

18. Best Subset for Dyadic Cohesion on CRI/Other for Husbands . . . . . . . . . . . . . . 92

19. Best Subset for Dyadic Cohesion on CRI/Other for Wives . . . . . . . . . . . . . . 93

20. Best Subset for Dyadic Consensus on CRI/Ideal . . . . . . . . . . . . . . . . . . . . 94

21. Best Subset for Dyadic Consensus on CRI/Ideal for Husbands . . . . . . . . . . . . . . 95

22. Best Subset for Dyadic Consensus on CRI/Ideal for wives . . . . . . . . . . . . . . . 96

23. Best Subset for Dyadic Satisfaction on CRI/Ideal. . . . . . . . . . . . . . . . . . 97

24. Best Subset for Dyadic Satisfaction on CRI/Ideal for Husbands . . . . . . . . . . . . 98

25. Best Subset for Dyadic Satisfaction on CRI/Ideal for Wives . . . . . . . . . . . . . . 99

26. Best Subset for Affectional Expression on CRI/Ideal . . . . . . . . . . . . . . . . . 100

27. Best Subset for Affectional Expression on CRI/Ideal for Husbands . . . . . . . . . . . . 101

28. Best Subset for Affectional Expression on CRI/Ideal for Wives... . . . . . . . . . . . . 102

29. Best Subset for Dyadic Cohesion on CRI/Ideal . . . 102

30. Best Subset for Dyadic Cohesion on CRI/Ideal for Husbands . . . . . . . . . . . . 104

31. Best Subset for Dyadic Cohesion on CRI/Ideal for wives . . . . . . . . . . . . . 104

32. Best Subset for DAS Total on CRI/Other . . . . . 105

33. Best subset for DAS Total on CRI/Other

for Husbands . . . . . . . . . . . . . . . . 106

34. Best subset for DAS Total on CRI/Other for Wives . . . . . . . . . . . . . . . . . . . 107

35. Best subset for DAS Total on CRI/Ideal . . . . . 108 viii 
36. Best Subset for DAS Tota! on CRI/Ideal

for Husbands... . . . . . . . . . . . . 109

37. Best Subset for DAS Total on CRI/Ideal

for Wives . . . . . . . . . . . . . . . . . 110

38. Best Subset for DAS on Friendship Scale of CRI/Other . . . . . . . . . . . . . . . . . 111

39. Best Subset for DAS on Friendship Scale of CRI/Other for Husbands . . . . . . . . . . . 111

40. Best Subset for DAS on Friendship Scale of CRI/Other for Wives . . . . . . . . . . . . . 112

41. Best Subset for DAS on Friendship Scale of CRI/Ideal . . . . . . . . . . . . . . . . . 113

42. Best Subset for DAS on Friendship Scale of CRI/Ideal for Husbands . . . . . . . . . . . . 114

43. Best Subset for DAS on Friendship Scale of CRI/Ideal for Wives . . . . . . . . . . . . . . II5

44. Canonical Correlation for Hypothesis 13 . . . . . 117

45. Canonical Correlation for Hypothesis 15-First Function. . . . . . . . . . . . . . . . . 119

46. Canonical Correlation for Hypothesis 15-Second Function ................. 119

47. Canonical Correlation for Hypothesis 15-Third Function. . . . . . . . . . . . . . . 120

48. Canonical Correlation for Hypothesis 15-Fourth Function . . . . . . . . . . . . . 120

49. Summary Findings--Hypotheses 1 Through 10 . . . . . . . . . . . . . . . . . . . . 129 


\section{ACKNOWLEDGEMENTS}

All praise is first given to God for granting strength, understanding, and perseverance.

It is with extreme gratitude that I thank each member of my committee for the patience, guidance, and support provided throughout this project: Dr. Lenore Brantley, Chairperson; Dr. Nancy Carbonell; Dr. Wilfred Futcher; Dr. Elsie Jackson; and Dr. Randal Wisbey. It has been a blessing to work with each of you.

I am very grateful to all the pastors and their congregations who were so willing to work with me in gathering the data for this project.

Special thanks to all my family members and many Eriends for the prayers and encouragement. 


\section{ABSTRACT \\ AN ANALYSIS OF THE RELATIONSHIP BETWEEN \\ NURTURING SPOUSAL FRIENDSHIP \\ AND MARITAL QUALITY}

by

Cherryl Anne Galley

Chair: Lenore S. Brantley 


\section{ABSTRACT OF GRADUATE STUDENT RESEARCH \\ Dissertation \\ Andrews University \\ School of Education}

Title: AN ANALYSIS OF THE RELATIONSHIP BETWEEN NURTURING SPOUSAI FRIENDSHIP AND MARITAL QUALITY

Name of researcher: Cherryl A. Galley

Name and degree of faculty chair: Lenore $s$. Brantley. Ed.D.

Date completed: September 1995

Problem

Limited research has addressed the value of friendship between husbands and wives to the health and well-being of their marital relationships. The present study evaluated the relationship between spousal friendship and maritsl quality. It made a gender analysis as well.

\section{Method}

The Dyadic Adjustment Scale, the Caring Relationship Inventory, and a demographic questionnaire were mailed to 500 couples ( 1000 married individuals). One or both spouses were members of a Lutheran or a Seventh-day Adventist church in the Columbus, Ohio, area. The sample 
consisted of 176 married individuals who volunteered to participate anonymously in the research project. A total of 69 couples (matched husbands and wives) were identified in the sample.

Data were analyzed by multiple linear regression and canonical correlation analyses.

\section{Results}

Spousal Eriendship combined with affection were found to relate positively with marital quality for the entire sample. This trend was stronger for wives than for husbands. Of the variables that composed marital adjustment, (a) Friendship and Affection related positively to Dyadic Consensus (agreement) and Dyadic Satisfaction (commitment to the marriage), (b) Friendship and Eros related positively to Affectional Expression (affection and romance), and (c) Friendship alone related positively to Dyadic Cohesion (shared interests and activities).

\section{Conclusions}

The findings in this study suggest that spousal friendship combined with affection is quite important for wives. When they sense that they are respected by their husbands, share common interests with them, and feel loved by them in spite of faults, wives have a strong sense of fulfillment in their marital relationships. Husbands tend to relate affection with marital quality, with a possibility of Exiendship being equally as important. 
Research recommendations include development of an instrument that focuses specifically on friendship in intimate relationships, and replication of the study with a more diverse sample to observe influences of ethnicity, socioeconomic status, and education level. 
CHAPTER I

\section{INTRODUCTION}

The word friendship, when spoken or read, hardly raises any questions, but would more likely initiate feelings of warm relationships, cherished memories, fun times, and enjoyable shared experiences. Underlying these feelings could be the assurance of another's trust, acceptance of and belief in one's self as well as others, the willingness to be vulnerable to some extent with at least one other person, and the capability to give and receive. In other cases, the word friendship may invoke feelings of loneliness and isolation complete with kaleidoscopic flashbacks of painful events, unexpressed hurt, and a still-to-be-filled inner void for connectedness.

Regardless of the type of friend or the nature of the friendship, friends and friendships are universal. They transcend familial, ethnic, cultural, and national boundaries, and are not necessarily restricted by age, gender, or socioecnnomic level.

Individual definitions of friends and friendships could possibly vary as much as the types of friends one 
has. Johnson and Troll (1994) suggest that it is quite difficult to define friendship in a simplistic way. Technically, a friend is defined as (1) "one attached to another by affection or esteem," and as (2) "a favored companion;" while friendship is defined as (1) "the state of being friends," and as (2) "the quality or state of being friendly" (Webster's Ninth New Collegiate Dictionary, 1990, p. 493). Shain (1978) describes friends as those who help others become more of themselves, more of who they are actualiy and fully meant to be. Friends tend to enjoy each other's company, are delighted to share the excitement of something interesting to them, enjoy doing things together, are happy to do special things that the other appreciates, and can continue to appreciate each other even under unfavorable circumstances or in difficult situations.

Bustanoby (1993) states quite adamantly that true friendship should be about something, such as a common interest. Additionally, Eriendship itself should not be confused with companionship, although companions have the potential of becoming friends. Friendship has to do with appreciation of qualities and not with need. He continues by stating that couples often have difficulty finding friendship in marriage, therefore, they look for it outside of their marriages.

When two pesple are bound together as closely as they are in a marriage, it seems that their friendship would possibly be a key factor in retaining mutual respect, in 
magnifying commitment, in working through difficulties, in developing other aspects of love, in accepting differences, in strengthening trust, in building interpersonal understanding, and in maintaining a constantly growing relationship. The previous descriptors of friends and friendship suggest an action-oriented component in the friendship bond. Some type of work or activity is insinuated in order to maintain the attachment and in order to continue the state of being friends. This suggests, then, that within this activity concept, some actions would be necessarily required from both spouses in order to successfully sustain their marital friendship.

Just as the Edenic marriage was the beginning of a new world and generations to come, every marital relationship today is the beginning of a new home that will potentially have inextricable influences upon its children, its children's children, the community, and ultimately the nation. When that primary nucleus is in constant turmoil, confusion is proliferated. When that core relationship is enjoyable and attractive, happiness and balance become the pattern.

The cultivation of friendship between a husband and a wife, then, can be thought of as a method of preventive marital care. From a Christian perspective, the first part of Prov. 17:17 states that "a friend loveth at all times." This concept, when applied to the marital relationship, establishes love as the basis for all interactions as 
partners view each other Erom a friendship perspective rather than an ownership perspective.

Many people can be married, but when they are not best or at least good friends, one or both of them could be quite lonely, unhappy, unfulfilled, and/or isolated in that relationship, regardless of how long it remains technically intact. As one author states:

The most basic principle in the establishing of a happy home is love, but love must have its beginning and foundation in Eriendship. This Eriendship or mutual esteem is the result of acquaintance and association, and develops into a unity of mind and interests leading to sympathy and helpfulness. (Bunch, 1958, p. 17)

\section{Statement of the Problem}

Research is well represented on marital growth and enrichment (Malcolm, 1992; Wright, 1994), adjustment (Fisiloglu \& Lorenzetti, 1994; Hansen, 1987), happiness (Antill \& Cotton, 1987; Honeycutt, 1993; Lavee, 1987), satisfaction (Aida \& Falbo, 1991; Bell, Daly, \& Gonzalez, 1987; Fincham, Garnier, Gano-Phillips, \& Osborne, 1995; Fowers \& Olson, 1993; Langis, Sabourin, Lussier, \& Mathieu, 1994), quality (Broom, 1994; Kenny \& Acitelli, 1994;

Truant, 1994; Tucker \& Aron, 1993), stability (Adams \& Sprenkle, 1990; Heaton \& Pratt, 1990), and divorce prevention (Moxley, Eggeman, \& Schumm, 1987; Weiner-Davis, 1992). However, research focusing specifically on friendship or the nurturing of Eriendship between spouses as it relates to marital quality, adjustment, or happiness 
is virtually non-existent. Grotstein (1989) makes this

clear by stating the following:

What has never been sufficiently explicated in the psychoanalytic Iiterature, however, is the importance of friendship, not only the friendship between ourselves and those whom we nominally call friends, but also, and especially, the nature of friendship in intimate relations, such as between lovers, mothers and infants, children and parents, siblings, exlovers, and with all other attachments of the close type. (p. 5)

Six years prior to Grotstein's comments, Tesch (1983)

stated that research focusing on Eriendship "has the potential to provide greater understanding of life-span social development than does the study of any other relationship" (p. 266).

Lewis (1988) suggests that friendship is essentially ignored in the modern world. He goes on to assert that "few value it because few experience it" (p. 58).

Perhaps the paucity of research on marital friendship is explicitly expressed by Shain (1978) who states, "Our society isn't very big on friendship, realiy. . . . Friendship in our society is still very much an underdeveloped resource" (pp. 84, 85). Apparently this condition is still prevalent within our society some 16 years later.

The majority of existing research on friendship appears to be primarily directed toward children, adolescents, and the elderly (Tesch, 1983). Several studies do, however, suggest that spousal friendship can be a critical factor in strengthening the quality of a 
marriage (Fenell, 1993; Lauer \& Lauer, 1986; Lauer, Lauer, \& Kerr, 1990), and thus is a topic worthy of further investigation.

\section{Purpose of the study}

The purpose of this study is twofold: (1) to investigate the relationship between spousal friendship and marital quality, and (2) to investigate gender differences in the relationship between spousal friendship and marital quality.

\section{Research Questions}

This research project examined the following questions :

1. Is there any relationship between spousal friendship and marital adjustment?

2. Does the relationship between spousal friendship and marital adjustment differ for husbands and wives?

\section{Hypothesis to Be Examined}

The general hypothesis upon which this research study is based is that a positive relationship exists between nurturing husband/wife friendship and marital quality. The specific hypothesis is as follows:

1. There will be a positive correlation between spousal friendship and marital quality.

Sub-hypotheses investigate gender differences in the relationship between marital adjustment and spousal 
Eriendship. The null hypotheses for this study are presented in chapter 3 .

\title{
Theoretical Frameworics
}

This study draws from several approaches as described in the following paragraphs.

\begin{abstract}
Alfred Adler
Adler's theory of Individual Psychology (Schultz \& Schultz, 1994) takes into consideration the value of each person as a unique individual. He describes people as having natural feelings of inferiority from which they all are motivated to compensate and strive for increasingly higher development. As humans reach for the ultimate goal of superiority, they also have an innate need to be cooperative with others as they work toward reaching their social and personal goals. People interact with others based on their own style of life or the character structure through which they strive for perfection. The four styles of Iife are: (1) Dominate-having a ruling nature, (2) Getting--being dependent on others, (3) Avoiding--not facing life problems, and (4) Socially Useful--cooperating with others and responding to their needs. He concludes that the creation of one's style of life is greatly influenced by one's birth order. That is, within the same home, siblings have differing social environments from which develop varying behavioral patterns and world perspectives.
\end{abstract}


This theory reinforces the following concepts: every individual is unique, all humans have a basic need for positive interrelationships with others, and every person will interact with others primarily from one of four lifestyle patterns. I consider the unique individuality that Adler discusses to be a vital human quality that should not be relinquished when one enters marriage. Given that humans need bonding with others regardless of their basic approach to relationships, a question follows. Can the nurturing of friendship with one's spouse help fulfill this basic need and simultaneously strengthen the quality of their marriage?

\section{Albert Bandura}

Bandura's (Schultz \& Schultz, 1994) Observational or Social Learning Theory purports that new responses or behaviors can be learned indirectly by observing behariors modeled by others. Also known as vicarious reinforcement, existing responses are strengthened or new responses can be learned through a visual experience as opposed to an actual personal or direct experience. Bandura suggests that the majority of human behaviors are learned in this manner. The process of Observational Learning requires four mechanisms in order for learning to take place:

Attentional Processes--the individual pays enough perceptual attention to the model to obtain sufficient information to be able to replicate the modeled 
behavior(s); (2) Retention Processes--the individual cognitively internalizes significant features of the modeled behavior(s) so that he or she can perform the behavior(s) at a later time; (3) Production Processes--the individual translates the previously stored cognitive information to accurate performance of the overt behavior(s); and (4) Incentive and Motivational Processes-the individual has sufficient motivation to carry out or imitate the modeled or desired behavior(s).

The relationship developed between husbands and wives will inevitably become the model from which their children will pattern their own interpersonal behaviors. Styles of communication, demonstrations of love and affection, decision-making tactics, indicators of self-worth, and values can all be transmitted through observation of the parental relationship. It becomes apparent, then, that cultivation of a well-balanced spousal relationship is a worthwhile endeavor. If spousal Eriendship can support this goal, then it will prove to be an investment for the couple and the future of their family.

\section{Murray Bowen}

In Bowen's Family Systems Theory (Goldenberg \& Goldenberg, 1991), families are seen as emotional units with a multitude of interrelationships that are most effectively examined from a multigenerational perspective. Therefore, an emotional disturbance in one family member 
stems from relationship ties that particular person has with others in the family. He suggests eight forces that mold family interactions: differentiation of self, triangles, nuclear family emotional system, family projection process, emotional cutoff, multigenerational transmission process, sibling position, and societal regression.

Differentiation of self has particular application to the present study. It refers to one's ability to separate between intellectual functioning and emotional functioning. The more aptly one can make this distinction, the less likely he or she is to become overtaken by the emotional reactivity that can occur within the family. This suggests how important it is for each spouse to develop individually and to understand himself/herself first before entering such a close relationship as marriage.

\section{Erik Erikson}

Erikson (Schultz \& Schultz, 1994) has outlined a pattern in which the personality matures through specific psychosocial stages of development. Each stage is equipped with its particular developmental crisis that is met and passed through either adaptively or maladaptively. The paradigm is inclusive of the entire life span. To accomplish normal development, the conflicts of one stage must be resolved in order for the system to have the 
necessary resources and strength with which to move on to the tasks of the succeeding stage.

Erikson's theory identifies the building of relationships with others as a basic developmental task for all humankind--i.e., acquiring an attitude of trust or mistrust toward others during the first year of life. He defines the challenge of young adulthood (ages 18-35) as the development of intimacy with others or isolation from them. The task of developing intimate relationships includes close friendships as well as sexual relationships. These relationships are understood to involve commitment and caring without a threat to one's self-identity. In looking at friendship in the current project, the need for close relationships is examined not only at the Young Adulthood stage, but throughout the life span.

\section{Abraham Maslow}

Maslow's Hierarchy of Needs (Schultz \& Schultz, 1994) presents a life span of human needs. As in a ladder, these needs in ascending order are: (1) physiological-food, water, and sex; (2) safety--security, order, and stability; (3) belongingness and love; (4) esteem--derived from self as well as from others; and (5) self-actualization (Schultz \& Schultz, 1994). The theory is built on the premise that each of these needs is innate. It is also evident that, beginning from the lowest rung of the hierarchical ladder, the first need--which is at the bottom--must at least be 
partially fulfilled before the higher needs become significant or influential.

This theory reiterates the need for close relationships as a requirement for basic human development and for the attainment of one's highest level of selfactualization. Why, then, could not spousal friendship be considered a catalyst for self-development for the marital partners and enrichment for the marital bond?

From these five theories, it can be summarized that even though we all are unique individuals, we have a basic need to bond with others. We all mature through sequential phases of development from which we obtain strengths for continuous life-long growth. The environment in which we are born teaches us about ourselves, the world, and ways of conducting ourselves in relationship to others. This process begins in the early stages of life when one's world consists merely of one's family. In the present study, the husband/wife nucleus is considered; i.e., its potential for edifying each partner, their relationship, and the power of its potential to influence its forthcoming generations.

\section{Significance of the study}

Statistics vividly reflect the short life span of today's wedding vows. In 1990, the United States documented 2,448,000 legal marriages that took place. In that same year, the nation also reported 1,175,000 divorces (U. S. Bureau of the Census, 1992). 
In the face of such stark marital instability, the motivation to address the previously stated research challenge tends to rise. Enhanced friendship between spouses may prove to be quite useful in increasing marital quality. In turn, it may contribute to increased marital longevity and thus assist in reducing the staggering numbers of divorces, separations, and annulments that are experienced in the world today.

The instrument used in this study to examine friendship was the Caring Relationship Inventory. It involves five components of relationship evaluation: Affection, Friendship, Eros, Empathy, and Self-Love. The present study focuses primarily on the Friendship component. However, limited discussion of the remaining four components is presented when they significantly relate to marital quality for the sample in this study.

This project explores a scarcely researched resource that can potentially make a positive contribution to couple relationship-building. It is intended that the results of this study will contribute to the breadth of literature on treatment foci for couples' therapy. As a result, it will be an addition to existing literature on friendship in intimate relationships and perhaps be a catalyst for further research devoted to the subject. 
Definition of Terms

The following section defines terminology as it is used in the present study.

Friendship: A peer love based on a common interest and respect for each party's equality and individual identity; a love based on an appreciation of the other person's principal talents and worth; a love that has a chosen quality. This "involves unconditional acceptance characterized by the love of another's personhood" (Shostrom, Knapp, \& Knapp, 1976, p. 47). "In love and marriage, friendship means doing things together, sharing common interests, recognizing each other's uniqueness and individuality" (Shostrom, 1975, p. 3).

Couples: Heterosexual couples-husbands and wives-who are currently in a legal marriage relationship.

"Ideal" scores: Scores produced on the Caring Relationship Inventory when spouses rate an ideal partner in a relationship. This rating is accomplished the second time the individual completes the inventory. Participants were asked to rate ideal mates so that differences in ratings of their present mates and ideal mates could be assessed.

Married Individual: A spouse from a marital dyad. In this study, a married individual is one member of a couple (husband or wife) who responded to the questionnaires.

Marital quality: The way in which a marital relationship functions and "how the partners feel about and 
are influenced by such functioning" (Spanier, 1979, p. 290). The evaluation of marital relationships ranges on a continuum from high to low, instead of a fixed classification of high or low. High quality tends to reflect good marital communication, adjustment, happiness, and satisfaction.

The author of the Dyadic Adjustment Scale indicates that the instrument focuses on adjustment as the "most general of the measurable indicators of marital quality" (p. 290). Therefore, the terms "marital quality" and "marital adjustment" are used interchangeably in the present study.

Nurture: To support or nourish others in ways that will help or motivate them to reach their greatest potential or highest level of development; caring enough to help others be the best that they can be. Nurturing would imply the actual practice of such endeavors.

"Other" scores: Scores produced on the Caring Relationship Inventory when spouses rate their mates. This rating is accomplished the first time the individual completes the inventory.

\section{Iimitation of the study}

This research project is a correlational investigation and, as such, does not reflect or imply causation.

\section{Delimitations of the study}

The sample for this study was generated from married 
couples from Christian communities. Additional delimitations are: all participants were (1) volunteers, (2) from the Columbus, Ohio, area, and (3) in legal heterosexual marriages. Therefore, the results should not be generalized to single individuals, unwed couples living together, unwed dating couples, divorced individuals, couples from non-Christian communities, or homosexual couples. Results could, however, be beneficial in a speculative manner to Christian groups other than those specifically included in the sample for this study.

\section{Organization of the study}

Five chapters are contained in this study.

Chapter 1 presents an introduction to the research project, statement of the problem, purpose of the study, research questions, hypotheses, theoretical frameworks, significance of the study, definition of terms, and limitation and delimitations of the study.

Chapter 2 reviews the Iiterature that focuses on Eriendship and marital quality.

Chapter 3 describes the methodology, which includes the research design, sample population, instrumentation used, procedures, and data collection and analyses.

Chapter 4 presents an outline of the findings and some interpretation of the results.

Chapter 5 provides a summary of the study, discussion 
17

of the results, conclusions, and recommendations for practice and Euture research. 


\section{CHAPTER II \\ REVIEW OF RELATED IITERATURE}

\section{Basic Need for Friends}

Is it possible that the need for Eriendship is an agespecific criterion, that when once achieved satisfies a lifetime requirement? The following review of literature tends to refute this suggestion by reflecting the innate need and desire that humans have for closeness with others throughout life.

According to Maslow's (Maslow, 1954; Schultz \& Schultz, 1994) Hierarchy of Needs, friendship is included in what he describes as the basic human need for belongingness and love. Once the physiological and safety needs have been reasonably satisfied, the need for connectedness in relationships moves to the surface. The strength of this need is noted as a "hunger for affectionate relations" (Maslow, 1954, p. 89). He observes that "in our society the thwarting of these needs is the most commonly found core in cases of maladjustment and more severe psychopathology" (p. 89). In a later publication, Maslow (1968) identifies individuals who have satisfied their physiological, safety, belongingness and love, and 
esteem needs as healthy people.

MCGinnis' (1979) clinical observations led him to conclude that friendship comprises the foundation from which all other love relationships grow. On the one hand, individuals without friends tend to have a Iimited ability to sustain any love relationship. On the other hand, individuals who have friends and who have learned how to Iove them tend to have good relationships with co-workers, meaningful and lengthy marriages, and experience enjoyment with their children.

Adler (1946) contends that the human need for connection with others is innate. His concept of "communal life" (p. 27) describes a need that regulates all human relationships and an environment in which humankind is able to maintain its existence.

Also from a clinical standpoint, Rangell (1963) states that friendship is usually an underlying theme to client problems and often, after years of treatment, it is discovered that Eriendship should have been the primary issue from the onset of treatment. He underscores the concept of equality and mutual respect in his definition of friendship, noting that friendship grows along a spectrum. Interestingly, he suggests that people vary in their need for friends and their ability to have friends and preserve friendships. He states further that "the status of one's friendships is often a sensitive barometer of the state of his mental health" (p. 41). This comment lends support to 
Maslow's previous suggestion of the correlation between friendship and health.

Grotstein (1989) tends to hold a similar belief in the importance of friendship. For him, "friendship represents the quintessence of shared experience" (p. 6). Not only does he conceive of friendship as bringing balance to one's individual life, he purports six purposes of friendship:

(1) reciprocity, (2) reassurance, (3) confirmation of meaningfulness, (4) support, (5) "'sparring partnerships' to hone one's abilities" (p. 6), and (6) reinforcement for one's values and goals. He suggests that in marital relationships, sharing and reciprocity form the basis for an intimate friendship which too often are pushed to the background until the relationships are in danger. He has been particularly attentive to patients suffering the loss of their best friend when they and their spouses or lovers end a relationship.

Attention will now be given to friendship during various developmental stages.

\section{Development of Friendship}

Adler's friendship life task has been reviewed by Hartshorne (1991), who found four necessary criteria that the development of this task should include. They are: (1) the ability to have a number of friends, (2) the ability to establish contacts with others easily, (3) the ability to be a good friend to others, and (4) the ability 
to be concerned for fellow human beings, i.e., the nation and humanity in general. He states further that "the friendship life task is an inclination and a readiness to participate with others that emerges from an interest in and a concern for others, and leads naturally to being a part of the community" (p. 478).

From a study involving over 250 participants ranging in age from 3 to 45, Selman and Selman (1979) constructed a paradigm of five developmental levels of friendship common to most friendship relationships. They are as follows:

Stage Zero: Momentary Playmateship (ages 3 to 7 .

During this phase, Eriends are defined by their proximity and are valued because of physical and/or material assets. Children cannot differentiate between their points of view and those of others.

Stage One: One Way Assistance (ages 4 to 9). At this level, friendship is determined by the fulfillment of the needs of one party. Children understand differences between their and others' perspectives but do not yet comprehend the significance of give-and-take in interpersonal relationships.

Stage Two: Two-Way Fair-Weather Cooperation lages 6 to 12). Friendships include the concept of concern for what each party thinks about the other. However, the basic purpose of the relationship is perceived as satisfying several self-interests.

Stage Three: Intimate, Mutually Shared Relationships 
(ages 9 to 15). Friendship is seen as ongoing and collaborative since children can now share others' viewpoints as well as an objective third-person perspective. Limited thinking or reasoning at this stage can cause individuals to view close friendships as exclusive and possessive in nature.

Stage Four: Autonomous Interdependent Friendships (ages 12 and above). Adolescents and adults perceive friendships as relationships in which each party lends psychological and emotional support while allowing each other to cultivate other independent relationships.

The authors have found that as individuals move from one stage to the next in the hierarchical pattern, they build on the learning gained in the lower developmental level. Additionally, they speculate that these stages could be qualitatively applicable to the development of any adult friendship.

Rangell (1963) looks at the development of friendship through an object relations approach. He suggests that adolescence represents the phase in which true friendships begin to develop, become a primary focus for the individual, and become more enduring.

Witmer and Sweeney (1992) developed a model for wellness that encompasses the entire life span involving the interrelatedness of the attributes of healthy people, Iife tasks, and life forces. They refer to their model as the Wheel of Wellness and Prevention. The attributes of a 
healthy person are presented under five life tasks: spirituality, self-regulation, work, friendship, and love. The life tasks are influenced by the life forces: family, religion, education, community, media, government, and business/industry. The authors describe the friendship life task as development of individual or community relationships that do not include marital, family, or sexual obligations. They suggest that individuals who do not develop friendships tend to be less satisfied with life, have shorter life expcctancy, and are more prone to contract illnesses.

A picture is being drawn that portrays Eriendship as a basic feature in normal human development. That is, friendship is seen as an innate need that strives to be met in the lives of all human beings.

\section{Friendahip in Childhood}

Bullock (1992) found that children with no friends represent 6 to $11 \%$ of all elementary-school-age children. They can be divided into two basic groups--those that are rejected and those that are neglected. Based on the similarities among peer reports, teacher evaluations, and direct observations, rejected children tend to be hostile, aggressive, argumentative, task-avoidant, and have low social sensitivity. Neglected children appear to spend more time alone, have few friends, engage in solitary activities, are neither disruptive nor aggressive, and are 
unable to interact well with their peers. Although both groups of children have behaviors that impede their progress toward successful social interaction, the rejected children are considered to be at risk for future problems and eventual school dropout. She concludes that peer relations are a necessary factor in children's normal and healthy development. The lack of friends subverts children's ability to develop a variety of competencies and contributes to their low self-esteem, loneliness, and incapacity to acquire necessary and appropriate social skills.

Rosenthal (1993), an educational psychologist, became interested in studying lonely, friendless children from three cases referred to him that were quite different from the scores of acting-out children with whom he usually works. He asserts that children without friends are educationaliy and emotionally at risk. Unfortunately, rejected and neglected children, who may be more numerous than imagined, are less likely to be tended to by classroom teachers and/or counseling professionals. His research findings agree with the vicious cycle concept of limited social skills, poor self-image, and social withdrawal contributing to neglect and rejection from others. He has been successful in using specialized group experiences to increase peer acceptance of friendless children as a tool in improving social skills among them. This approach has, in turn, resulted in significant academic improvement, 
happier countenances, increased sharing, and cooperative experiences.

Similarly, Reisman (1985) states that being without friends indicates some type of disturbance. Specific psychological disturbances to which he refers that suggest deficient interpersonal relationship functioning are schizophrenia, avoidant disorder, pervasive developmental disorder, and undersocialized conduct disorder. He then brings attention to the fact that peer rejection is not always the child's fault or failure but often results from peer groups that choose to remain exclusive in their memberships and from cases in which exceptional children choose limited relationships. He argues that when a child has at least one or two friendships, the quality of the friendships are of more significance than the quantity of friends. Regardless of the number of friends one has, however, acquiring a friend and maintaining a friendship fulfills a developmental landmark that no other factor or experience can supply. Interestingly, he differs somewhat from Erikson by placing emphasis on the importance of friendship during adolescence rather than young adulthood. Since adolescence is a period filled with physical maturity, emotional changes, and social pressures, he suggests that friendships during this stage of development are quite a distinctive and powerful source of reinforcement (identifying with others who are coping with similar developmental challenges) and satisfaction (i.e., 
increased individual desirability and value).

In a longitudinal study of school-related loneliness among 128 third-, fourth-, fifth-, and sixth-graders in Western Australia, Renshaw and Brown (1993) found the following to be predictors of loneliness across age groups: social withdrawal, low peer acceptance, few friends or none at all, and an internal-stable attributional style. More pointedly, they report that children who are unsuccessful in establishing close peer Eriendships show higher levels of loneliness. The authors note the unfortunate possibility that many children may fall into a selfperpetuating cycle in which continued social difficulties heighten loneliness, which, in turn, increase social difficulties. This corroborates the previously discussed vicious cycle phenomenon.

Gettinger, Doll, and Salmon (1994) placed a group of 16 boys ( 9 to 11 years of age) experiencing difficulties making and maintaining friends in an 8-week intervention program focused on enriching their peer relations. The two components of the program involved goal setting and problem solving. The boys were placed in one of four treatment groups: (1) goal setting alone, (2) problem solving alone, (3) goal setting and problem solving combined, or (4) no treatment intervention. Findings indicated that the boys who were exposed to both the goal setting and problem solving components showed the greatest changes behaviorally in their interactions with peers and cognitively in their 
beliefs about friendships. Their findings support the effectiveness of a social-cognitive intervention approach to building peer relations among children. The authors suggest that efforts put forth to increase the quality of children's interpersonal relationships are invaluable since these early relationships set the stage for children's Euture social adjustment.

Berndt (1989) points out the advantage that having a close friendship increases one's ability to adjust to difficult or stressful situations. Further, he identifies four essential features of friendships that appear to be present in both the friendships of children and of adults: esteem support, informational support, instrumental support, and companionship support.

\section{Friendship in Adolescence}

Looking at friendship in a higher age group, Claes and Simard (1992) studied over 350 adolescents--delinquents and non-delinquents--in an examination of the elements and functioning of friendship within the two groups. The nondelinquent croup tended to make friends at school, reported 6\% use of illicit drugs, and came from two-parent, higher socioeconomic families. The delinquent group made friends away from school, reported $72 \%$ use of illicit drugs (at least trial use), and came from broken, lower socioeconomic homes. The delinquent group reported having more friends and acquaintances but less close friends than the non- 
delinquent group. The authors suggest that because delinquent adolescents interact primarily in large groups, their opportunities to cultivate close or intimate relationships are decreased. Even though a higher number of friends was indicated by the delinquent group, their friendships involved more overall conflict--confrontation, misunderstanding, and rejection. The findings indicate that delinquent adolescents are able to fulfill their connectedness needs with others. However, these "others" with whom they associate tend to be non-conventional peers with whom they engage in antisocial activities that limit their development of more appropriate social skills.

It appears from the previous study then that peer acceptance, albeit in a negative environment such as in delinquent groups, can substitute somewhat for in-depth and meaningful friendship experiences. These relationships are used to satisfy the basic need for friends to some extent. Shulman, Seiffge-Krenke, and Dimitrovsky (1994) considered the degree to which pen pals represent Eriendship for adolescents. A sample of 132 Israeli adolescents 11 to 19 years of age rated characteristics they looked for in pen pals. The following four preferred characteristics were identified: confidant for selfdisclosure, similarity of interests, attractiveness, and letter-writing skill. Although pen pals were desired more often in early adolescence, the authors suggest that pen pal relationships are one means of fulfilling the 
adolescent developmental task of interpersonal connectedness. Of the identified preferred pen pal characteristics, similarity of interests is also a specific component of friendship as defined in this study. This suggests then an expansion in the meaning or perception of friendships during adolescence that includes a greater appreciation of the other person in the relationship.

Quite similarly, Shostrom (1975) reports that during the adolescent years (ages 12 to 21 ), the focus of friendship changes. The friendship emphasis is redirected from the dependent and independent phases to a concept of interdependence.

\section{Friendship in Young and Middle Adulthood}

In a study of friend and sibling relationship differences among young adults, Pulakos (1989) discovered that friend relationships were considered more important than sibling relationships. The sampled students, ages 17 to 25, indicated that not only did they feel closer to their friends, but they participated in a greater number of activities with their friends, communicated about a larger variety of topics with their friends, and had more reciprocal and positive relationships with them. These findings tend to point to the need to become independent of family--siblings in this case--and in so doing, fulfilling the need to build relationship strengths. This was 
accomplished through the greater rewards received in friend relationships.

With a sample of 83 pairs of university students, Sprecher and Duck (1994) considered the importance of communication quality on dating attraction and friendship attraction. Paired students, unacquainted prior to participating in the research project, were sent on getacquainted dates. They completed pre- and post-test inventories. Findings for both men and women insicated that perceived physical attractiveness of the partner was the strongest predictor of dating attraction, and similarity--things they had in common--was the second strongest. Concerning friendship attraction, similarity and physical attractiveness were the strongest predictors for men. For women, quality of communication and similarity were the strongest predictors of friendship attraction. Again, similarity, a component described in the operational definition of friendship, is shown to be significantly related to friendship relationships in young adulthood.

Transitions in same-sex friendships were studied by Fiebert and Wright (1989). They observed perceived changes in Eriendship behaviors from young adulthood to midlife as well as gender differences in same-sex friendships. Their sample consisted of 28 married university faculty members (14 men, 14 women) between 40 and 55 years of age. These participants evaluated a current best same-sex friendship 
and a best friendship of earlier adulthood--between 20 to 30 years of age. They were also questioned in a 40-minute structured interview about their friendships. Both men and women reported the following changes: (I) spending less time with close friends in midlife--most likely due to marital, Eamily, and job commitments; (2) increased strength of friendships in midlife--possibly reflects greater trust in the friendship; (3) increased selfdisclosure in midlife friendships--stronger emotional support developed in these friendships; and (4) increased duration of midlife friendships--possibly because they have a longer period of time to develop long-term friendships. Women tended to be more emotionally involved with their midlife same-sex friends. So stronger, more mature, and long-term friendship relationships are manifested during middle adulthood.

Friendship variances among separate age groups were also studied by a another team of researchers. Patterson and Bettini (1993) investigated differences in individuals' concepts of friendship depending on their stage of life. Their sample consisted of 265 young adults (mean age 31 ) and 249 elderly adults (mean age 73). They found that across age groups, the structure of friendships involved dedication to the relationship, reciprocity in the relationship, mutual benefits in the relationship, and strength of the relationship. The strength of the 
Eriendship was found to increase as chronological age increased.

The following discussion on friendship and gender issues is presented at this point as it also involves the young and middle adulthood phases of life.

Gender-related friendship issues

Differences between men and women can be noted in their obvious physical structures as well as in the unwritten role expectations placed upon them by society. The literature has also done its part in identifying scientific differences between the genders.

In one such study, Tannen (1990), from her research on communication, goes so far as to classify the communication between men and women as cross-cultural conversation. That is, women talk and listen from an intimacy and a connection standpoint while men listen and speak from a standpoint of independence and status. She contributes much of these variances to basic differences in the ways that boys and girls are raised and to societal pressures placed upon them. "Even if they grow up in the same neighborhood, on the same block, or in the same house, girls and boys grow in different worlds of words. Others talk to them differently and expect and accept different ways of talking from them" (p. 43).

Thus far the literature does not appear to suggest that men and women differ in their fundamental need for 
relatedness or connectedness with others. Humans in general, regardless of gender, have an innate need to develop relationship closeness. Gender differences tend to become more apparent, however, in the ways that men and women interact in close relationships.

Wright and Scanlon (1991) examined the theory that women's friendships tend to be expressive and men's friendships tend to be instrumental. They surveyed 105 women and 101 men ranging in age from early 20 s to late 50s. Their findings supported the existing theory for men for but challenged the theory for women. That is, women's friendships were found to be both expressive and instrumental.

Duck and Wright (1993) examined the literature on gender differences in same-sex friendships. They report two sets of findings: one which describes women's Eriendships as expressive and communal, involving greater reciprocity and affect, while men's Eriendships are described as task-oriented or instrumental, focusing more on commonalities and the associative, and another that suggests little or no communication differences between genders. They attribute some of the disparity in these findings to the ways that data have been analyzed, that is, primarily by observation of between-gender tendencies without much examination of within-gender trends. In this particular project, the authors conducted two studies that re-examined data gathered in several of their previous 
individual research projects with an intentional focus on the differences as well as the similarities in men's and women's friendships. They discovered that in same-sex friendships, both men and women get together just to talk and both are inclined to provide support, encouragement, and caring in their relationships. Women, however, tend to be more overtly expressive of the socioemotional aspects of their friendships than men. The authors warn that a clearer understanding of caring and intimacy is probably necessary at this point. Whereas caring is typically thought to be represented by overt behaviors such as selfdisclosure and affection shown explicitly, it should be understood that these actions are only one way of expressing caring and do not in themselves define caring or closeness itself. In this light, the ways in which men and women express socioemotional concerns can both be legitimately accepted as genuine demonstrations of closeness and caring in a friendship.

Walker (1994) interviewed 33 women and 19 men regarding culturally-specific issues about friendship. The men tended to focus on shared activities in friendships, whereas the women tended to focus on shared feelings in friendships. These findings support earlier suggestions to gender differences in interpersonal relationships, i.e., women are more emotionally-oriented and men are more action-oriented. Her findings also showed that in response to specific questions about same-sex friends, men showed an 
increase and women showed a decrease in shared feelings than their responses to the general questions about friendship initially revealed. This suggests that men have the capacity to share feelings, but they may be more comfortable doing so with male friends.

In the present study, mutual respect has been identified as a component of friendship. Gaines (1994) examined men and women's respectful and affectionate behaviors in cross-gender platonic friendships. A total of 62 male-female Eriendship pairs comprised the sample (mean ages 19.0 years for men and 18.6 for women). Results of his study showed that in cross-gender frjendships, men and women tended to show reciprocal behaviors of respect. A similar trend was not shown for affectional behaviors.

Elkins and Peterson (1993), who evaluated gender differences in best friendships, compared how men and women rated their actual and ideal same-sex and cross-sex friendships. From the assumption that having a best friend is therapeutic, the authors also examined whether those individuals who did not have a meaningful best friendship would have greater levels of dysphoria or unhappiness. A total of 123 college students (65 women, 58 men) rated friendships and responded to a dysphoria instrument. Results showed that actual male-female friendships tended to be rated as most satisfying. The second most satisfying relationships were actual female-female friendships. Actual and ideal male-male friendships were least 
satisfying. Feelings of dysphoria were positively correlated between discrepancies in what people wanted in a Eriend and what they actually found (Erom "actual" and "ideal" ratings). In other words, when ratings of ideal Eriendships differed significantly from ratings of actual Eriendships, more dysphoria was reported by the individuals on both same- and opposite-gender friendship ratings.

Closest friend relationships among college students was studied by parker and deVries (1993). The 95 women and 95 men in the study rated their closest friends and themselves in relation to each of those friends regarding the structural and affective components of the friendships. Findings showed that women and men similarly rated the importance of the structural and affective dimensions in both same-sex and cross-sex friendships. Further analyses indicated that men's friendships tended to be less reciprocal than women's. In addition, men's same-sex Eriendships were characterized by less giving and receiving.

\section{Friendship in Later Life}

The nature of the basic need for bonding with another is unique in that it is on-going throughout the life and is often substituted by non-human beings when human bonding relationships have been severed, are unavailable, or are unprovided.

Hoffman (1991) raises the point that friendship is 
justifiably as important in the latter phases of life as it is during the earlier stages. The possibility of loneliness is certainly an issue to be considered and addressed for the more than 8 million senior citizens who live alone. As a combatant against stress due to lack of companionship and as an avenue of health improvement, she discusses the therapeutic value that companion animals provide for the elderly. The unconditional love and Eriendship that appropriately selected animals give in nursing homes and other settings for the aged, as well as the disabled, increase their feelings of self-worth and tend to boost their morale.

From a medical standpoint, siegel (1986), a physician and surgeon, developed ECaP (Exceptional Cancer Patients), which utilizes specialized group and individual therapy to enhance patient healing potential through awareness of the mind/body connection. Included in these treatment modalities are the patients' family members and friends who tend to promote the patients' healing and recovery by their interest and support. He writes:

I feel that all disease is ultimately related to a lack of love, or to love that is only conditional, for the exhaustion and depression of the immune system thus created leads to physical vulnerability. I also Feel that all healing is related to the ability to give and accept unconditional love. (p. 180)

He alerts husbands and wives to the need for on-going connectedness even when facing disease or physical changes that come with age. 
It's equally important for couples to continue some form of physical intimacy through illness. Like many of the elderly, severely ill patients often suffer from "skin starvation," a literal separation from life, when touching stops. If lovemaking becomes difficult, there are usually alternative ways of sexual gratification possible within a couple's values, ingenuity, and physical condition. Caresses, hugs, kisses, and hand holding are always possible. (p. 189)

Johnson and Troll (1994) examined the friendship trends of 111 individuals who were 85 years old and above. The majority of the sample had on-going weekly contact with friends and reported having a close friend. Nearly half the sample continued to develop new friendships despite constraints associated with their age, e.g., physical limitations. Their friendships tended to be of the expressive type, providing companionship and fun. Four primary factors were found to either facilitate or constrain friendship in later life: (1) social context-living in a social environment can sustain long-term friendships and easy access to friends; (2) increased age of friends--increases likelihood that friends will die or become physically unable to continue interaction; (3) physical status--dictates ability to maintain direct contact with friends; and (4) personality characteristics-influence whether patterns of socialization are maintained. The ability to be a friend and to make a friend appears to be a requirement for all healthy human development. Developing friendship maturity prior to marriage could increase the ability of friendship becoming 
a source of strength within the marital structure.

Attention will now be turned to individual development as a friend.

\section{Self as Friend/Self Development}

This section presents the premise that the ability to recognize and respect another person's individuality, which is included in the operational definition of friendship, seems to begin with the ability to recognize and understand one's own individuality.

When two people join together in marriage, they each bring into the new relationship all of whom they are individually. This includes both their positive as well as their negative character traits; their varying levels of maturity, patience, and understanding; their unique personalities; their levels of self-esteem; their differing expectations; and their cultural and familial pre-dispositions. Ideally, the more whole they each can be separately before beginning their marriage, the more flexibly and symmetrically they can function as a unit.

Within a marriage, people retain their individuality, which then becomes a factor in increasing the longevity of the couple's friendship (Southard, 1974). Continued development of their own particular gifts and talents enhances the attraction that is so fundamental to "true comradeship" (p. 24). A friendship with oneself has been described as possibly the most significant of human 
affiliations (Grotstein, 1989). According to Adler (1946), "self understanding is the first law of happiness" (p. vii).

Paul and Paul (1983) use the term "evolving relationship" (p. 3) to describe a marriage in which spouses are active in a growth process that increases individual self-awareness and self-expression, produces individual freedom and integrity, and at the same time develops their bond of intimacy. From this process comes mutual acceptance and support, fun, and luxuriant feelings of love. In other words, it produces an environment that enhances both the individual partners as well as the marital relationship. The authors note, however, that couples must be willing to step out of the norm and take some emotional risks in order to achieve a relationship of this nature.

Hendrick and Hendrick (1983) emphasize the point that everyone is a person or an individual first, after which follow the various roles that each person assumes. However, it is imperative that each person discover who he/she is for himself/herself regardless of the difficulties involved in the process (Shain, 1978).

This personhood is what every individual would do well to learn, understand, and appreciate first in order to acquire the ability to cultivate understanding, acceptance, and constructive interactions with others. This premise is identified as a direct commandment in Mark 12:31 which 
41

reads, "Thou shalt love thy neighbour as thyself."

Development of the capacity to like, know, and love one's self should precede the extension of love to another person. This being the case, then, one would be more likely to enter the marital partnership with greater independence, adaptability, and sense of responsibility once a wholeness of self has been cultivated. Nelson-Jones (1990) states the following:

Your capacity to experience your own feelings indicates both the degree to which you are able to accept yourself and also how open you are to others' feelings. . . . If you are out of touch with your feelings you are alienated from the core of your personhood. Relationships are most satisfactory when each person has a secure sense of his or her own identity as a separate individual as well as the identity he or she possesses in relation to another. (pp. 26-27)

He goes on to say that partners also bring into their marital relationship their feelings of insecurity, anxiety, and self-worth. When feelings of anxiety and insecurity are not addressed, partners stymie their own personal growth and limit their ability to respond to the fears and insecurities of their spouses, thus opening the door to misery and hatred within their relationship. In daily communication, spouses not only send messages to each other about the way they value themselves and their partners, but will eventually send equally poignant messages of selfworth to their children.

The term "making contact" is used by Satir (1976) to. describe the process of relationship-building. The process 
42

involves honest sharing of human concerns, which

facilitates the growth of one's self-esteem and enhances one's relationship with himself or herself as well as with others. Although she warns that this development is the work of a lifetime, the key to its accomplishment is knowledge of one's self and the making of contact with other people. Each person is advised to be very patient with himself or herself, however, because the most complete contact made with self and others is rewarded with better health, with the ability to feel valued, and with the capability of having greater problem-solving strategies as a resource. Her plan for accomplishing this task is outlined in one of her poems as follows:

\section{Goals for Me}

I want to love you without clutching, appreciate you without judging, join you without invading, invite you with demanding, leave you without guilt, criticize you without blaming, and help you without insulting.

If I can have the same from you then we can truly meet and enrich each other. (p. 4)

Hudson (1971) writes specifically to the point that people who have not developed a healthy love of themselves are unable to love others. Pervasive overt behaviors such as hatred, gossip, and criticism toward others represent ill feelings toward the self. From a Christian standpoint, he suggests further that this very issue is at the center 
43

of the majority of spiritual and moral dilemmas that we observe and experience. The reason for this is that a spiritual life stands on the fact that God loves every person. Therefore, when people lack appropriate love of self, their religious experience is out of kilter, they are unable to love those around them or those with whom they come in contact, and they fail to believe that God or other people love them. As a result, record numbers of suicides are recorded each year that, too often, decry long-standing hatred of self.

It should be noted here that any references to selflove or love of self in no way include what is known as narcissism. All inferences to love of self depict or refer to healthy and/or appropriate value and acceptance of self, which grows most often from being loved.

If someone loves us, warmly accepts us with all of our individuality and weakness, we learn to give love to others. If this does not occur to us in childhood, we feel inadequate, unworthy, empty, inferior, and worthless.

If we are ever to be comfortable, valuable, selfreliant, and self-directing--under God--individuals, we must make peace with ourselves. This is where the love of God becomes effective. Salvation consists of God's coming to us in love and teaching us that in His sight we are valuable. Then we can love others and enjoy their love. (Hudson, 1971, pp. 48-49)

The concept that friendship stands on the individuality of the people involved is strongly reinforced by Bustanoby (1993). He makes the following comment: "The greatest untapped opportunity for friendship lies within ourselves. If we would develop those qualities that make a 
person a good friend, we would find our own company enjoyable. Then we'd never be without a Eriend" (p. 71). The significance of individuality is shown in his formula for togetherness in a marital relationship: $1+1=3$; i.e., two separate individuals unite to create a couple or a new unit. When spouses fail to develop themselves as separate entities, they are unable to make a strong contribution to the "us" or "we" portion of their relationship.

\section{Value of Nurturing Spousal Friendship}

As two individuals unite themselves in marriage, they become a new family unit. The way that they treat or mistreat each other will contribute to the ways they continue to respond to each other as the social learning theory is in effect. The modeled interactions of this unit will become the stage from which their children will receive their own initial instructions on acceptable interpersonal behaviors and from which their children will begin to develop an understanding of their own self-worth.

The following discussion on parental influence and positive indications is intended to demonstrate how spousal relationships can influence children, and to present suggestions of the importance of spousal friendship in marital relationship-building.

\section{Parental Influence}

Research has established the fact that parental 
behaviors and parental interactions--positive and/or negative--influence children one way or another. Following are some particular instances.

1. Familial Aspirations. Willetts-Bloom and Nock (1992) undertook an examination of the influence of childhood family structure and perceptions of parents' marital happiness on familial aspirations. They chose to sample college students $(\underline{n}=500)$ as it was felt that this group would developmentally be concerned with family issues, would not be Iiving with their parents, and would not yet have started a family. They found that those participants who perceived their parents' marital relationships as unhappy were more cautious in their aspirations about marriage, they indicated a desire to marry at an older age, and they reported their intent to become parents at an older age.

2. Parental Divorce. It has been shown that the impact of parental divorce can have any number of ramifications on the lives of the children who witness their parents' marital disruption and suffer familial destruction. Research indicates that children of divorce are at risk for social, behavioral, and emotional problems, depression, low self-esteem, and isolation (Kalter, 1987; Wallerstein \& Blakeslee, 1989). Within the context of social learning, children from broken homes learn that giving up is an acceptable problem-solving alternative. Unfortunately, they do not receive the vicarious 
instruction of working through difficult issues and arriving at solutions that empower the family structure as well as its individual members.

3. Alcoholism. Not only does parental divorce present a less than ideal model for children to emulate, but alcoholism in one or both parents equally deprives children of a sound family foundation so necessary and important to healthy developmental growth. From a sample of over 450 adolescents (ages 10.5 to 15.5 ) and their parents, Chassin, Pillow, Curran, Molina, and Barrera (1993) found that adolescents with an alcoholic parent were 2.17 times as likely to use alcohol and 3.96 times as likely to use illicit drugs than those adolescents who did not have an alcoholic parent. They suggest that not only parental modeling but also the lack of positive parenting skills negatively influence children in alcoholic homes.

In a 12-year longitudinal study, Newcomb and Rickards (1995) found that men with drug-using parents (primarily alcohol) were highly dependent and poorly adjusted in intimate relationships. These men had less competence and less skill in dating in direct proportion to the increased numbers of negative consequences experienced by their drugusing parents.

4. Parental Violence. Violent behaviors are understood to be intergenerationally transmitted from parents to their children (Davis, 1988). These parents most often themselves have a low sense of self-worth and 
harbor unrealistic expectations for themselves as well as their children.

When spouses fail to invest in maintaining the health of their relationship, they rob each other of the opportunity for greater personal and marital happiness and growth. They also deprive their children of the blessing of warm and caring parents who can provide a loving and accepting environment in which to develop and from which their perceptions of the world will spring. If parents themselves are united, work together, and have developed effective problem-solving skills, they then are a strong support unit Erom which their children can draw and on which they can consistently depend. The benefit of such a unit is shown in the following: "High parental support and high parental monitoring are key socialization factors in the prevention of adolescent alcohol abuse and more generalized deviance" (Barnes \& Farrell, 1992, p. 773).

\section{Positive Indications}

It appears then that the foundation upon which a marriage is built has ramifications that ripple far beyond the two individuals who stand at the altar and say "I do" in any given wedding ceremony. Based on the foregoing discussion of friendship as a basic human need, friendship--its development and nurturance--between spouses has the potential of being a relationship ingredient that could enhance all other aspects of marital interrelations. 
It has been noted that when people train in Eriendship, they also prepare themselves for marriage (Reisman, 1985). Friendship, then, may be an essential link in a couple's marital support network.

A sample of 351 couples, each of whom had been married at least 15 years, was asked to indicate those factors, from a list of 39 factors, that they perceived as most important to maintaining their marriage. The item listed first by both husbands and wives was that their spouse is their best friend (Lauer \& Lauer, 1986). "Without the sense of friendship, the enjoyment of being with the other and sharing in various activities, sex or passion or romantic feelings are powerless to weld a long-term, meaningful union" (p. 179).

The consistency of these findings remained stable in another study conducted 4 years later. Lauer et al. (1990) asked 100 couples who had been married a minimum of 45 years to identify factors that the couples considered essential in maintaining satisfactory and stable relationships. Husbands and wives in this sample listed the following items as the first three of the top-10 perceived reasons for successful long-term marriages: mate is best friend, like mate as a person, and marriage is a long-term commitment. Additionally, $86 \%$ of the couples indicated that they confide in their mate most or all of the time, $87 \%$ stated that they kiss their mate every day or 
almost every day, and $87 \%$ said that at least once a day or more they laugh together.

The importance of spousal friendship was shown somewhat differently in a study that sought to identify the 10 most significant characteristics of long-term satisfactory first marriages. Fenell (1993) worked with a sample of 147 couples who had been married over 20 years and whose marriages were shown to be satisfactory in quality as determined by Spanier's Dyadic Adjustment Scale. When spouses were asked to specify the 10 characteristics they individually considered to be most important to the longevity of their marriage, results were (ranked in descending order): (1) lifetime commitment to marriage, (2) loyalty to spouse, (3) strong moral values, (4) respect for spouse as best Eriend, (5) commitment to sexual fidelity, (6) desire to be a good parent, (7) Eaith in God and spiritual commitment, (8) desire to please and support spouse, (9) good companion to spouse, and (10) willingness to forgive and be forgiven. Although friendship ranked in fourth place, the eighth and ninth characteristics appear to pair themselves closely to the concept of friendship, thus adding support to the importance of the friendship factor. The author gleaned from participants that their level of caring stands on "the values of a good friendship" (p. 454), which provides relationship endurance when other features, e.g., passion, may at times wane.

In an earlier study, Gottman (1982) introduced the 
concept of symmetry in emotional responsiveness as the basic factor in perpetuating marital closeness. He suggests a significant correlation between symmetry in emotional responsiveness and the determination of whether or not spouses are friends. His concluding statements assert that friendship between husbands and wives develops the bond of affection that makes couples desirous of enduring the difficult processes of relationship growth and repair.

Fields (1993) comments on the need to actively invest in the marital relationship with hard work in order to keep it alive and well. He suggests that ongoing dating and romance, termed "preventive maintenance," between spouses is an effective method of achieving this goal. Specifically, he notes that dating strengthens the relationship with couple time together, by creating positive memories, giving partners something to look forward to, and modeling marriage for children.

Erdahl and Erdahl (1981) comment that friendship originates and flourishes as it is nurtured by sharing mutual interests.

\section{Marital Quality}

Spanier (1979) asserts that the measurement of marital quality involves examination of how a marriage functions and how each spouse feels about and is impacted by that functioning. He presents marital quality on a continuum, 
51

ranging from high (good adjustment) to Iow (poor adjustment), rather than in a fixed category. He contends that the term itself encompasses the meanings of several specific concepts, namely, marital satisfaction, marital adjustment, marital happiness, and marital integration. His development of the Dyadic Adjustment Scale allowed him to include the specific elements of overall adjustment as highly predictive of marital quality. These components are consensus, satisfaction, affectional expression, and cohesion.

Marital quality has been measured against several variables, of which a few are cited below.

Kenny and Acitelli (1994) theorized that consensus is an essential factor in maintaining coherence among family members. They studied interpersonal perceptions with a sample of 42 couples to determine the relationship between partner similarity and marital quality. Although the findings did not support their hypothesis, supportive results in a previous study allow them to hold to the validity of the theory as they encourage additional research.

The Dyadic Adjustment Scale was used by Terry, McHugh, and Noller (1991) to examine marital quality during the transition into parenthood. Their sample of 59 primiparous couples was tested during the last trimester of pregnancy and again 3 months following the birth of the child. Results indicated that levels of affectional expression for 
both spouses were lower 3 months after delivery than during prepartum.

Kurdeck (1993) used the Dyadic Adjustment Scale to observe the changes in marital quality for first-time parents and non-parent couples. This longitudinal study tested 49 couples during the first 5 years of their marriage: (1) shortly after marriage, (2) during the year prior to pregnancy, (3) during pregnancy, (4) during child's first year, and (5) during child's second year. Data were gathered from a sample of 68 non-parent couples at the same time intervals as the parent sample. Findings showed no differences in changes in the components of marital quality in the two groups of couples.

The relationship between personality type and marital quality was measured by Russell and Wells (1994) with a sample of 94 couples. They found that neuroticism negatively influenced marital quality. However, the stronger finding was that the quality of the marriage for one partner was found to be influenced most by the quality of the marriage for their mate. That is, things that affect one partner tend to have a strong influence on the other partner.

In an early study, Rhyne (1981) found, from a sampling of 2,190 married Canadians 18 years of age and above, that men were more satisfied with their marriages than women. For both men and women, greater marital satisfaction was positively related to greater satisfaction with love, 
affection, and friendship in those relationships.

Although having a good friendship would not of itself constitute a sufficient single reason to get married, friendship is suggested as being a necessary ingredient for a quality spousal relationship and for marital longevity (Erdhal \& Erdhal, 1981). These authors suggest further that friendship starts and flourishes through the nurturance of sharing mutual interests and tends to contribute to passionate fulfillment in the relationship. Therefore, if friendship has been outweighed by other components of the relationship, such as passion, "it is not too late to become friends" (pp. 21, 22). This coincides with comments made by participants in Fenell's (1993) study previously mentioned, that friendship can stand on its own as a bond in the spousal relationship when other components may be lacking. It also suggests that development of spousal friendship does not have to begin at a certain point in the marriage to benefit the couple.

Woititz (1985) offers timely comments on a healthy or quality relationship. She describes it as an environment in which "(1) I can be me, (2) you can be you, (3) we can be us, (4) I can grow, (5) you can grow, and (6) we can grow together" (p. 20). Her explanation centers around freedom to be oneself and extending that same freedom to one's mate. Although this will be expressed differently by each couple, the concept is built on shared interests and values and unconditional acceptance. 


\section{Summary}

Spousal friendship, for purposes of this study, is one type of love that represents one aspect of the marital relationship.

All successful relationships require growth, and developmental processes tend to imply a need for some degree of training. A pointed comment from olson (1983) provides food for thought. He observes that people typically make a thorough investment in their academic and vocational training. However, their training for marriage and for family life--in which are found some of life's richest experiences and fulfillment--is most often their most inadequate preparation.

The nurturing of spousal friendship represents one area in which couples can combine their efforts to enhance their relationship on an ongoing basis. In so doing, they stand to benefit by individual and couple growth, and their relationship increases its potential of becoming a stronger model for observers such as their children.

The review of current research tends to suggest the importance of friendship bonding throughout the life span. It also suggests that friendships between husbands and wives can be quite rewarding even though husbands and wives may experience and express friendship differently. Although the literature is scant on the specific topic of spousal friendship, it is anticipated that this project will provide helpful information on friendship in intimate 
55

adult relationships and possibly lead to increased marital preservation. 
CHAPTER III

METHODOLOGY

The purpose of this study was to examine the relationship between spousal friendship and marital quality among legally married husbands and wives.

This chapter discusses the following: (1) the research design, (2) the sample population and selection procedure, (3) instrumentation used, (4) survey administration procedure, (5) the null hypotheses, and (6) the statistical approach used for data analysis.

\section{Research Design}

This study was a correlational research project that utilized a survey approach. Its intent was to examine the relationship between nurturing spousal friendship and marital quality.

The variables used in this project were the five variables on the Dyadic Adjustment Scale and the 10 variables on the Caring Relationship Inventory. The five Dyadic Adjustment Scale variables are dyadic consensus, dyadic satisfaction, affectional expression, dyadic cohesion, and total adjustment. The 10 Caring Relationship 
Inventory variables are affection, friendship, eros, empathy, and self-love for one's spouse ("Other" scores) and affection, friendship, eros, empathy, and self-love for an ideal mate ("Ideal" scores).

\section{Sample and Selection Procedures}

The participants for this study were 176 married individuals who agreed to take part in this research project. Couples' mailing lists were initially solicited from Baptist, Lutheran, and Seventh-day Adventist churches in the Columbus, Ohio, area. The Einal sample was generated, however, from mailing lists received from Lutheran and Seventh-day Adventist churches only.

A total of 500 survey packets was mailed to couples (1000 married individuals) identified on mailing lists generated by church pastors. Couples were given an opportunity to remove their names from mailing lists before such lists were given to me.

The following delimitations were noted in the sample: most participants were Seventh-day Adventists, Caucasians, volunteers, over age 35, living in Columbus, Ohio, and were in first-time stable marriages (over 20 years).

\section{Instrumentation}

Data collection was accomplished by the use of the following three instruments: (1) a Demographic Questionnaire, (2) the Dyadic Adjustment scale, and (3) the 
Caring Relationship Inventory. Descriptions of each instrument are provided below.

\section{Demographic Questionnaire}

The Demographic Questionnaire, which I constructed, consisted of 11 questions (Appendix B). The questions were. of a general but relevant nature. Typewritten instructions asked participants to circle their responses to six items, and to write in their responses to seven items. It required only a few minutes to complete this questionnaire.

\section{Dyadic Adjustment Scale}

The Dyadic Adjustment Scale (DAS) (Spanier, 1976) is a well-established self-report instrument designed to measure marital quality by examining the adjustment between partners in dyadic relationships. It generates a total score as well as scores on four subscales: Dyadic Consensus (13 items), Dyadic Satisfaction (10 items), Affectional Expression ( 4 items), and Dyadic Cohesion ( 5 items). Estimated test-taking time for this one-page instrument is from 5 to 10 minutes.

The four scales are described as follows:

Dyadic Consensus assesses the extent of agreement between partners on matters important to the relationship, such as money, religion, recreation, friends, household tasks, and time spent together.

Dyadic satisfaction measures the amount of tension in the relationship, as well as the extent to which the individual has considered ending the relationship. High scores on Dyadic Satisfaction indicate satisfaction with the present state of the relationship and commitment to its continuance. 
Affectional Expression measures the individual's satisfaction with the expression of affection and sex in the relationship.

Dyadic Cohesion assesses the common interests and activities shared by the couple. (Spanier, 1989, p. 12)

The DAS contains 32 items that primarily follow a Likert-type format. Responses to 30 items make use of 5-, 6-, and 7-point response patterns. Two items require a "Yes" or "No" response. Examples of ratings range from "Always Agree" and "AlI the Time" to "Always Disagree" and "Never." Instructions are given in both statement and question forms as the following two examples demonstrate: "Please indicate below the appropriate extent of agreement or disagreement between you and your partner for each item on the following list," and "How often would you say the following events occur between you and your mate?" (Spanier, 1976).

Total scores on the DAS range from 0-151. When raw scores are transferred to the Profile Forms attached to the inventory, they are converted to $\underline{T}$-scores. These standard scores have a mean of 50 and a standard deviation of 10 . The following interpretive guidelines were provided by the author:

1. Above 70--very much above average

2. 66 to $70--m u c h$ above average

3. 61 to $65--$ above average

4. 56 to $60--s l i g h t l y$ above average

5. 45 to 55 --average 
60

6. 40 to 44--slightly below average

7. 35 to 39--below average

8. 30 to 34 --much below average

9. Below 30--very much below average.

The author reports a reliability coefficient for the scale of .96 . The reliability estimate for the total scale was corroborated by Sharpley and Cross (1982) who used the scale with a sample of 95 unrelated married individuals.

Reliability estimates for the subscales are as follows (Spanier, 1976, p. 24): Dyadic Consensus, .90; Dyadic Satisfaction, .94; Affectional Expression, .73; Dyadic Cohesion; .86; Dyadic Adjustment Scale, .96 .

Content validity was established from a thorough review by three judges (Spanier, 1976). Items were included if the judges considered them appropriate measures of adjustment in dyadic relationships, compatible with nominal definitions of adjustment, and appropriately worded with proper fixed-choice responses.

Construct validity was established through a correlational comparison with the Lock-Wallace Marital Adjustment scale, which is another widely used scale. Among married participants the correlation between scales was .86 , and among divorced participants it was .88 .

The scoring key is underneath the answer sheet so that responses made on the answer sheet are automatically transferred to the scoring key. The key is a grid on which horizontal boxes are provided for the scorer to write the 
numerical value that corresponds to that response. Scores for subscales are achieved by adding numbers in the boxes for each subscale column. These totals are written in labeled boxes provided at the bottom of the key for each subscale (e.g., "Total I: Dyadic Consensus," etc.). The four subscale scores are totaled and that figure is placed in the box labeled "Total of I to IV: DYADIC ADJUSTMENT."

I was granted permission by the publisher to reproduce six DAS items as a sample of the questions used on the instrument. These items are shown in Appendix B. The items on the DAS tend to fit into the following categories (numbers of items fitting in a category follow the name of the category): finances--1, recreation and time together-5, religion--1, showing affection and intimacy--5, relationships with others--3, philosophy of life--1, goals --1 , career--1, decision-making--1, household concerns--1, condition of relationship and feelings about relationship-10, and handing anger and differences of opinion--2.

\section{Caring Relationship Inventory}

The Caring Relationship Inventory (CRI) (Shostrom et al., 1976) was used to measure friendship within marital dyads. It is a self-report instrument. As an extensive search did not produce an instrument that would singularly measure friendship, the CRI was used for this purpose in the study. Of the five major scales that the CRI includes, 
special attention was directed to scores produced on the Friendship scale.

The CRI provides scores on five major scales: Affection (15 items), Friendship (16 items), Eros (18 items), Empathy (18 items), and Self-Love (16 items). It includes two subscales that were not utilized in this study: Deficiency Love and Being Love. The instrument does not generate a total score. This study focuses on the 10 primary scores that the instrument yields: five major scale scores that rate one's spouse (labeled "Other") and five major scale scores that rate an ideal mate (labeled "Ideal" ).

The five major categories are described as follows:

Affection: "Agape," a helping, nurturing form of love. It involves unconditional giving and acceptance of the kind that characterizes the love of a parent for a child or of man by God.

Friendship: A peer love based on appreciation of common interests and respect for each other's equality.

Eros: A possessive, romantic form of love which includes features such as inquisitiveness, jealousy, exclusiveness.

Empathy: A charitable, altruistic form of love which feels deeply for the other individual as another unique human being. It involves compassion, appreciation and tolerance.

Self-Love: The ability to accept, in the relationship rated, one's weaknesses as well as to appreciate one's individual unique sense of personal worth. It includes the acceptance of one' a full range of positive and negative feelings toward the person rated. (Shostrom, 1975, p. 4)

A separate "Male Form" and a "Female Form" were 
63

provided for husbands and wives respectively. Written instructions ask individuals to complete the inventory by first rating their partners. These "True/Ealse" responses are recorded in the columns marked "Other." Instructions continue by asking individuals to fold the flaps of the form out and complete the inventory a second time, this time rating an "Ideal" mate. These "True/False" responses are recorded in the columns marked "Ideal." The first rating reflects the attitudes and feelings of one member of the couple toward the other member. The second rating gives an indication of what each member of the pair would like in a relationship with an ideal partner. In the therapeutic setting, gaps in the two ratings are noted and used to address areas of current conflict or dissatisfaction and to generate goals for the individual and/or the couple.

Since the procedures for administering the CRI include rating both "Other" and "Ideal" mates, ratings of "Other" and "Ideal" mates have been gathered in the present study. "Ideal" ratings receive less attention than "Other" ratings due to the small number of responses received on the "Ideal" scales.

Each form contains 83 "True/False" items as well as explicit directions for completing the forms. Estimated test-taking time is 40 minutes.

From a sample ( $\underline{n}=272$ ) of successfully married or actualizing couples, troubled couples, and divorcees, the 
author indicates split-half reliability coefficients (corrected by the Spearman-Brown formula) for the scales as follows: A (Affection), .76; E (Friendship), .82; E (Eros), .87; M (Empathy),.80; S (Self-Love), .74. These coefficients are presented for the "Other" scales of the CRI. Reliability coefficients were not provided for the "Ideal" scales.

The author of the instrument states (Shostrom et al., 1976) that the validity of the CRI was established by administering the instrument to 75 actualizing couples (married a minimum of 5 years), 50 troubled couples (involved in marital therapy), and 108 divorced individuals. Significant differences were found in means for all scales among the three groups. However, the greatest mean differences were shown on the Friendship scale. The author indicates that the initial development of the instrument was based partially on the theories of $E$. Fromm, C. S. Lewis, A. Maslow, and F. Perls. He does not, however, provide a description of the item-selection process or indicate any factor analysis. Several authors have used the instrument with positive results (Dailey, 1979; Kosch \& Reiner, 1984; Silverman \& Urbaniak, 1983; Travis \& Travis, 1975; Tsoi-Hoshmand, 1976).

The forms were scored by overlaying stencils on the forms and counting the number of blackened responses that show through the drilled holes in the key. A separate stencil was provided for each scale. Totals for each scale 
were written on the lines labeled for each scale. This procedure was followed in scoring both the "Other" and the "Ideal" responses. A separate Profile Sheet provided Iscore conversions of raw scores. The standard scores have a mean of 50 and a standard deviation of 10 . The mean of 50 is interpreted as successfully married.

I was granted permission by the publisher to reproduce five items from the CRI. The five selected items are shown in Appendix B. The items on each of the CRI scales tend to fit into the following categories (numbers of items fitting in a category follow the name of the category): Affection: caregiving--4, contentment--1, need--1, understanding--3, comfort with relationship--1, kissing--1, admiration--1, openness--1, responsibility--1, long-term caring--1, care-receiving--1; (2) Friendship: respect--1, camaraderie--2, commonality--2, trust-4, specialness--1, togetherness--2, support--1, appreciation--1, closeness-1, unselfishness--1; (3) Eros: interest-1, demands--1, possessiveness--1, privacy with spouse--1, playfulness--1, physical attraction--2, think of spouse--1, quality of feelings--1, touching--1, commitment--1, caring--3, sacrifice--1, jealousy--1, closeness--1, control--1;

Empathy: understanding spouse--4, spouse's individuality and worth--2, share spouse's pain--1, weaknesses--1, caring --4, appreciation--2, rejection--1, forgiveness--1, patience--1, compassion and sympathy--1; (5) Self-Love: selfishness--1, fear--5, defensiveness--2, criticism--1, 
vulnerability--1, caring--1, prioritizing needs--1, openness--3, being demanding--1.

\section{Procedures}

I prepared three separate alphabetical lists of all Baptist, Lutheran, and Seventh-day Adventist churches as recorded in the Ameritech Yellow Pages for Columbus, Ohio (1994). These lists were then ranked in random order by denomination.

Telephone contact was made with pastors of local Baptist, Lutheran, and Seventh-day Adventist churches in random-order sequence to briefly explain the study and to request their churches' participation in the project. When an affirmative response was received, pastors were asked:

1. to inform their congregations about the project through a verbal announcement and a printed bulletin announcement for at least 2 consecutive weeks; the sample bulletin announcement was mailed to each pastor with a cover letter (Appendix B)

2. to inform their members that their responses would be anonymous

3. to include instructions that any couples not wishing to participate should notify their pastor accordingly

4. to tell their congregations that once the mailing list was given to me, survey forms would be mailed directly to their homes 
5. to provide the researcher with the resulting mailing list.

I made telephone contact with the pastors of two Baptist churches who agreed to provide lists of married couples in their congregations. Follow-up letters with bulletin announcements were mailed after initial telephone conversations. When I called the pastors back after the agreed 2-week period, I was asked to call back at later dates to receive the mailing lists or possibly to deliver the packets to them and let their staff distribute them. When I did call back I was told that one pastor was not available, and I received no answer at the second church. I made several succeeding calls that were not answered. I then mailed letters asking if che lists could be mailed to me since I was unable to reach them via telephone. I received no further communication from either pastor. I made telephone calls to three Iutheran churches. The first two churches indicated that they did not give out mailing lists and did not entertain the possibility of distributing packets in an alternative method. The third Lutheran church asked that I submit copies of my questionnaires, which were reviewed at their monthly council meeting. The council approved my request but asked that I bring the postage-paid packets to the church office and let their pastoral staff affix mailing labels on them and mail them to married couples. I followed the procedures they preferred and delivered 130 packets to the pastor. 
I made telephone calls to nine Seventh-day Adventist churches. Positive responses were received from eight churches. I was never able to reach anyone at the ninth church on the list. The pastor of one seventh-day Adventist church reported that a mailing list could not be given out. He did, however, invite me to bring the packets to his church for distribution. I was given time to introduce my project to the congregation and to pass packets out immediately following the worship service. A total of 370 packets were distributed among seventh-day Adventist congregations.

I spoke with a former faculty member and alumna of a local university about my project and asked who I might contact about getting a mailing list from the university-possibly university students, faculty, or a clinic. I was given the name and telephone number of an individual who could at least point me in the right direction. That person was out of the office for the week when I first called. The following week I called again and left with the secretary a description of my research project and the assistance I was seeking. I received no return call from this individual. I did not continue to pursue contacts at the university because my supply of questionnaires was quickly being depleted by the church responses I was receiving .

After appropriate church-based mailing lists were procured, I distributed to the identified couples survey 
packets containing: (1) a cover letter to the couple, (2) a separate letter for husbands and wives placed in their respective envelopes, (3) the one-page Demographic Questionnaire for each spouse, (4) a Dyadic Adjustment Scale Eor each spouse, (b) a Caring Relationship Inventory for each spouse, and (6) a self-addressed, stamped return envelope for each spouse. Both husbands and wives were asked to follow written instructions on each instrument and complete the questionnaires separately and without conferring with their spouse. They were then instructed to return their completed forms to me in the individual return envelopes provided.

Questionnaires were coded alpha-numerically to identify couples, matching husbands and wives. All responses were anonymous. Packets were mailed to a total of 500 couples (1000 individuals).

Approximately 3 weeks after packets were mailed, reminder letters were mailed to couples who had not yet responded (see Appendix A).

\section{Null Hypotheses}

The first research question, which asked if a relationship existed between spousal friendship and marital adjustment, generated the null hypotheses shown below. The second research question, which asked if the relationship between spousal friendship and marital adjustment differed for husbands and wives, was addressed in sub-hypotheses 
that are presented and discussed in chapter 4 .

1. There is no significant multiple correlation between the Dyadic Consensus component of the DAS and a linear combination of the other scores on the five CRI scales.

2. There is no significant multiple correlation between the Dyadic Satisfaction component of the DAS and a linear combination of the other scores on the five CRI scales.

3. There is no significant multiple correlation between the Affectional Expression component of the DAS and a linear combination of the other scores on the five CRI scales.

4. There is no significant multiple correlation between the Dyadic Cohesion component of the DAS and a linear combination of the other scores on the five CRI scales.

5. There is no significant multiple correlation between the Dyadic Consensus component of the DAS and a linear combination of the Ideal scores on the five CRI scales.

6. There is no significant multiple correlation between the Dyadic Satisfaction component of the DAS and a linear combination of the Ideal scores on the five CRI scales.

7. There is no significant multiple correlation between the Affectional Expression component of the DAS and 
a Iinear combination of the Ideal scores on the five CRI scales.

8. There is no significant multiple correlation between the Dyadic Cohesion component of the DAS and a linear combination of the Ideal scores on the five CRI scales.

9. There is no significant multiple correlation between the Total score of the DAS and a linear combination of the other scores on the five CRI scales.

10. There is no significant multiple correlation between the Total score of the DAS and a linear combination of the Ideal scores on the five CRI scales.

11. There is no significant multiple correlation between the other scores on the Friendship scale of the CRI and a linear combination of the four DAS components.

12. There is no significant multiple correlation between the Ideal scores on the Friendship scale of the CRI and a linear combination of the four DAS components.

13. There is no significant canonical correlation between a linear combination of the four DAS components and a Iinear combination of the five other CRI scales.

14. There is no significant canonical correlation between a linear combination of the four DAS components and a linear combination of the five Ideal CRI scales.

15. There is no significant canonical correlation between a linear combination of the four DAS components for 
husbands and a linear combination of the four DAS components for wives.

16. There is no significant canonical correlation between a linear combination of the five Other scores on the CRI scales for husbands and a linear combination of the other scores on the five CRI scales for wives.

17. There is no significant canonical correlation between a Iinear combination of the five Ideal scores on the CRI scales for husbands and a linear combination of the Ideal scores on the Eive CRI scales for wives.

\section{Statistical Analysis}

This research project is a correlational study. Multiple linear regression analyses and canonical correlations were used to examine the relationship between the predictor variables. Several scales were generated from the CRI. However, the Friendship scale was given specific attention in relation to marital quality as indicated by the DAS. The relationship between Eriendship and marital quality was observed separately for husbands and wives as well. Since the total number of participants included such a limited number of matched couples (husbands and wives), an examination of responses from the entire sample on gender levels was considered appropriate.

Hypotheses 1 to 12 were tested by multiple linear regression analysis. These hypotheses were also tested separately for husbands and wives by multiple linear 
73

regression analyses. Hypotheses 13 to 17 were tested by canonical correlation analysis. For all hypotheses tests, $\alpha$ was set at the .05 level of significance. 
CHAPTER IV

\section{RESULTS}

\section{Introduction}

The focus of the present study was the relationship between spousal friendship and marital quality. Chapter 4 presents: (1) a descriptive profile of the sample, (2) basic data, and (3) tests of the hypotheses. Brief interpretations are provided for each finding.

\section{Demographic Data}

Married couples from Christian-based churches were contacted to participate in this study. One or both spouses were members of either a Lutheran or a Seventh-day Adventist Church in the Columbus, Ohio, area. Responses were received from 176 individuals, which included 84 husbands and 92 wives. Of the 176 respondents, 69 couples (matched husbands and wives) were identified. Their anonymous responses were received between February and June, 1995 .

Data obtained from the Demographic Questionnaire (Appendix B) are shown in Table 1. The majority of the participants were Caucasian between 36 and 50 years of age. 
Table 1

Demographic Distribution of Sample $\underline{(n}=176)$

\begin{tabular}{ll}
\hline Description & Sample \\
\hline
\end{tabular}

1. Gender

Male

Female

2. Age Group

No response

19 or Iess

$20-35$

$36-50$

$51-65$

Over 65

3. Ethnicity

No response

Asian

Black

Hispanic

White

Other

4. Length of Present Marriage

Less than 1 year

1 - 5 years

6 - 10 years

11 - 20 years

Over 20 years

over 50 years

5. Which Marriage

No response

First

Second

Third

other

6. Children Below Age 6

0

1

2

7. Children Ages $6-12$

0

1

2

3

4
84

92

7.7

52.3

$\begin{array}{rr}1 & .6 \\ 0 & 0.0 \\ 35 & 19.9 \\ 64 & 36.4 \\ 49 & 27.8 \\ 27 & 15.3\end{array}$

$\begin{array}{rr}6 & 3.4 \\ 6 & 3.4 \\ 29 & 16.5 \\ 4 & 2.3 \\ 129 & 73.3 \\ 2 & 1.1\end{array}$

$\begin{array}{rr}0 & 0.0 \\ 24 & 13.6 \\ 26 & 14.8 \\ 35 & 19.9 \\ 80 & 45.5 \\ 11 & 6.2\end{array}$

$\begin{array}{rr}6 & 3.4 \\ 131 & 74.4 \\ 33 & 18.8 \\ 4 & 2.3 \\ 2 & 1.1\end{array}$

158

12

89.8

6.8

2.3

1.1

141
22
11
1
1

80.1

12.5

6.2

.6

Reproduced with permission of the copyright owner. Further reproduction prohibited without permission. 
Table 1--Continued.

Description
8. Children Ages $13-21$
$\frac{1}{2}$
3

\section{sample}

Percentage

9. Children Over Age 21

$$
\begin{aligned}
& 0 \\
& 1 \\
& 2 \\
& 3 \\
& 4 \\
& 6
\end{aligned}
$$

10. Children Living at Home Aged Below 6

$$
\begin{aligned}
& 0 \\
& 1 \\
& 2 \\
& 3
\end{aligned}
$$

11. Children Living at Home Ages $6-12$

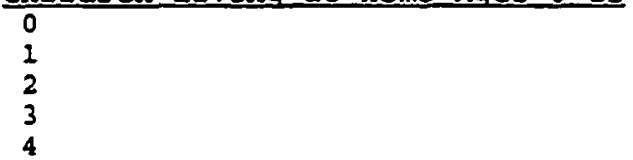

12. Children Iiving at Home Ages 13-21

$$
\begin{aligned}
& \text { Chi } \\
& 1 \\
& 2 \\
& 3
\end{aligned}
$$

13. Children Living at Home Aged Over 21

$$
\begin{aligned}
& 0 \\
& 1 \\
& 2
\end{aligned}
$$

14. Time known Spouse prior to Marriage

$$
\begin{aligned}
& \text { No response } \\
& \text { Less than } 1 \text { year } \\
& 1-5 \text { years } \\
& \text { Other (over } 5 \text { years) }
\end{aligned}
$$

15. Religious Preference

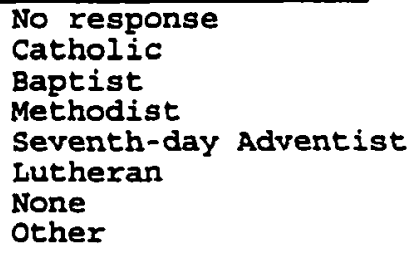

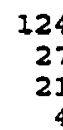

70.5

15.3

11.9

2.3

50.0

6.8

21.0

14.2

6.8

1.1

$\begin{array}{rr}158 & 89.8 \\ 12 & 6.8 \\ 4 & 2.3 \\ 2 & 1.1\end{array}$

143

81.2

11.4

6.2

.6

1

128
32
14
2

72.7

18.2

8. 0

1.1

$\begin{array}{rr}167 & 94.9 \\ 8 & 4.5 \\ 1 & .6\end{array}$

$2 \frac{1}{5}$

118

14.6

67.0

18.2

$\begin{array}{rr}6 & 3.4 \\ 4 & 2.3 \\ 0 & 0.0 \\ 2 & 1.1 \\ 124 & 70.5 \\ 33 & 18.8 \\ 3 & 1.7 \\ 4 & 2.3\end{array}$


Table 1 indicates that all participants in this study had been married to their present spouse for at least 1 year. More than half of the participants had been married for more than 20 years $(51.7 \%)$. Furthermore, this was the first marriage for at least $74 \%$ of the participants. of the participants who had children, the largest group of children was over 21 years of age. Of those with children living at home, the largest group of children tended to be between 13 and 21 years of age. It is not surprising that young children were not represented since most respondents had been married over 20 years.

The majority of participants $(67 \%)$ had known their spouses from 1 to 5 years before their marriage. An additional $18 \%$ of participants had been acquainted with their spouses more than 5 years prior to marriage.

As was expected, the largest religious preference was Seventh-day Adventist $(70.5 \%)$. The second largest preference was Lutheran $(18.8 \%)$. These findings underscore delimitations of this study. That is, the majority of the sample were Seventh-day Adventists, Caucasians, volunteers, living in Columbus, Ohio, were over 35 years of age, and were in first-time stable marriages, i.e., over 20 years.

\section{Basic Data}

Sample means, standard deviations, ranges of possible and actual scores for the four DAS variables and its total score are displayed in Table 2 . Table 3 presents means and 
Table 2

Means, Standard Deviations, and Score Ranges of Dyadic Adjustment Scale Variables $(\underline{n}=176)$

\begin{tabular}{|c|c|c|c|c|c|c|c|}
\hline Variables & Mean & $\underline{\text { SD }}$ & & $\begin{array}{l}\text { ssible } \\
\text { nge }\end{array}$ & $\begin{array}{l}\text { Act } \\
\text { Ran }\end{array}$ & ual & $\begin{array}{l}T-\text {-Scores } \\
\text { of Means }\end{array}$ \\
\hline $\begin{array}{l}\text { Dyadic } \\
\text { Consensus }\end{array}$ & 48.750 & 7.177 & 0 & -65 & 20 & -65 & 47 \\
\hline $\begin{array}{l}\text { Dyadic } \\
\text { Satisfaction }\end{array}$ & 39.153 & 5.665 & 0 & -50 & 16 & -50 & 48 \\
\hline $\begin{array}{l}\text { Affectional } \\
\text { Expression }\end{array}$ & 8.539 & 2.402 & 0 & $-\quad 12$ & 2 & $-\quad 12$ & 48 \\
\hline $\begin{array}{l}\text { Dyadic } \\
\text { Cohesion }\end{array}$ & 15.926 & 4.145 & 0 & -24 & 5 & 24 & 56 \\
\hline Total & 112.318 & 15.758 & 0 & -151 & 57 & -142 & 48 \\
\hline
\end{tabular}

Table 3

Summary Scores for the DAS

\begin{tabular}{|c|c|c|c|c|c|c|}
\hline \multirow[b]{2}{*}{ scale } & \multicolumn{2}{|c|}{$\frac{\text { Married }}{n=218}$} & \multicolumn{2}{|c|}{$\frac{\text { Divorced }}{n=94}$} & \multicolumn{2}{|c|}{$\frac{\text { Total }}{n=312}$} \\
\hline & Mean & $\underline{\text { SD }}$ & Mean & $\underline{\text { SD }}$ & Mean & $\underline{\text { SD }}$ \\
\hline Dyadic Consensus & 51.9 & 8.5 & 35.4 & 11.1 & 46.9 & 12.1 \\
\hline Dyadic Satisfaction & 40.5 & 7.2 & 22.2 & 10.3 & 35.0 & 11.8 \\
\hline Affectional Expression & 9.0 & 2.3 & 5.1 & 2.8 & 7.8 & 3.0 \\
\hline Dyadic Cohesion & 13.4 & 4.2 & 8.0 & 4.9 & 11.8 & 5.1 \\
\hline Total & 114.8 & 17.8 & 70.7 & 23.8 & 101.5 & 28.3 \\
\hline
\end{tabular}

Note: From Dyadic Adjustment Scale Manual (p. 27) by G. B. Spanier, 1989, Toronto, Canada: Multi-Health Systems, Inc. Copyright 1989 by Multi-Health systems, Inc. Reproduced with permission.

standard deviations for the group on which the instrument was normed. The four DAS variables are dyadic consensus, dyadic satisfaction, affectional expression, and dyadic cohesion. 
Participants in this study generated a wide variety of scores that utilized nearly the full range of possible scores. Variable means shown in Table 2 tend to be higher than the mid-point of their corresponding possible range. With the exception of Cohesion, the sample means are lower than means obtained by the normed group of married persons (Table 3).

Mean scores shown for the normed group ail represent I-scores of 50 . When sample means were converted to $I$ scores, they ranged Erom 47 to 56. I-scores for the sample are less than one standard deviation from the standardized mean of 50 in either direction. These scores are interpreted as ranging from "average" to "slightly above average" in marital adjustment according to the guidelines presented by the author of the instrument (see chapter 3 , p. 59).

Table 4 presents means, standard deviations, and actual and possible ranges for the $10 \mathrm{CRI}$ variables for the entire sample. These 10 variables are affection, Eriendship, eros, empathy, and self-love for the other scale and affection, friendship, eros, empathy, and selflove for the Ideal scale. The raw scores produced by the sample spanned nearly the full range of possible scores. Table 5 presents means and standard deviations for the group on which the instrument was normed.

When the other scale means were converted to $\underline{I}$-scores for the sample of this study, they ranged from 46 to 50 . 
Table 4

Means, Standard Deviations, and Score Ranges of Caring Relationship Inventory Variables $(\underline{n}=176)$

\begin{tabular}{|c|c|c|c|c|c|c|c|c|}
\hline \multirow{2}{*}{$\begin{array}{l}\text { Variables } \\
\text { Affection/Other }\end{array}$} & \multirow{2}{*}{$\frac{\text { Mean }}{10.789}$} & \multirow{2}{*}{$\frac{\underline{S D}}{2.499}$} & \multicolumn{3}{|c|}{$\begin{array}{l}\text { Possible } \\
\text { Range }\end{array}$} & \multicolumn{2}{|c|}{$\begin{array}{l}\text { Actual } \\
\text { Range }\end{array}$} & \multirow{2}{*}{$\frac{\begin{array}{c}\text { T-Scores } \\
\text { of Means }\end{array}}{49}$} \\
\hline & & & 0 & - & 15 & 0 & 15 & \\
\hline Friendship/other & 13.318 & 2.890 & 0 & - & 16 & 0 & 16 & 50 \\
\hline Eros/Other & 9.090 & 3.401 & 0 & - & 18 & 0 & 17 & 49 \\
\hline Empathy/other & 13.198 & 2.769 & 0 & - & 18 & 0 & 18 & 50 \\
\hline Self-Love/Other & 10.267 & 2.872 & 0 & - & 16 & 0 & 15 & 46 \\
\hline Affection/Ideal & 12.316 & 1.719 & 0 & - & 15 & 4 & 15 & 53 \\
\hline Friendship/Ideal & 14.774 & 1.741 & 0 & - & 16 & 6 & 16 & 57 \\
\hline Eros/Ideal & 10.593 & 2.615 & 0 & - & 18 & 1 & 17 & 53 \\
\hline Empathy/Ideal & 14.774 & 2.037 & 0 & - & 18 & 6 & 18 & 57 \\
\hline Self-Love/Ideal & 11.812 & 2.557 & 0 & - & 16 & 3 & 16 & 52 \\
\hline
\end{tabular}

Table 5

Means and Standard Deviations of Married. Troubled and Divorced Couples

(1)

Variables Successfully Married

Mean $\quad(n=150)$ SD

\begin{tabular}{lrr}
\hline Affection & 11.0 & 2.2 \\
Friendship & 12.9 & 2.2 \\
Eros & 9.5 & 3.3 \\
Empathy & 12.9 & 2.2
\end{tabular}

Self-Love $11.1 \quad 2.9$
(2) Troubled couples $(n=100)$ Mean

8.4
8.4
8.2
12.2
8.3
SD
(3) Divorced Couples Mean $(n=108)$ SD

Note: From "Caring Relationship Inventory: EdITS Manual" by Everett L. Shostrom, 1975, p. 7. Reproduced with permission.

This range is less than one standard deviation away from the standardized mean of 50 in either direction. This suggests that married individuals in the sample were 
primarily successfully married people.

When Ideal scale means were converted to $\mathrm{T}$-scores for the sample of this study, they ranged from 52 to 57 . This range is less than one standard deviation away from the standardized mean of 50. A comparison of other and Ideal I-scores suggests that what married individuals in this study want Erom ideal mates is stronger bonding in each of the measured areas of caring. They indicate wanting the greatest strength in the areas of both Eriendship and empathy, with self-love following these two primary areas. It must be remembered, however, that all participants did not complete the Ideal section of the CRI.

\section{Data Analysis}

Each of the 17 null hypotheses is presented along with the appropriate statistical analysis. The correlation matrices for the entire regression are shown in Tables 6 and 7 , indicating the intercorrelation among all the variables.

\section{Hypothesis 1}

There is no significant multiple correlation between the Dyadic Consensus component of the DAS and a Iinear combination of the other scores on the five CRI scales.

A multiple linear regression was used to examine this hypothesis, which utilized the "best" subsets regression program. A subset is considered best when, among other criteria, it generates a low $C_{p}$ value and all variables 
Table 6

Correlation Matrix for CRI/Other on DAS

\begin{tabular}{|c|c|c|c|c|c|c|c|c|c|c|}
\hline & Af fection & Friend. & Eros & Empathy & Self - Love & Consensus & Satisf. & Aff Exp. & Cohesion & DAS Total \\
\hline $\begin{array}{l}\text { Affection } \\
\text { Friendship } \\
\text { Eros } \\
\text { Empathy } \\
\text { Self-Love } \\
\text { Consensus } \\
\text { Satisfation } \\
\text { Affec. Expr. } \\
\text { Cohesion } \\
\text { DAS Total }\end{array}$ & $\begin{array}{l}1.000 \\
0.551 \\
0.516 \\
0.624 \\
0.355 \\
0.343 \\
0.425 \\
0.305 \\
0.243 \\
0.422\end{array}$ & $\begin{array}{l}1.000 \\
0.425 \\
0.646 \\
0.573 \\
0.389 \\
0.500 \\
0.426 \\
0.379 \\
0.524\end{array}$ & $\begin{array}{l}1.000 \\
0.405 \\
0.224 \\
0.180 \\
0.318 \\
0.319 \\
0.159 \\
0.286\end{array}$ & $\begin{array}{l}1.000 \\
0.375 \\
0.307 \\
0.347 \\
0.318 \\
0.246 \\
0.379\end{array}$ & $\begin{array}{l}1.000 \\
0.254 \\
0.335 \\
0.253 \\
0.320 \\
0.363\end{array}$ & $\begin{array}{l}1.000 \\
0.583 \\
0.549 \\
0.438 \\
0.868\end{array}$ & $\begin{array}{l}1.000 \\
0.585 \\
0.510 \\
0.853\end{array}$ & $\begin{array}{l}1.000 \\
0.325 \\
0.700\end{array}$ & $\begin{array}{l}1.000 \\
0.701\end{array}$ & 1,000 \\
\hline
\end{tabular}

Table 7

Correlation Matrix for CRI/Ideal on DAS

\begin{tabular}{|c|c|c|c|c|c|c|c|c|c|c|}
\hline & Affection & Friend. & Eros & Empathy & Self-Love & Consensus & Satisf. & Aff. Exp. & Cohesion & DAS Total \\
\hline $\begin{array}{l}\text { Affection } \\
\text { Eriendship } \\
\text { Eros } \\
\text { Empathy } \\
\text { Self-Love } \\
\text { Consensus } \\
\text { Satisfaction } \\
\text { Affec. Expr. } \\
\text { Cohesion } \\
\text { DAS Total }\end{array}$ & $\begin{array}{r}1.000 \\
0.371 \\
0.386 \\
0.532 \\
0.322 \\
-0.054 \\
0.064 \\
0.049 \\
0.060 \\
0.028\end{array}$ & $\begin{array}{l}1.000 \\
0.274 \\
0.540 \\
0.527 \\
0.211 \\
0.245 \\
0.190 \\
0.274 \\
0.294\end{array}$ & $\begin{array}{r}1.000 \\
0.202 \\
0.161 \\
-0.127 \\
-0.068 \\
-0.028 \\
-0.002 \\
-0.092\end{array}$ & $\begin{array}{l}1.000 \\
0.282 \\
0.103 \\
0.121 \\
0.083 \\
0.111 \\
0.139\end{array}$ & $\begin{array}{l}1.000 \\
0.044 \\
0.117 \\
0.099 \\
0.082 \\
0.111\end{array}$ & $\begin{array}{l}1.000 \\
0.534 \\
0.521 \\
0.468 \\
0.849\end{array}$ & $\begin{array}{l}1.000 \\
0.585 \\
0.568 \\
0.846\end{array}$ & $\begin{array}{l}1.000 \\
0.342 \\
0.690\end{array}$ & $\begin{array}{l}1.000 \\
0.746\end{array}$ & 1.000 \\
\hline
\end{tabular}


included in the subset have significant $I$ values.

The best subset for Dyadic Consensus is presented in

Table 8. It generated a multiple correlation of .41836, and shows that Affection and Friendship in combination explained $17 \%(.17502)$ of the variance. The results were significant with $E(2,173)=18.35$ and $\underline{\mathrm{e}}<.00005$. The null hypothesis was therefore rejected. The results indicate that Friendship and Affection scores on the CRI/Other scale are positively related to Dyadic Consensus scores on the DAS.

Table 8

Best Subset for Dyadic Consensus on CRI/Other

\begin{tabular}{llll}
\hline Variables & $\begin{array}{l}\text { Standardized } \\
\text { Regression } \\
\text { Coefficient }\end{array}$ & $\begin{array}{l}\text { Stat. } \\
\text { S-Tail } \\
\text { Significance }\end{array}$ & \\
\hline Affection & 0.185 & 2.23 & $0.027 *$ \\
Friendship & 0.287 & 3.47 & $0.0011^{\star}$ \\
\hline $\mathrm{D}<.05$ & & &
\end{tabular}

Hypothesis 1 was tested on separate gender levels, which required two additional analyses.

Hypothesis 1 a

There is no significant multiple correlation between the Dyadic Consensus component of the DAS and a Iinear combination of the Other scores on the five CRI scales for husbands . 
Hypothesis la was examined with a multiple linear regression analysis. As Table 9 indicates, Affection was found to be the single most significant predictor. It generated a multiple correlation of .28358. This variable alone explained $8 \%(.08042)$ of the variance. Significant $E$ $(1,82)$ of 7.17 and $\mathrm{p}$ of .0009 caused the null hypothesis to be rejected. Affection scores on the CRI/Other scale for husbands are positively related to Dyadic Consensus scores on the DAS.

Table 9

Best Subset for Dyadic Consensus on CRI/Other for Husbands

\begin{tabular}{llll}
\hline Variable & $\begin{array}{l}\text { Standardized } \\
\text { Regression } \\
\text { Coefficient }\end{array}$ & $\frac{t}{\text { Stat. }}$ & $\begin{array}{l}2 \text {-Tail } \\
\text { Significance }\end{array}$ \\
\hline Affection & 0.284 & 2.68 & $0.009 *$ \\
\hline
\end{tabular}

$\star \mathrm{p}<.05$.

Hypothesis $1 b$

There is no significant multiple correlation between the Dyadic Consensus component of the DAS and a linear combination of the other scores on the five CRI scales for wives.

Hypothesis $1 b$ was also tested with a multiple linear regression analysis. Affection and Friendship in combination were selected as the best subset (Table 10). The pair generated a multiple correlation of .56998 and 
Table 10

Best Subset for Dyadic Consensus on CRI/Other for wives

\begin{tabular}{llll}
\hline Variables & $\begin{array}{l}\text { Standardized } \\
\text { Regression } \\
\text { Coefficient }\end{array}$ & $\begin{array}{l}\text { Stat. } \\
\text { S-Tail } \\
\text { Significance }\end{array}$ \\
\hline Affection & 0.229 & 2.39 & $0.019 *$ \\
Friendship & 0.434 & 4.52 & $0.000^{*}$ \\
* $\mathrm{p}<.05$. & & &
\end{tabular}

explained $32 \%(.32488)$ of the variance. Based on an E (2, 89) of 21.41 and $\underline{D}<.00005$, the null hypothesis was rejected. This indicates that Friendship and Affection scores on the CRI/Other scale for wives are positively related to Dyadic Consensus scores on the DAS.

\section{Eypothesis 2}

There is no significant multiple correlation between the Dyadic Satisfaction component of the DAS and a Iinear combination of the Other scores on the five CRI scales.

Hypothesis 2 was tested with multiple linear regression analysis in the same manner in which Hypothesis 1 was tested. Table 11 shows the best subset selected for Dyadic Satisfaction. The model produced a multiple correlation of .53132 . The combination of the two factors, Friendship and Affection, explained $28 \%(.28230)$ of the variance. $E(2,173)$ was significant at 34.02 , with $\underline{p}<$ .00005 . The null hypothesis was therefore rejected. The findings indicate that Friendship and Affection scores on 
Table 11

Best Subset for Dyadic Satisfaction on CRI/Other

\begin{tabular}{llll}
\hline Variables & $\begin{array}{l}\text { Standardized } \\
\text { Regression } \\
\text { Coefficient }\end{array}$ & $\frac{t}{S t a t .}$ & $\begin{array}{l}2 \text {-Tail } \\
\text { Significance }\end{array}$
\end{tabular}

$\begin{array}{llll}\text { Affection } & 0.215 & 2.78 & 0.006 * \\ \text { Friendship } & 0.382 & 4.95 & 0.000 *\end{array}$

$\star \mathrm{D}<.05$.

the CRI/Other scale are positively related to Dyadic

Satisfaction scores on the DAS.

Hypothesis 2 was tested on separate gender levels which required two separate analyses.

Hypothesis $2 a$

There is no significant multiple correlation between the Dyadic Satisfaction component of the DAS and a linear combination of the other scores on the five CRI scales for husbands.

A multiple linear regression analysis was used to test this hypothesis. Friendship was significant with a multiple correlation of .30956 (Table 12). The null hypothesis was rejected based on a significant $E(1,82)$ of 8.69 and $\mathrm{p}=.0042$. This variable explained almost $10 \%$ (.09583) of the variance. Therefore, Friendship scores on the CRI/Other scale are positively related to Dyadic Satisfaction scores on the DAS for husbands. 
Table 12

Best Subset for Dyadic Satisfaction on CRI/Other for Husbands

Variable

Standardized

Regression

Coefficient

t 2-Tail

Stat. Significance

Friendship

0.310

2.95

0.004 *

* $\underline{0}<.05$.

Hypothesis $2 b$

There is no significant multiple correlation between the Dyadic Satisfaction component of the DAS and a linear combination of the other scores on the five CRI scales for wives.

Hypothesis $2 b$ was tested by a multiple linear regression analysis. Affection and Friendship were selected as the best subset as shown in Table 13. Together the factors yielded a multiple correlation of .72670 and explained nearly $53 \%(.52809)$ of the variance. $F(2,89)$ was significant at 49.80 , and $\underline{D}<.00005$. Therefore, the null hypothesis was rejected. Findings show that, for wives, scores on Friendship and Affection on the CRI/Other scale are positively related to scores on the Dyadic Satisfaction scale of the DAS.

\section{Eypothesis 3}

There is no significant multiple correlacion between the Affectional Expression component of the DAS and a 
Table 13

Best Subset for Dyadic Satisfaction on CRI/Other for Wives

\begin{tabular}{llll}
\hline Variables & $\begin{array}{l}\text { Standardized } \\
\text { Regression } \\
\text { Coefficient }\end{array}$ & $\frac{t}{\text { Stat. }}$ & $\begin{array}{l}2 \text {-Tail } \\
\text { Significance }\end{array}$ \\
\hline Affection & 0.354 & 4.41 & $0.000^{*}$ \\
Friendship & 0.503 & 6.26 & $0.000^{*}$ \\
\hline
\end{tabular}

$\star \underline{D}<.05$.

Iinear combination of the other scores on the five CRI scales.

A multiple linear regression was used to analyze Hypothesis 3 in the same way as Hypothesis 1 was analyzed. The best subset is shown in Table 14. Friendship and Eros in combination with each other explained .20468 (20\%) of the variance. The model yielded a multiple correlation of .45241 , with a significant $E(2,173)$ of 22.26 , and $\mathrm{Q}<$ .00005 . Null Hypothesis 3 was rejected based on the foregoing. These results imply that Friendship and Eros scores on the CRI/Other scale are positively related to Affectional Expression scores on the DAS.

Hypothesis 3 was analyzed with two separate analyses on individual gender levels.

Hypothesis $3 a$

There is no significant multiple correlation between the Affectional Expression component of the DAS and a linear combination of the other scores on the five CRI 
Table 14

Best Subset for Affectional Expression on CRI/Other

\begin{tabular}{llll}
\hline Variables & $\begin{array}{l}\text { Standardized } \\
\text { Regression } \\
\text { Coefficient }\end{array}$ & $\frac{t}{\text { Stat. }}$ & $\begin{array}{l}\text { 2-Tail } \\
\text { Significance }\end{array}$ \\
\hline Friendship & 0.355 & 4.73 & $0.000^{*}$ \\
Eros & 0.168 & 2.24 & $0.026^{*}$ \\
\hline
\end{tabular}

\# $<<.05$.

scales for husbands.

A multiple linear regression analysis was utilized to examine this hypothesis. The best subset identified two variables, Eros and Self-Love, that were not significant. When measured alone, however, Eros proved to be significant (Table 15). It explained $7 \%(.0726)$ of the variance and generated a t statistic of 2.53 and a correlation coefficient of .270 . P was significant at .05, therefore, the null hypothesis was rejected. These results suggest that Eros scores on the CRI/Other scale are positively related to scores on the Affectional Expression scale of the DAS for husbands.

Hypothesis $3 b$

There is no significant multiple correlation between the Affectional Expression component of the DAS and a Iinear combination of the Other scores on the five CRI scales for wives. 
Table 15

Best Subset for CRI/Other on Affectional Expression for Husbands

\begin{tabular}{lccc}
\hline Variable & $\begin{array}{l}\text { Standardized } \\
\text { Regression } \\
\text { Coefficient }\end{array}$ & $\frac{t}{\text { stat. }}$ & $\begin{array}{l}\text { 2-Tail } \\
\text { Significance }\end{array}$ \\
\hline Eros & 0.270 & 2.53 & $.014 *$ \\
\hline$\underline{p}<.05$ & & &
\end{tabular}

This hypothesis was tested with a multiple linear regression analysis. The best subset generated by the analysis involved three significant variables (Table 16)-Friendship, Eros, and Empathy. The combination generated a multiple correlation of .62818, and explained $39 \%$ (.39460) of the variance. Based on significant $E(3,88)$ of 19.12 and $\underline{D}<.00005$, the null hypothesis was rejected. Therefore, combined Friendship, Eros, and Empathy scores on the CRI/Other scale are positively related to Affectional Expression scores on the DAS for wives.

\section{Eypothesis 4}

There is no significant multiple correlation between the Dyadic Cohesion component of the DAS and a linear combination of the Other scores on the five CRI scales. Hypothesis 4 was tested in the same manner that Hypothesis 1 was tested with a multiple linear regression. Friendship and Self-Love were selected as the best subset; however, Friendship was the only significant variable of 
Table 16

Best Subset for Affectional Expression on CRI/Other for Wives

Variables Standardized Regression t 2-Tail Coefficient Stat. Significance

$\begin{array}{llll} & & & \\ \text { Friendship } & 0.388 & 3.69 & 0.000 \star \\ \text { Eros } & 0.185 & 2.08 & 0.041 \star \\ \text { Empathy } & 0.209 & 2.03 & 0.046 \star\end{array}$

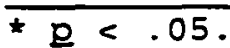

the two. When Friendship was tested alone, it was found to be significant (t statistic $=5.40)($ Table 17). It generated a correlation coefficient of .379 , an $\underline{E}(1,174)$ of 29.16, and explained $14 \%$ (.14364I) of the variance. Hypothesis 4 was therefore rejected. These findings indicate that Friendship scores on the CRI/Other scale are positively related to Dyadic Cohesion scores on the DAS.

Table 17

Best Subset for Dyadic Cohesion on CRI/Other

\begin{tabular}{lccc}
\hline Variable & $\begin{array}{l}\text { Standardized } \\
\text { Regression } \\
\text { Coefficient }\end{array}$ & $\frac{t}{\text { Stat. }}$ & $\begin{array}{l}2 \text {-Tail } \\
\text { Significance }\end{array}$ \\
\hline Friendship & 0.379 & 5.40 & $0.000^{*}$ \\
\hline D $<.05$. & &
\end{tabular}


Hypothesis 4 was further tested on individual gender levels with two separate analyses.

Hypothesis $4 a$

There is no significant multiple correlation between the Dyadic Cohesion component of the DAS and a linear combination of the other scores on the five CRI scales for husbands.

A multiple linear regression was used to analyze Hypothesis $4 a$. Table 18 shows the best subset involving Friendship alone, which generated a multiple correlation of .22701 . This variable alone explained $5 \%(.05153)$ of the variance. With an $\underline{E}(1,82)$ of 4.46 and $\underline{p}<.0378$, the null hypothesis was rejected. Therefore, Friendship scores on the CRI/Other scale are positively related to Dyadic Cohesion scores on the DAS for husbands.

Table 18

Best Subset for Dyadic Cohesion on CRI/Other for Husbands

\begin{tabular}{lccc}
\hline Variable & $\begin{array}{l}\text { Standardized } \\
\text { Regression } \\
\text { Coefficient }\end{array}$ & $\begin{array}{l}\text { Stat. } \\
\text { 2-Tail } \\
\text { Significance }\end{array}$ \\
\hline Friendship & 0.227 & 2.11 & $0.038 *$ \\
\hline$\underline{D}<.05$. & & &
\end{tabular}


Hypothesis $4 \mathrm{~b}$

There is no significant multiple correlation between the Dyadic Cohesion component of the DAS and a linear combination of the other scores on the five CRI scales for wives.

Hypothesis $4 b$ was examined by a multiple linear regression analysis. Friendship and Self-Love in combination were identified as the best subset (Table 19). The combination yielded a multiple correlation of .56148, and explained close to $32 \%(.31525)$ of the variance. Based

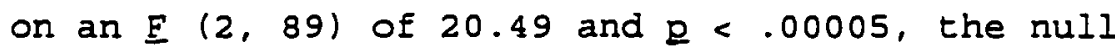
hypothesis was rejected. These findings indicate that combined Friendship and Self-Love scores for wives on the CRI/Other scale are positively related to scores on the Dyadic Cohesion scale of the DAS.

Table 19

Best subset for Dyadic Cohesion on CRI/Other for wives

\begin{tabular}{llll}
\hline Variables & $\begin{array}{l}\text { Standardized } \\
\text { Regression } \\
\text { Coefficient }\end{array}$ & $\frac{t}{\text { Stat. }}$ & $\begin{array}{l}2 \text {-Tail } \\
\text { Significance }\end{array}$ \\
\hline Friendship & $\begin{array}{l}0.396 \\
0.241\end{array}$ & $\begin{array}{l}3.83 \\
2.33\end{array}$ & $\begin{array}{l}0.000 * \\
0.022 *\end{array}$ \\
\hline
\end{tabular}

* $<<.05$. 


\section{Bypothesis 5}

There is no significant multiple correlation between the Dyadic Consensus component of the DAS and a linear combination of the Ideal scores on the five CRI scales.

A multiple linear regression was used to analyze Hypothesis 5 as was performed for Hypothesis 1 . Friendship and Eros were determined to produce the best subset, as is shown in Table 20. The multiple correlation of the model was .28543. The combination of these two factors explained $8 \%(.08147)$ of the variance. With a significant $\underline{E}(2,152)$ of 6.74 , and $\mathrm{p}$ of .0016 , the null hypothesis was rejected. These findings imply that of the CRI/Ideal scores, Friendship scores relate positively and Eros scores relate negatively to Dyadic Consensus scores on the DAS.

Hypothesis 5 was also tested on gender levels with two separate analyses.

Table 20

Best Subset for Dyadic Consensus on CRI/Ideal

\begin{tabular}{lcrc}
\hline Variables & $\begin{array}{l}\text { Standardized } \\
\text { Regression } \\
\text { Coefficient }\end{array}$ & $\frac{t}{\text { Stat. }}$ & $\begin{array}{l}2 \text {-Tail } \\
\text { Significance }\end{array}$ \\
\hline Friendship & $\begin{array}{l}0.266 \\
-0.200\end{array}$ & $\begin{array}{r}3.29 \\
-2.48\end{array}$ & $\begin{array}{l}0.001 * \\
0.014 *\end{array}$ \\
Eros & & &
\end{tabular}


Hypothesis $5 a$

There is no significant multiple correlation between the Dyadic Consensus component of the DAS and a linear combination of the Ideal scores on the five CRI scales for husbands.

A multiple linear regression analysis was used to test Hypothesis 5a. In the best subset (Table 21), Friendship was significant when combined with Self-Love. Self-Love, however, was not a significant variable in the subset. When measured alone, Friendship was not a significant

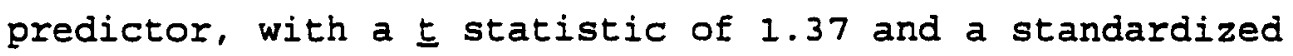
coefficient of .562807 . In this case, the null hypothesis was retained.

Table 21

Best Subset for Dyadic Consensus on CRI/Ideal for Husbands

\begin{tabular}{lcrc}
\hline Variables & $\begin{array}{l}\text { Standardized } \\
\text { Regression } \\
\text { Coefficient }\end{array}$ & $\frac{t}{\text { Stat. }}$ & $\begin{array}{l}2 \text {-Tail } \\
\text { Significance }\end{array}$ \\
\hline Friendship & $\begin{array}{r}0.313 \\
-0.267\end{array}$ & $\begin{array}{r}2.25 \\
-1.91\end{array}$ & $\begin{array}{l}0.028 * \\
0.060\end{array}$ \\
\hline
\end{tabular}

$\star \mathrm{Q}<.05$.

Hypothesis $5 b$

There is no significant multiple correlation between the Dyadic Consensus component of the DAS and a Iinear 
combination of the Ideal scores on the Eive CRI scales for wives.

Hypothesis 5b was tested with a multiple linear regression analysis. The combination of Friendship and Eros was identified as the best subset (Table 22).

Together they generated a multiple correlation of .34491 and explained approximately $12 \%(.11896)$ of the variance. With $\underline{E}(2,77)$ of 5.20 and $\underline{\underline{Q}}=.0076$, the null hypothesis was rejected. These results indicate that on the CRI/Ideal scale, Friendship scores relate positively and Eros scores relate negatively to scores on the DAS Dyadic Consensus scale for wives.

Table 22

Best Subset for Dyadic Consensus on CRI/Ideal for Wives

\begin{tabular}{llll}
\hline Variables & $\begin{array}{l}\text { Standardized } \\
\text { Regression } \\
\text { Coefficient }\end{array}$ & Stat. & $\begin{array}{l}2 \text {-Tail } \\
\text { Significance }\end{array}$ \\
\hline Friendsinip & $\begin{array}{r}0.310 \\
-0.230\end{array}$ & $\begin{array}{r}2.84 \\
-2.10\end{array}$ & $\begin{array}{l}0.006^{*} \\
0.039^{\star}\end{array}$ \\
\hline
\end{tabular}

$\star \underline{p}<.05$.

\section{Hypothesis 6}

There is no significant miltiple correlation between the Dyadic Satisfaction component of the DAS and a Iinear combination of the Ideal scores on the five CRI scales. Hypothesis 6 was tested as was Hypothesis 1 with a 
multiple linear regression. The best subset selected involved two variables, Friendship and Eros, of which only one, Friendship, was significant. When retested as a single variable (Table 23), Friendship yielded a significant $\underline{t}$ statistic of 3.13 and a correlation coefficient of .245 . It accounted for $6 \%(.060020)$ of the variance. In this case, the null hypothesis was rejected. These findings suggest that Friendship scores on the CRI/Ideal scale are positively related to Dyadic Satisfaction scores on the DAS.

Table 23

Best Subset for Dyadic Satisfaction on CRI/Ideal

\begin{tabular}{llll}
\hline Variable & $\begin{array}{l}\text { Standardized } \\
\text { Regression } \\
\text { Coefficient }\end{array}$ & $\frac{t}{\text { stat. }}$ & $\begin{array}{l}2 \text {-Tail } \\
\text { Significance }\end{array}$ \\
\hline Friendship & 0.245 & 3.13 & $.002 *$ \\
\hline
\end{tabular}

$\star \underline{p}<.05$.

Hypothesis 6 was examined on gender levels with two additional analyses.

Hypothesis $6 a$

There is no significant multiple correlation between the Dyadic Satisfaction component of the DAS and a linear combination of the Ideal scores on the five CRI scales for husbands. 
This hypothesis was tested with a multiple linear regression analysis. The resulting two-variable subset identified Friendship and Eros as predictors; however, Eros is not significant in the model (Table 24). Eriendship tends to be a good predictor when paired with another factor. However, when measured alone, it was not found to be a significant variable ( $\underline{t}$ statistic $=1.85, \underline{R^{2}}=.044$, standardized coefficient $=.515)$. Null hypothesis 6 a was therefore retained.

Table 24

Best Subset for Dyadic Satisfaction on CRI/Ideal for Husbands

\begin{tabular}{|c|c|c|c|}
\hline Variables & $\begin{array}{l}\text { Standardized } \\
\text { Regression } \\
\text { Coefficient }\end{array}$ & $\frac{t}{\text { stat }}$ & $\begin{array}{l}\text { 2-Tail } \\
\text { Significance }\end{array}$ \\
\hline $\begin{array}{l}\text { Friendship } \\
\text { Eros }\end{array}$ & $\begin{array}{r}0.278 \\
-\quad 0.196\end{array}$ & $\begin{array}{r}2.31 \\
-1.63\end{array}$ & $\begin{array}{l}0.024 \text { * } \\
0.107\end{array}$ \\
\hline
\end{tabular}

$\star \underline{p}<.05$.

Hypothesis $6 \mathrm{~b}$

There is no significant multiple correlation between the Dyadic Satisfaction component of the DAS and a linear combination of the Ideal scores on the five CRI scales for wives.

This hypothesis was tested with a multiple linear regression analysis. Friendship was identified as the single most significant factor (Table 25). It yielded a 
multiple correlation of .29328 , and explained approximately $9 \%(.08601)$ of the variance. The $\underline{E}(1,78)$ of 7.34 and $\underline{\text { D }}$ of .0083 caused the null hypothesis to be rejected. Results imply that, for wives, Friendship scores on the CRI/Ideal scale are positively related to scores on the Dyadic Satisfaction scale of the DAS.

Table 25

Best Subset for Dyadic Satisfaction on CRI/Ideal for Wives

\begin{tabular}{lccc}
\hline Variables & $\begin{array}{l}\text { Standardized } \\
\text { Regression } \\
\text { Coefficient }\end{array}$ & $\frac{t}{\text { Stat. }}$ & $\begin{array}{l}2 \text {-Tail } \\
\text { Significance }\end{array}$ \\
\hline Friendship & 0.293 & 2.71 & $0.008 *$ \\
\hline $\mathrm{D}<.05$. & & &
\end{tabular}

\section{HYpothesis 7}

There is no significant multiple correlation between the Affectional Expression component of the DAS and a linear combination of the Ideal scores on the five CRI scales.

A multiple linear regression was used to analyze Hypothesis 7 in the same manner that Hypothesis 1 was analyzed. Friendship was identified as the best predictor, as shown in Table 26. It generated a multiple correlation of .18953, and by itself explained approximately $4 \%$ (.03592) of the variance. The significant $E(1,153)$ was 5.70, and $\mathrm{g}$ was .0182 . Consequently, the null hypothesis 
Table 26

Best Subset for Affectional Expression on CRI/Ideal

\begin{tabular}{lccc}
\hline Variable & $\begin{array}{l}\text { Standardized } \\
\text { Regression } \\
\text { Coefficient }\end{array}$ & $\frac{t}{\text { Stat. }}$ & $\begin{array}{l}2 \text {-Tail } \\
\text { Significance }\end{array}$ \\
\hline Eriendship & 0.190 & 2.39 & $0.018 *$ \\
\hline$\underline{D}<.05$ & & &
\end{tabular}

was rejected. This suggests that Friendship scores on the CRI/Ideal scale are positively related to Affectional Expression scores on the DAS.

Hypotheses 7 was further tested on gender levels with two separate analyses.

Hypothesis $7 a$

There is no significant multiple correlation between the Affectional Expression component of the DAS and a linear combination of the Ideal scores on the five CRI scales for husbands.

Hypothesis 7a was examined by a multiple linear regression analysis. As Table 27 reflects, Affection alone was identified as the best predictor. It generated a multiple correlation of .22737 , and explained 5\% (.05170) of the variance. The $\underline{E}(1,73)$ of 3.98 and $\mathrm{p}$ of .0498 caused the null hypothesis to be rejected. These findings suggest that, for husbands, Affection scores on the 
Table 27

Best Subset for Affectional Expression on CRI/Ideal for Husbands

Variable

Standardized Regression Coefficient

$$
\begin{array}{ll}
t & 2-T a i l \\
\text { stat. } & \text { Significance }
\end{array}
$$

Affection

0.227

1.99

$0.050 *$

\# $2<.05$.

CRI/Ideal scale are positively related to Affectional Expression scores on the DAS.

Hypothesis $7 b$

There is no significant multiple correlation between the Affectional Expression component of the DAS and a linear combination of the Ideal scores on the five CRI scales for wives.

A multiple linear regression analysis was used to examine the hypothesis. Table 28 presents the best subset from the analysis. Friendship was not significant nor was any other single variable or combination of variables. The null hypothesis was therefore retained.

\section{Bypothesis 8}

There is no significant multiple correlation between the Dyadic Cohesion component of the DAS and a linear combination of the Ideal scores on the five CRI scales. Hypothesis 8 was examined with a multiple linear 
Table 28

Best Subset for Affectional Expression on CRI/Ideal for Wives

\begin{tabular}{llll}
\hline Variable & $\begin{array}{l}\text { Standardized } \\
\text { Regression } \\
\text { Coefficient }\end{array}$ & $\frac{t}{\text { Stat. }}$ & $\begin{array}{l}2 \text {-Tail } \\
\text { Significance }\end{array}$ \\
\hline Friendship & 0.197 & 1.78 & 0.079 \\
\hline
\end{tabular}

regression identical to the examination of Hypothesis 1. The best predictor identified was Friendship (Table 29). This factor yielded a multiple correlation of .27360 , and accounted for $7 \%(.07486)$ of the variance. Based on a significant $E(1,153)$ of 12.38 , and $\mathrm{p}$ of .0006 , the null hypothesis was rejected. This finding indicates that Friendship scores on the CRI/Ideal scale are positively related to Dyadic Cohesion scores on the DAS.

Table 29

Best Subset for Dyadic Cohesion on CRI/Ideal

\begin{tabular}{lccc}
\hline Variable & $\begin{array}{l}\text { Standardized } \\
\text { Regression } \\
\text { Coefficient }\end{array}$ & $\frac{t}{\text { Stat. }}$ & $\begin{array}{l}2 \text {-Tail } \\
\text { Significance }\end{array}$ \\
\hline Friendship & 0.274 & 3.52 & $0.001 *$ \\
* $\mathrm{D}<.05$. & & &
\end{tabular}


Additional tests were completed on Hypothesis 8 . Gender levels were examined with two separate analyses.

Hypothesis 8 a

There is no significant multiple correlation between the Dyadic Cohesion component of the DAS and a linear combination of the Ideal scores on the five CRI scales for husbands.

A multiple linear regression program was used to analyze Hypothesis $8 a$. The findings indicate that in the best subset selected, Friendship was significant when combined with Self-Love, but Self-Love was not significant in the model. When tested individually, Friendship yielded

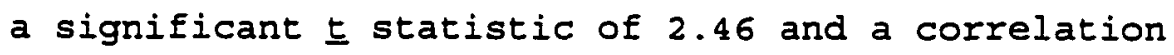
coefficient of .277 (Table 30 ). It generated a significant $E(1,73)$ of 6.05 , and explained nearly $8 \%(.07672)$ of the variance. The null hypothesis was rejected in this case. The results indicate that Friendship scores on the CRI/Ideal scale are positively related to Dyadic Cohesion scores on the DAS for husbands.

Hypothesis $8 b$

There is no significant multiple correlation between the Dyadic Cohesion component of the DAS and a linear combination of the Ideal scores on the five CRI scales for wives.

This hypothesis was tested with a multiple linear regression analysis. Friendship was found to be the single 
Table 30

Best Subset for Dyadic Cohesion on CRI/Ideal for Husbands

\begin{tabular}{lccc}
\hline Variable & $\begin{array}{l}\text { Standardized } \\
\text { Regression } \\
\text { Coefficient }\end{array}$ & $\frac{t}{\text { Stat. }}$ & $\begin{array}{l}2 \text {-Tail } \\
\text { Significance }\end{array}$ \\
\hline Friendship & 0.277 & 2.46 & $.017 *$ \\
\hline $\mathbf{p}<.05$ & & &
\end{tabular}

most significant variable (Table 31). Its multiple correlation was .28641 , and it accounted for $8 \%(.08203)$ of the variance. With an $E(1,78)$ of 6.97 and $\mathrm{p}$ of .0100 , the null hypothesis was rejected. These findings suggest that Friendship scores on the CRI/Ideal scale are positively related to scores on the Dyadic Cohesion scale of the DAS for wives.

Table 31

Best Subset for Dyadic Cohesion on CRI/Ideal for Wives

\begin{tabular}{lccc}
\hline Variable & $\begin{array}{l}\text { Standardized } \\
\text { Regression } \\
\text { Coefficient }\end{array}$ & $\frac{t}{\text { Stat. }}$ & $\begin{array}{l}2 \text {-Tail } \\
\text { Significance }\end{array}$ \\
\hline Friendship & 0.286 & 2.64 & $0.010 *$ \\
\hline
\end{tabular}

$\star \underline{D}<.05$.

Eypothesis 9

There is no significant multiple correlation between the Total score of the DAS and a linear combination of the 
other scores on the five CRI scales.

A multiple linear regression was used to analyze Hypothesis 9 in the same way that Hypothesis 1 was analyzed. The best subset selected is shown in Table 32 . This subset yielded a multiple correlation of .54790 . The combination of the two factors, Friendship and Affection, explained $30 \%(.30020)$ of the variance. The $E(2,173)$ of 37.11 and the $\mathrm{D}<.00005$ caused the null hypothesis to be rejected. Results suggest that Friendship and Affection scores on the CRI/Other scale are positively related to total scores on the DAS.

Table 32

Best Subset for DAS Total on CRI/Other

\begin{tabular}{llll}
\hline Variables & $\begin{array}{l}\text { Standardized } \\
\text { Regression } \\
\text { Coefficient }\end{array}$ & $\frac{t}{\text { Stat. }}$ & $\begin{array}{l}2 \text { Tail } \\
\text { Significance }\end{array}$ \\
\hline Affection & 0.191 & 2.50 & $0.013^{*}$ \\
Friendship & 0.419 & 5.50 & $0.000^{*}$ \\
\hline$\underline{\mathrm{p}}<.05$. & & &
\end{tabular}

Gender levels were tested on Hypothesis 9 with two separate analyses.

Hypothesis 9 a

There is no significant multiple correlation between the total score of the DAS and a Iinear combination of the 
Other scores on the five CRI scales for husbands.

A multiple linear regression was used to examine Hypothesis 9a. Affection was identified as the single most significant predictor (Table 33). It generated a multiple correlation of .32432 , and explained almost $11 \%$ (.10519) of the variance. The null hypothesis was rejected based on an $E(1,82)$ of 9.64 and $p$ of .0026 . Affection scores for husbands on the CRI/Other scale are therefore positively related to total scores on the DAS.

Table 33

Best Subset for DAS Total on CRI/Other for Husbands

\begin{tabular}{lccc}
\hline Variable & $\begin{array}{l}\text { Standardized } \\
\text { Regression } \\
\text { Coefficient }\end{array}$ & $\frac{t}{\text { Stat. }}$ & $\begin{array}{l}2 \text {-Tail } \\
\text { Significance }\end{array}$ \\
\hline Affection & 0.324 & 3.10 & $0.003^{*}$ \\
\hline $\mathrm{D}<.05$ & & &
\end{tabular}

Hypothesis $9 b$

There is no significant multiple correlation between the Total score of the DAS and a linear combination of the Other scores on the five CRI scales for wives.

This hypothesis was tested by a multiple linear regression analysis. As shown in Table 34, the combination of Friendship and Affection formed the best subset. The pair yielded a multiple correlation of .73524 , and together they explained $54 \%(.54057)$ of the variance. The $\underline{E}(2,89)$ 
Table 34

Best Subset for DAS Total on CRI/Other for Wives

\begin{tabular}{|c|c|c|c|}
\hline Variables & $\begin{array}{l}\text { Standardized } \\
\text { Regression } \\
\text { Coefficient }\end{array}$ & $\frac{t}{\text { stat. }}$ & $\begin{array}{l}\text { 2-Tail } \\
\text { Significa }\end{array}$ \\
\hline $\begin{array}{l}\text { Affection } \\
\text { Friendship }\end{array}$ & $\begin{array}{l}0.275 \\
0.575\end{array}$ & $\begin{array}{l}3.48 \\
7.26\end{array}$ & $\begin{array}{l}0.001 * \\
0.000 *\end{array}$ \\
\hline
\end{tabular}

$\star 2<.05$.

was significant at 52.36 and $\underline{D}<.00005$. Therefore, the

null hypothesis was rejected. Results indicate that

Friendship and Affection scores on the CRI/Other scale for wives are positively related to total scores on the DAS.

\section{Hypothesis 10}

There is no significant multiple correlation between the Total score of the DAS and a linear combination of the Ideal scores on the five CRI scales.

Multiple linear regression analysis was used to test Hypothesis 10 identical to the analysis of Hypothesis 1. The best subset selected involved the two variables Friendship and Eros (Table 35). It yielded a multiple correlation of .34448 and explained approximately $12 \%$ (.11866) of the variance. The null hypothesis was rejected, based on $\underline{E}(2,152)=10.23$ and $\underline{p}=.0001$. These results suggest that of the CRI/Ideal scale scores, Friendship relates positively and Eros relates negatively to the DAS total score. 
Table 35

Best subset for DAS Total on CRI/IdeaI

\begin{tabular}{|c|c|c|c|}
\hline Variables & $\begin{array}{l}\text { Standardized } \\
\text { Regression } \\
\text { Coefficient }\end{array}$ & $\frac{t}{\text { stat. }}$ & $\begin{array}{l}\text { 2-Tail } \\
\text { Significance }\end{array}$ \\
\hline $\begin{array}{l}\text { Friendship } \\
\text { Eros }\end{array}$ & $\begin{array}{r}0.345 \\
-0.186\end{array}$ & $\begin{array}{r}4.36 \\
-2.35\end{array}$ & $\begin{array}{l}0.000 * \\
0.020 *\end{array}$ \\
\hline
\end{tabular}

$\star 2<.05$.

Hypothesis 10 was examined on gender levels with two additional analyses.

Hypothesis $10 a$

There is no significant multiple correlation between the Total score of the DAS and a linear combination of the Ideal scores on the five CRI scales for husbands.

A multiple Iinear regression was used to test Hypothesis 10a. The best subset indicated that Friendship was a significant factor when combined with Eros, but Eros was not significant. When measured alone, Friendship was Found to be significant (Table 36). It generated a t statistic of 2.44 and a correlation coefficient of .274 . It explained over $7 \%(.075)$ of the variance, and yielded a significant $E(1,73)$ of 5.95 . The null hypothesis was therefore rejected. This indicates that Friendship scores on the CRI/Ideal scale are positively related to DAS total scores for husbands. 
Table 36

Best Subset for DAS Total on CRI/Ideal for Husbands

\begin{tabular}{lccc}
\hline Variable & $\begin{array}{l}\text { Standardized } \\
\text { Regression } \\
\text { Coefficient }\end{array}$ & $\begin{array}{l}\frac{t}{\text { Stat. }} \\
\text { Friendship }\end{array}$ & $\begin{array}{l}2 \text {-Tail } \\
\text { Significance }\end{array}$ \\
\hline * 0.274 & 2.44 & $.018 *$ \\
\hline
\end{tabular}

Hypothesis $10 \mathrm{~b}$

There is no significant multiple correlation between the Total score of the DAS and a linear combination of the Ideal scores on the five CRI scales for wives.

Hypothesis $10 \mathrm{~b}$ was tested with a multiple Iinear regression analysis. When Friendship was paired with Eros, it was significant but Eros was not. However, Friendship as a single factor generated a significant $\underline{t}$ statistic of 3.02 and a correlation coefficient of .324 (Table 37 ). It yielded a significant $E$ !! 70! of 2.12, and it expiainad $10 \%(.105)$ of the variance. Based on the foregoing, the hypothesis was rejected. Findings indicate that Friendship scores on the CRI/Ideal scale are positively related to a DAS total score for wives.

\section{Bypothesis 11}

There is no significant multiple correlation between the other scores on the Friendship scale of the CRI and a linear combination of the four DAS components. 
Table 37

Best Subset for DAS Total on CRI/Ideal for Wives

\begin{tabular}{lccc}
\hline Variable & $\begin{array}{l}\text { Standardized } \\
\text { Regression } \\
\text { Coefficient }\end{array}$ & $\frac{t}{\text { Stat. }}$ & $\begin{array}{l}\text { 2-Tail } \\
\text { Significance }\end{array}$ \\
\hline Friendship & 0.324 & 3.02 & $.003^{*}$ \\
\hline \# $<.05$. & & &
\end{tabular}

Hypothesis 11 was tested by a multiple linear regression in the same fashion that Hypothesis 1 was tested. The best subset selected involved three significant factors as shown in Table 38. The multiple correlation for the subset was .54437 . The three factors in combination explained close to $30 \%(.29634)$ of the variance. The $E(3,172)$ of 24.15 and the $\underline{D}<.0005$ caused the null hypothesis to be rejected. The results indicate that Dyadic Satisfaction, Affectional Expression, and Dyadic Cohesion scores together are positively ralated to Friendship scores on the CRI/Other scale.

Hypothesis 11 was further tested on gender levels with two separate analyses.

Hypothesis 11 a

There is no significant multiple correlation between the other scores on the Friendship scale of the CRI and a Iinear combination of the four DAS components for husbands. A multiple linear regression was used to examine this 
Table 38

Best Subset for DAS on Friendship Scale of CRI/Other

\begin{tabular}{|c|c|c|c|}
\hline Variables & $\begin{array}{l}\text { Standardized } \\
\text { Regression } \\
\text { Coefficient }\end{array}$ & $\frac{t}{\text { stat }}$ & $\begin{array}{l}\text { 2-Tail } \\
\text { Significance }\end{array}$ \\
\hline $\begin{array}{l}\text { Dyadic Satis. } \\
\text { Affectional } \\
\text { Expression }\end{array}$ & $\begin{array}{l}0.303 \\
0.196\end{array}$ & $\begin{array}{l}3.49 \\
2.49\end{array}$ & $\begin{array}{l}0.001 * \\
0.014^{*}\end{array}$ \\
\hline $\begin{array}{l}\text { Dyadic } \\
\text { Cohesion }\end{array}$ & 0.161 & 2.16 & $0.032 *$ \\
\hline
\end{tabular}

hypothesis. As shown in Table 39, Dyadic Satisfaction was identified as the single most significant variable. It generated a multiple correlation of .30956, and explained approximately 10\% $(.09583)$ of the variance. The significant $E(1,82)$ of 8.69 and $p$ of .0042 caused the null hypothesis to be rejected. Therefore, for husbands, Friendship scores on the CRI/Other scale are positively related to Dyadic Satisfaction scores on the DAS.

Table 39

Best Subset for DAS on Friendship Scale of CRI/Other for Husbands

\begin{tabular}{lccc}
\hline Variable & $\begin{array}{l}\text { Standardized } \\
\text { Regression } \\
\text { Coefficient }\end{array}$ & $\frac{t}{\text { Stat. }}$ & $\begin{array}{l}2 \text {-Tail } \\
\text { Significance }\end{array}$ \\
\hline $\begin{array}{l}\text { Dyadic } \\
\text { Satisfaction }\end{array}$ & 0.310 & 2.95 & $0.004 *$ \\
$\star \mathrm{P}<.05$.
\end{tabular}


Hypothesis $11 b$

There is no significant multiple correlation between the Other scores on the Friendship scale of the CRI and a Iinear combination of the four DAS components for wives.

Hypothesis 1 Ib was tested with a multiple linear regression analysis. The best subset involving three significant variables is shown in Table 40 . The subset generated a multiple correlation of .71064, and explained $50 \%(.50501)$ of the variance. Based on $E(3,88)$ of 29.93 and $\underline{D}<.00005$, the null hypothesis was rejected. These findings suggest that scores on Dyadic Satisfaction, Affectional Expression, and Dyadic Cohesion scales of the DAS are positively related to Friendship scores on the CRI/Other scale for wives.

Table 40

Best Subset for DAS on Friendship scale of CRI/Other for Wives

\begin{tabular}{llll}
\hline Variables & $\begin{array}{l}\text { Standardized } \\
\text { Regression } \\
\text { Coefficient }\end{array}$ & stat. & $\begin{array}{l}2 \text {-Tail } \\
\text { Significance }\end{array}$
\end{tabular}

$\begin{array}{llll}\text { Dyadic Satis. } & 0.360 & 3.33 & 0.001 * \\ \text { Affec. Expr. } & 0.262 & 2.69 & 0.008^{\star} \\ \text { Dyadic Cohe. } & 0.230 & 2.56 & 0.012^{\star}\end{array}$

$\star \underline{D}<.05$. 


\section{Bypothesis 12}

There is no significant multiple correlation between the Ideal scores on the Friendship scale of the CRI and a Iinear combination of the four DAS components.

Multiple linear regression was utilized to test Hypothesis 12 in the same manner as it was used to analyze Hypothesis 1 . The single factor Dyadic Cohesion was identified as the best predictor (Table 41). Alone, this factor generated a multiple correlation of .27360 , and explained $7 \%(.07486)$ of the variance. Based on an $\underline{F}$ ( 1 , 153) of 12.38 and $a p$ of .0006 , the null hypothesis was rejected. These findings imply that scores on Dyadic Cohesion are positively related to Friendship scores on the CRI/Ideal scale.

Table 41

Best subset for DAS on Friendship scale of CRI/Ideal

\begin{tabular}{lccc}
\hline Variables & $\begin{array}{l}\text { Standardized } \\
\text { Regression } \\
\text { Coefficient }\end{array}$ & $\frac{t}{\text { Stat. }}$ & $\begin{array}{l}2 \text {-Tail } \\
\text { Significance }\end{array}$ \\
\hline Dyadic Cohe. & 0.274 & 3.52 & $0.001 *$ \\
\hline
\end{tabular}

$\star \underline{p}<.05$. 
Hypothesis 12 was Eurther tested on gender levels with two additional analyses.

Hypothesis $12 a$

There is no significant multiple correlation between the Ideal scores on the Friendship scale of the CRI and a linear combination of the four DAS components for husbands. Hypothesis $12 a$ was examined with a multiple linear regression analysis. Table 42 shows that Dyadic Cohesion was the single most significant variable. It yielded a multiple correlation of .27713 , and accounted for nearly $8 \%$ $(.07680)$ of the variance. With an $\underline{E}(1,73)$ of 6.07 and $\underline{D}$ of .0161 , the null hypothesis was rejected. These results suggest that scores on the Dyadic Cohesion scale of the DAS are positively related to Friendship scores on the CRI/Ideal scale for husbands.

Table 42

Best Subset for DAS on Friendship scale of CRI/Ideal for Husbands

\begin{tabular}{|c|c|c|c|}
\hline Variable & $\begin{array}{l}\text { Standardized } \\
\text { Regression } \\
\text { Coefficient }\end{array}$ & $\frac{t}{\text { stat. }}$ & $\begin{array}{l}2 \text {-Tail } \\
\text { Significance }\end{array}$ \\
\hline Dyadic Cohe. & 0.277 & 2.46 & $0.016 *$ \\
\hline
\end{tabular}


Hypothesis $12 b$

There is no significant multiple correlation between the Ideal scores on the Friendship scale of the CRI and a linear combination of the four DAS components for wives. Hypothesis $12 \mathrm{~b}$ was also tested with a multiple linear regression analysis. As shown in Table 43 , the best subset involved Dyadic satisfaction as a single variable. It yielded a multiple correlation of .29328 , and explained nearly $9 \%(.08601)$ of the variance. $E(1,78)$ was significant at 7.34, with p of .0083 . The null hypothesis was therefore rejected. The results imply that Friendship scores on the CRI/Ideal scale are positively related to Dyadic Satisfaction scores on the DAS for wives.

Table 43

Best Subset for DAS on Friendship scale of CRI/Ideal for Wives

\begin{tabular}{|c|c|c|c|}
\hline Variable & $\begin{array}{l}\text { Standardized } \\
\text { Regression } \\
\text { Coefficient }\end{array}$ & $\frac{t}{\text { stat }}$ & $\begin{array}{l}\text { 2-Tail } \\
\text { Significance }\end{array}$ \\
\hline Dyadic Satis. & 0.293 & 2.71 & $0.008 *$ \\
\hline
\end{tabular}

\section{Bypothesis 13}

There is no significant canonical correlation between a linear combination of the four DAS components and a Iinear combination of the five other CRI scales. 
Hypothesis 13 was included to observe the relationship between the two primary instruments used in the study--the DAS and the CRI. The hypothesis was analyzed by a canonical correlation to determine any significant relationship between the two sets of variables. In the analysis of this and the following hypotheses, the variables to be included in the interpretation of a canonical function are initially selected as those whose loadings are at least approximately $50 \%$ of the maximum loading of that set.

The first eigenvalue (.33007) was the only significant function produced in the analysis. It yielded a canonical correlation of .57452 and generated a chi-square of 80.74 , with df 20 , and $\underline{p}<.00005$. The null hypothesis was therefore rejected. Table 44 presents the loadings of the two sets of variables. Results of the analysis indicate that participants tending to be high on all five CRI/Other variables tend also to be high on all four DAs variables.

That is, each variable of the DAS is highly related to the variables of the CRI on the other scale rating one's mate. Because they are so compatible, results of previous hypotheses tests involving these two scales can be supported with greater meaning. It would be anticipated then that individuals reporting more consensus, satisfaction, affectionate expression, and cohesion in their marital relationships would also report sensing more affection, friendship, romance, and empathy from their 
Table 44

Canonical Correlation for Hypothesis 13

\begin{tabular}{llll}
\hline Sets & Variables & Loadings \\
\hline Set one: & Dyadic Consensus & $+.712(3)$ \\
(DAS) & $\begin{array}{l}\text { Dyadic Satisfaction } \\
\text { Affectional Expression }\end{array}$ & $+.935(1)$ \\
& Dyadic Cohesion & $+.768(2)$ \\
Set Two: & Affection & $+.749(2)$ \\
(CRI/Other) & Eriendship & $+.949(1)$ \\
& Eros & $+.583(5)$ \\
& Empathy & $+.671(3)$ \\
& Self-Love & $+.644(4)$ \\
\hline
\end{tabular}

mates and acceptance of their own strengths and weaknesses.

\section{Bypothesis 14}

There is no significant canonical correlation between a linear combination of the four DAS components and a linear combination of the five Ideal CRI scales.

A canonical correlation analysis was used to test Hypothesis 14 in the same manner that Hypothesis 13 was tested. The first eigenvalue (.12036) was not significant (chi-square $=25.45 ; \underline{\mathrm{df}}=20 ; \underline{\underline{Q}}=.1846)$. Based on the foregoing, the null hypothesis was retained. There is, therefore, no canonical correlation between the four DAS factors and the five CRI/Ideal factors.

This finding suggests that no expected trend in results could be offered when the DAS and the CRI/Ideal scales are used together due to their lack of 
intercorrelation. This finding might partially have been influenced by the fact that all participants did not complete the Ideal portion of the CRI.

\section{Hypothesis 15}

There is no significant canonical correlation between a linear combination of the four DAS components for husbands and a Iinear combination of the four DAS components for wives.

A canonical correlation analysis was used to test Hypothesis 15, identical to the test of Hypothesis 13. Four significant functions were produced by the analysis. The first eigenvalue of .46828 with a canonical correlation of .68431 produced a chi-square of 74.48 (df $=16$; $\underline{\text { d }}<$ $.00005)$. The second eigenvalue of .22771 with a canonical correlation of .47719 generated a chi-square of 34.37 (df $=$ $9 ; \mathrm{D}=.00001)$. The third eigenvalue of .16065 with a canonical correlation of .40081 yielded a chi-square of $17.97(\underline{\mathrm{d} f}=4 ; \underline{\underline{ }}=.0013)$. The fourth eigenvalue of .10220 with a canonical correlation of .31968 generated a chisquare of 6.85 ( $\underline{\text { df }}=1 ; \underline{Q}=.0089$ ). The canonical correlations for each function are shown in Tables 45 to 48. Only responses from matched couples (69 husband/wife pairs) were used in the test of Hypothesis 15.

Results from Function 1 indicate that when husbands are high on all DAS scales, wives tend to be high on all DAS scales also. This is considered to be the most 
Table 45

Canonical Correlation for Hyoothesis 15--First Function

\begin{tabular}{|c|c|c|}
\hline Sets & Variables & Loadings \\
\hline $\begin{array}{l}\text { Set One: } \\
\text { (DAS-- } \\
\text { Husbands) }\end{array}$ & $\begin{array}{l}\text { Dyadic Consensus } \\
\text { Dyadic Satisfaction } \\
\text { Affectional Expression } \\
\text { Dyadic Cohesion }\end{array}$ & $\begin{array}{l}+.708(3) \\
+.937(1) \\
+.715(2) \\
+.559(4)\end{array}$ \\
\hline $\begin{array}{c}\text { Set Two: } \\
\text { (DAS-- } \\
\text { Wives) }\end{array}$ & $\begin{array}{l}\text { Dyadic Consensus } \\
\text { Dyadic Satisfaction } \\
\text { Affectional Expression } \\
\text { Dyadic Cohesion }\end{array}$ & $\begin{array}{l}+.841(1) \\
+.835(2) \\
+.816(3) \\
+.661(4)\end{array}$ \\
\hline
\end{tabular}

Table 46

Canonical Correlation Eor Hypothesis 15 --Second Function

\begin{tabular}{|c|c|c|c|}
\hline Sets & Variables & Loading & \\
\hline $\begin{array}{l}\text { Set One: } \\
\text { (DAS-- } \\
\text { Husbands) }\end{array}$ & $\begin{array}{l}\text { Dyadic Consensus } \\
\text { Dyadic Satisfaction } \\
\text { Affectional Expression } \\
\text { Dyadic Cohesion }\end{array}$ & $\begin{array}{l}-.357 \\
+. .216 \\
-.458 \\
+.502\end{array}$ & $\begin{array}{l}(3) \\
(4) \\
(2) \\
(1)\end{array}$ \\
\hline $\begin{array}{l}\text { Set Two: } \\
\text { (DAS-- } \\
\text { Wives) }\end{array}$ & $\begin{array}{l}\text { Dyadic Consensus } \\
\text { Dyadic Satisfaction } \\
\text { Affectional Expression } \\
\text { Dyadic Cohesion }\end{array}$ & $\begin{array}{l}-.299 \\
+\quad .364 \\
-.307 \\
+\quad .590\end{array}$ & $\begin{array}{l}(4) \\
(2) \\
(3) \\
(1)\end{array}$ \\
\hline
\end{tabular}


Table 47

Canonical Correlation for Hypothesis 15--Third Function

\begin{tabular}{lll}
\hline Sets & Variables & Loadings \\
\hline $\begin{array}{c}\text { Set One: } \\
\text { (DAs-- } \\
\text { Husbands) }\end{array}$ & $\begin{array}{l}\text { Dyadic Consensus } \\
\text { Dyadic Satisfaction }\end{array}$ & $+.604(1)$ \\
& $\begin{array}{l}\text { Affectional Expression } \\
\text { Dyadic Cohesion }\end{array}$ & $-.142(3)$ \\
Set Two: & Dyadic Consensus & $+.521(2)$ \\
(DAS-- & Dyadic Satisfaction & $-.349(2)$ \\
Wives) & Affectional Expression & $-.346(3)$ \\
& Dyadic Cohesion & $+.310(4)$ \\
\hline
\end{tabular}

Table 48

Canonical Correlation for Hypothesis 15 --Fourth Function

\begin{tabular}{|c|c|c|c|}
\hline Sets & Variables & Loading & \\
\hline $\begin{array}{l}\text { Set One: } \\
\text { (DAS-- } \\
\text { Husbands) }\end{array}$ & $\begin{array}{l}\text { Dyadic Consensus } \\
\text { Dyadic Satisfaction } \\
\text { Affectional Expression } \\
\text { Dyadic Cohesion }\end{array}$ & $\begin{array}{l}-.081 \\
+\quad .146 \\
+.508 \\
+.405\end{array}$ & $\begin{array}{l}(4) \\
(3) \\
(1) \\
(2)\end{array}$ \\
\hline $\begin{array}{l}\text { Set Two: } \\
\text { (DAS-- } \\
\text { Wives) }\end{array}$ & $\begin{array}{l}\text { Dyadic Consensus } \\
\text { Dyadic Satisfaction } \\
\text { Affectional Expression } \\
\text { Dyadic Cohesion }\end{array}$ & $\begin{array}{l}-\quad .286 \\
-\quad .224 \\
+\quad .342 \\
+\quad .344\end{array}$ & $\begin{array}{l}(3) \\
(4) \\
(2) \\
(1)\end{array}$ \\
\hline
\end{tabular}

important finding. It implies that husbands and wives are equally capable of expressing their perceptions of their marital relationships on the DAS. Thus, when one spouse 
Eeels positive about the relationship, the other spouse is also inclined to feel positive about the relationship possibly because they communicate their feelings clearly to one another. It is suggested that when husbands and wives have positive perceptions of their relationships, they both are committed to the relationship and are happy with the agreement they share on relationship matters, their expression of affection, and their shared activities.

Function 2 results suggest that when husbands are high on Dyadic Cohesion and low on Affectional Expression and Dyadic Consensus and possibly high on Dyadic Satisfaction (loading somewhat less than $50 \%$ of the maximum loading), wives tend to score in the same directions on the DAS. This implies that perhaps some shared activities may contribute to their commitment to their marriages even though there is a lack of affection and agreement between them.

Findings on Function 3 indicate that when husbands are high on Dyadic Consensus and Dyadic Cohesion, wives tend to be high on Dyadic Consensus and Dyadic Cohesion and lower on Dyadic Satisfaction and Affectional Expression. This function suggests that although husbands and wives are in agreement on issues such as finances, religion, household tasks, and share activities together, wives may be unsatisfied in the relationship when affection is lacking between them.

Results of Function 4 indicate that when husbands are 
high on Affectional Expression and Dyadic Cohesion, wives tend to be high on Dyadic Cohesion and Affectional Expression and lower on Dyadic Consensus and Dyadic Satisfaction. These findings suggest that even though couples are romantic and share affection and common interests, wives tend to feel unsatisfied and less committed to the relationship when there is a deficit in mutual decision-making and when they and their spouses do not agree on relationship issues such as finances, religion, friends, and/or household tasks.

\section{HYpothesis 16}

There is no significant canonical correlation between a linear combination of the five other scores on the CRI scales for husbands and a linear combination of the other scores on the five CRI scales for wives.

Hypothesis 16 was tested with a canonical correlation analysis in the same way that Hypothesis 13 was tested. Only husband/wife pairs were used in this analysis. There were no significant functions produced in the analysis. Therefore, the null hypothesis was retained. There is then no significant relationship between the five CRI/Other scores for husbands and five CRI/Other scores for wives. Again, this may be due in part to the small number of matched couples in the sample.

\section{Eypothesis 17}

There is no significant canonical correlation between 
a Iinear combination of the five Ideal scores on the CRI scales for husbands and a Iinear combination of the Ideal scores on the five CRI scales for wives.

A canonical correlation was used to analyze Hypothesis 17 in the same way that Hypothesis 13 was analyzed. Only husband/wife pairs were used for the analysis. No significant eigenvalues or functions were produced in this analysis. The null hypothesis was therefore retained. The results indicate that there is no significant relationship between the five CRI/Ideal scores for husbands and the five CRI/Ideal scores for wives.

Only 54 complete couples (paired husbands and wives) responded to the Ideal section of the CRI. Since this hypothesis takes the data from both spouses as a family unit, the number of cases is Iimited, providing only 5.4 cases per variable rather than the preferred 10. Therefore, the results presented for Hypothesis 17 should not be regarded as stable.

\section{Chapter summary}

Chapter 4 presented an analysis of data received from 176 married individuals from church-based populations in the Columbus, Ohio, area. Discussions were provided in the following sequence: (1) demographic sketch of the sample, (2) basic data, and (3) statistical tests of null hypotheses with brief interpretations of findings. Of the 
17 hypotheses included in the study, 14 were rejected. Of the 24 sub-hypotheses presented, 21 were rejected. 


\section{CHAPTER V}

SUMMARY, IMPLICATIONS, CONCLUSIONS, AND RECOMMENDATIONS

Chapter 5 summarizes the study by briefly restating the problem, the purpose of the study, and the methodology. In addition, this chapter presents implications and conclusions, and ends with recommendations for practice and Euture research.

\section{Summary}

\section{Statement of the Problem}

United States census statistics suggest that almost half of today's marriages end in divorce. The literature suggests that friendship between spouses is an aspect of marital relationships that is crucial to the quality and stability of marriages (Fenell, 1993; Lauer \& Lauer, 1986; Lauer et al., 1990). To date, however, existing research involving marital adjustment or quality has not extensively evaluated its relationship to spousal Eriendship.

\section{Purpose of the study}

The twofold purpose of this study was to examine the relationship between spousal Eriendship and marital 
quality, and to examine gender differences in the relationship between spousal Eriendship and marital quality

\section{Methodology}

This correlational study utilized the survey approach. Pastors of Baptist, Lutheran, and Seventh-day Adventist churches in the Columbus, Ohio, area were contacted by phone and by follow-up letters to solicit mailing lists of couples in their congregations. Lists were received, however, from Lutheran and Seventh-day Adventist churches only. Survey packets were mailed to 500 couples. Each packet contained a cover letter, a separate set of questionnaires for the husband and the wife, and separate stamped, self-addressed envelopes for them to return the completed questionnaires to me. Letters to the couples asked them to follow instructions printed on each questionnaire. Reminder letters were sent approximately 3 weeks following the initial mailing to couples who had not responded.

Once responses were received, they were hand-scored, and data were input on computer disk for analysis. Multiple linear regression and canonical correlation analyses were used to examine the data. The sample was analyzed as a whole as well as separately on gender levels.

\section{Subjects}

The sample for this study consisted of 176 married 
individuals gleaned from mailing lists of married couples provided by Lutheran and Seventh-day Adventist churches in the Columbus, Ohio, area. Of these 176 married individuals, 69 couples (matched husbands and wives) were identified. One or both spouses were members of either a Lutheran or Seventh-day Adventist church. All responses were made anonymously.

Delimitations were noted in that the majority of the respondents were: (1) Caucasian, (2) Seventh-day Adventists, (3) over 35 years of age, (4) married 20+ years to their first spouse, (5) geographically restricted, and (6) volunteers.

\section{Instrumentation}

Three self-report instruments were used for data collection. First, an 11-item questionnaire which I designed was used to gather general demographic information about the participants.

Second, the Dyadic Adjustment Scale (DAS), developed by Graham B. Spanier (Spanier, 1976), was used to measure marital adjustment. It generated scores on four subscales as well as a total score. The subscales are titled Dyadic Consensus, Dyadic Satisfaction, Affectional Expression, and Dyadic Cohesion respectively.

Third, the Caring Relationship Inventory (CRI), developed by Everett L. Shostrom (Shostrom, 1975), was used to measure friendship. This instrument is composed of five 
major scales and two subscales. The five major scales in order were titled Affection, Friendship, Eros, Empathy, and Self-Love. This study did not use the two subscales. Ten scores are generated from the instrument: five "Other" scores derived from rating one's partner on each of the major scales, and five "Ideal" scores generated from rating an ideal partner on each of the major scales. These 10 scores result from completion of the inventory twice lonce rating the actual partner and once rating the ideal partner) as written instructions indicate. The present study paid special attention to scores generated on the Friendship/other scale.

\section{Statistical Analysis}

Multiple linear regression analyses were used to test Hypotheses 1 through 12. Sub-hypotheses $1 a$ and $1 b$ through $12 a$ and $12 b$ which examined gender differences were also tested with multiple linear regression analyses. Canonical correlation analyses were performed for Hypotheses 13 through 17.

\section{Implications}

Table 49 presents an overview of findings for Hypotheses 1 through 10.

The first research question asked if there is a relationship between spousal friendship and marital quality. The response is yes, in light of present findings. Results for the entire sample showed that 
Table 49

Summary Findings--Hyootheses 1 Through 10

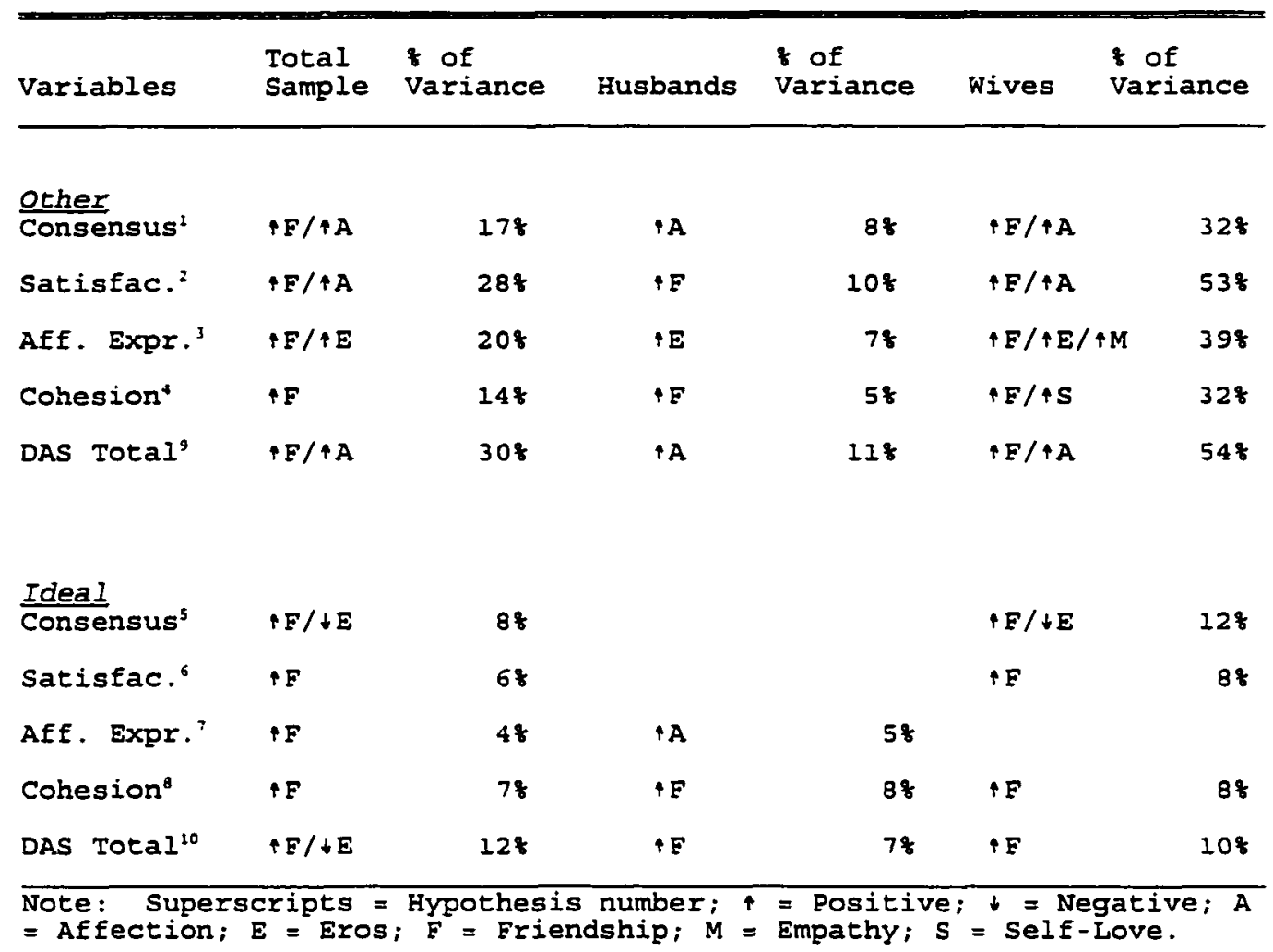


Friendship and Affection together were the best predictors of marital quality. This implies that the attributes of Eriendship (i.e., a peer love, appreciation of common interests, mutual respect for the partner's time, talent, and worth) blend well with the attributes of Affection (i.e., a nurturing love, and unconditional giving and acceptance) in strengthening the quality of the husband/wife relationship. It is suggested then that a stronger marital bond becomes evident when spouses take the time to acknowledge each other's principle worth, engage in mutuajly enjoyable activities, are strong enough to give and take, and are able to show warmth and caring concern for each other. These implications are made from the test of Null Hypothesis 9.

$$
\text { For the four components of marital quality, (1) }
$$
Friendship and Affection combined were the best predictors of both Consensus and Satisfaction, (2) Friendship and Eros together were the best predictors of Affectional Expression, and (3) Friendship alone was the best predictor of Cohesion. These findings were generated from tests of Null Hypotheses I through 4. The appreciation of mutual respect for spouses' individual worth represented by Friendship tends to promote agreement and communication between spouses, commitment to the marriage, willingness to be affectionate, and sharing common activities together. It appears that when one partner is made to feel special as an individual in the relationship by his/her mate, the 
first partner feels more connected to his/her spouse and demonstrates more comradeship in their relationship.

The second research question asked if the relationship between spousal friendship and marital quality is different for husbands and wives. For husbands, overall marital quality was predicted by Affection, and for wives it was predicted by Friendship and Affection combinea. These predictions were stronger for wives than they were Eor husbands. The foregoing observations are made from tests of Null Hypothesis $9 a$ and $9 b$. The stated results for husbands should be weighed, however, in light of the correlation between Friendship and Affection (.551), between Total Marital Adjustment and Affection (.422), and between Total Marital Adjustment and Friendship (.524) (Table 6, p. 78). It may be suggested at this point that Friendship could also be a significant predictor of marital quality for husbands. That is, if Friendship and Affection explain the same portion of variance for husbands, only one variable would be identified as the best subset predictor for them. Therefore, this possibility for husbands will be included in concluding statements.

As discussed in chapter 3 , the relationship qualities suggested by the CRI items may show connections between the Friendship and Affection scales. The Friendship scale suggests respect, camaraderie, commonality, trust, specialness, togetherness, support, appreciation, closeness, and unselfishness. The Affection scale suggests 
care giving, contentment, understanding, need, comfort, kissing, admiration, openness, responsibility, and care receiving. The Friendship scale tends to be feelingoriented and the Affection scale tends to be actionoriented. Both scales tend to imply closeness and value for one's spouse as a person.

When considering Friendship and the four components of marital quality, Friendship predicted Satisfaction and Cohesion for husbands. It was not, however, a strong predictor for them. For wives, (1) Friendship together with Affection predicted Consensus and Satisfaction; (2) Friendship, Eros and Empathy combined predicted Affectional Expression; and (3) Friendship and Self-Love together predicted Cohesion. The strongest combination was Friendship and Affection predicting Satisfaction. These findings are observed from tests of Null Hypothesas la cind Ib through $4 a$ and $4 b$. It is suggested then that Eriendship tends to be a stronger predictor of each of the four components of marital quality for wives than it is for husbands.

Results from the tests of Null Hypotheses 5 through 8 and Null Hypothesis 10 showed that for the entire sample, Friendship was positively related to overall Marital Quality and each of its components for ideal relationships. For both overall Marital Quality and Consensus, Friendship was significant when combined with Eros. For wives rating Ideal relationships, Friendship was found to relate 
positively with Consensus when combined with Eros and by itself for total Marital Quality, Satisfaction, and Cohesion. For husbands rating Ideal relationships, Friendship was found to relate positively to total marital Quality and Cohesion. Percentages of variance explained by Friendship and Eros in ratings of Ideal mates tended to be much lower than other ratings of spouses for the entire sample as well as for husbands and wives separately. This implies that married individuals would still want a friendship bond in an ideal mate, but they are not sensing a strong lack of friendship in their present marriages.

From a comparison of ratings of one's spouse and an ideal mate, it is suggested that married individuals from the entire sample are not necessarily discontent with their present marriages. They tended not to be wishing for significant changes in their partners in order to be fulfilled in their present relationship.

When Friendship was measured alone against the four components of marital adjustment, it was found to predict most strongly the combination of Satisfaction, Affectional Expression, and Cohesion for the entire sample. This implies that being appreciated and respected in a marital bond tends to contribute to commitment to the relationship, intimate expressions, and the sharing of common interests and activities. For wives, this measurement showed that Friendship predicted the same combination of marital adjustment components. However, for husbands, it tended to 
predict Satisfaction but not very strongly. These findings stem from tests of Null Hypotheses 11 and its corresponding sub-hypotheses.

When Friendship for an ideal mate was measured alone against the four components of marital adjustment, it was found to predict Cohesion for the entire sample, however, not very strongly. Wives related Friendship with Satisfaction and husbands related Friendship with Cohesion in ideal relationships. Both of the gender predict:ons, however, were not strong. This suggests that husbands and wives are not feeling deficits in their friendship connection with their mates. These implications are made from tests of NuIl Hypothesis 12 and its zender-related sub-hypotheses.

The results of this study lend some support to research that has suggested that friendship between husbands and wives could be quite important to the growth and development of their marriages (Bustanoby, 1993; Fenel1, 1993; Grotstein, 1989; Lauer \& Lauer, 1986; Lauer et al., 1990; Shain, 1978). Married individuals in the present sample related marital adjustment to the combination of friendship and affection. Bunch (1958) suggested that the most basic principle in building a happy home is love that is founded on friendship. Results for wives tended to support this theory most strongly. Drawing from Adler's (Schultz \& Schultz, 1994) observations of individual uniqueness, findings from this 
study suggest that well adjusted married individuals tend to respect and appreciate their mates' individuality and tend to feel supported by their mates in a similar manner. Since the entire sample related Friendship and Affection combined with marital quality, this suggests that sharing a nurturing, unconditional love tends to facilitate the ability to appreciate the personal worth of one's mate and ultimately contributes to the quality of their marriage. With Bandura's theory of Social Learning (Schultz \& Schultz, 1994) in mind, marriages that relate quality with friendship and affection will have greater potential of providing positive models from which children can pattern their interpersonal behaviors. As children observe these parents respecting each other as individuals, engaging in mutually enjoyable activities, and offering a caring love to each other, children will be vicariously learning how to interact with others in a similar manner. This, in turn, will encourage healthy development of the relationships that children will form as well as each person in those relationships.

The indication that spousal friendship and affection do relate to marital adjustment, and more so for wives, emphasizes the importance of self-development as suggested in Bowen's Family Systems Theory (Goldenberg \& Goldenberg, 1991). People must know what makes them unique in order to know when they are being appreciated for their uniqueness. 
They will also be more capable of recognizing the same in their partners.

Although Erikson (Schultz \& Schultz, 1994) identifies Young Adulthood as the developmental stage for intimate relationships, findings from this study coincide with other studies suggesting that the importance of maintaining those close relationships continues beyond that one particular life phase. This implication is based on the fact that $70.5 \%$ of the individuals in this study ranged from 36 to 65 years of age and reported a positive connection becween a friendship bond with their mates and the quality of their marriages. This finding supports Hoffman's (1991) and Siegel's (1986) assertions that friendship in later life is equally as important as in earlier stages of life.

Duck and Wright (1993) suggested that the separate ways in which men and women express socioemotional concerns are equally valid as genuine manifestations of closeness and caring in a Eriendship. The data from this study reflected the strong value that wives place on spousal friendship, which was not as evident for husbands. However, it is suggested that husbands are interacting in such a way that wives are sensing appreciation and respect from them.

Results of this study found that the majority of participants were above 36 years of age $(79.5 \%)$, were in their first marriage $(74.4 \%)$, had been married at least 20 years $(51.7 \%)$, and had known their mates between 1 and 5 
years prior to marriage $(67 \%)$, with another $18.2 \%$ having known their mates over 5 years prior to marriage. It could be implied that the marital stability reported by these individuals played a significant role in generating the results of the study, especially where friendship is concerned. Shostrom (1975) suggests that friendsin involving interdependence develops between ages 12 to 21 years, and that agape, involving affection and respect, develops during ages 21 years and above. This implies that friendship and affection can be more fully expressed in marital relationships after individuals reach particular developmental milestones.

\section{ConcIusions}

The following conclusions have been generated from the results of this study:

1. Friendship and affection are positively related to marital quality. This suggests that married individuals enjoy being appreciated for their uniqueness. As they also feel cared for and accepted by their spouses, their perception of their marital adjustment tends to increase.

2. Spousal friendship, especially when combined with affection, tends to be more strongly related to marital quality for wives than for husbands. This implies that in quality marriages wives feel (a) they are good friends with their husbands, (b) they and their husbands are a team, (c) they share common interests with their husbands, (d) they 
appreciate their husbands, (e) they trust their husbands, (f) their husbands bring out the best in them, and (g) they are loved in a nurturing, unconditional manner.

3. Affection tends to relate especially well with marital quality for husbands. It is implied then that husbands tend to feel unconditionally accepted and nurtured by their wives in quality husband/wife relationships. Friendship possibly has a more significant relationship with marital quality for husbands than was shown in this study.

4. Wives tend to appreciate being free to express their own uniqueness in their marriages which generates further quality in their bond with their husbands.

5. When husbands and wives are aware of these factors that contribute to marital quality for themselves and their mates, time spent in nurturing these aspects of their relationship is suggested as a valuable marital investment.

6. In cases in which marital quality is low but spouses have a desire to work on improving their marriage, strengthening friendship and affection could bring the relationship to a level at which other areas of concern may be more readily addressed. At a minimum, this would involve searching for common interests, starting to participate in mutually enjoyable activities, identifying ways that appreciation can be shown, and beginning to show not only respect for each other as valuable individuals but 
also beginning to add affection or nurturing into their interactions.

\section{Recommendations}

From the preceding discussion of findings and conclusions generated from this study, several recommendations are presented both for practice and research.

\section{Practice}

1. Implementing a treatment approach for wives geared toward supporting their desire for spousal friendship and affection may have therapeutic benefits. One such benefit may result from wives' increased awareness of her own value of spousal friendship and affection.

2. Implementing a treatment approach to increase husbands' awareness of their relationship behaviors that strengthen their wives' sense of a friendship connection between them. This should include an educational component that alerts husbands to the importance that their mates place on spousal friendship and affection.

3. Implementing a treatment approach to increase wives' awareness of their relationship behaviors that strengthen their husbands' sense of an affectionate bond with them.

4. Clinicians conducting couples' therapy might consider giving couples homework assignments specifically designed to enhance friendship between the two. Since 
results showed friendship to have some bearing on marital adjustment (although most significant for wives), such assignments may begin to increase couples' awareness of spousal friendship and its potential contribution to the quality of their marriage when combined with affection.

5. Clinicians providing premarital counseling might include an assessment of the friendship and affection in the couples' relationships. Alerting them to the benefit these elements offer to marital quality may give them an opportunity to build on present friendship and affection strengths or recognize relationship weaknesses that could limit their marital quality over time.

6. In light of present findings, marriage improvement seminars and workshops would do well to include a segment on spousal friendship, especially when combined with affection.

\section{Research}

1. Replication of this study using a larger sample would test the consistency of findings observed in this research project.

2. Replication of this study with a more extensive ethnic representation would allow ethnic differences concerning Eriendship to be observed.

3. Replication of this study with a larger sampling of geographic locations, age groups, socioeconomic levels, 
and educational levels would allow greater generalization of findings.

4. Replication of this study using a non-church-based population would expand the capacity to generalize findings.

5. Replication of this study with a larger sample would allow for an examination of the relationship between spousal friendship and the length of time mates knew their spouses :-ior to marriage--e.g., those who knew their mates less than one year prior to marriage.

6. A longitudinal study with a larger sample to examine whether spousal friendship increases with the length of time the couple is married.

7. Further investigation of the relationship between friendship and marital quality for husbands will clarify the possibility, as suggested in this study, that a significant relationship exists.

8. Further studies on friendship in various intimate relationships (e.g., unwed dating couples, unwed cohabitating couples) would expand the body of Iiterature on the topic.

9. Longitudinal research would allow observance of the fluctuations in spousal friendship in response to family dynamics over time.

10. Replication of this study with a larger number of matched couples would increase the capacity to make specific couple observations and recommendations. 
11. Development of an instrument dedicated specifically to measuring friendship in intimate relationships would conserve time analyzing and interpreting the data and would provide more focused results. Hopefully, test-taking time requirements would also be reduced. 
APPENDIX

Reproduced with permission of the copyright owner. Further reproduction prohibited without permission. 


\section{APPENDIX A}

\section{CORRESPONDENCE}

Reproduced with permission of the copyright owner. Further reproduction prohibited without permission. 


\title{
CHERRYL ANNE GALLEY
}

\author{
P. O. Box 26 \\ Berrien Springs, MI 49103 \\ (616) $471-6998$ \\ June 14. 1994
}

Dr. James S. Grotstein

522 Dalehurst Avenue

Los Angeles, CA 90024

Dear Dr. Grotstein:

I am a doctoral student presently developing my dissertation proposal for my $\mathrm{Ph} . \mathrm{D}$. degree in Counseling Psychology at Andrews University. Berrien Springs, MI. My topic is, "An Analysis of the Relationship Between Nurturing Spousal Friendship and Marital Quality."

As part of my literature review, I have read your article entitled, "Of Human Bonding and of Human Bondage: The Role of Friendship in Intimacy." In this article you make the point that the importance and the nature of friendship in intimate relations have been insufficiently explained in psychoanalytic literature. Quite similarly, I have discovered that the paucity of research on friendship in intimate relationships still exists.

In this regard, I wanted to share with you the focus of my research project. I would certain appreciate any comments you would care to make and/or any research studies you wouldn't mind recommending. I, too, feel that the importance of friendship is phenomenal and that its unique value in close relationships has been overlooked, undermined, or taken for granted. I am enjoying the challenge that this study is providing and look forward to the forthcoming results.

I appreciate the opportunity to communicate with you and hope that time will allow you to respond. Thank you for your consideration.

Sincerely,

Cherryl A. Galley

cag 


\section{JAMES S. GROTSTEIN. M. D. INCORPORATED 522 DALEHURST AVENUE LOS ANCELES. CALIFORNIA 90024 (310) $276-3456 \cdot \operatorname{FAX}(310) \triangle 84-8075$ PSTCHOANACYSIS}

July 7,1994

Ms. Cherryl Anne Galley

P.O. Box 26

Berrien Springs, MI 49103

Dear Ms. Galley:

Thank you very much for your gracious letter of June 14 th. I am delighted that you are tackling the issue of friendship.

I must tell you that my first awareness of its importance was accidental. I had so many patients who were misusing friendships for analysis in between sessions that I then began to realize that psychoanalysis and psychotherapy have helped us to re-define what friendship really is and what its limitations are, on one hand, and on the other to re-evaluate its importance in a way that has never hitherto been done. It was only then that I began to realize that eriendship is the important ingredient of bonding and attachment (a la Bowlby), and that passionate attachments, love, and other forms of closeness may very well be harmonics variations of friendship as the fundamental cord.

Currently, I am writing a paper on, "Why Oedipus and Not Christ?" In that paper, I am dealing with the concept of covenants. I think that covenants are very important in friendship, as well as in all attachments and relationships. I am reminded of the title of one of Larry McMurtry's novels, Terms of Endearment. That seems to say it all--for friendship and everything else.

Good luck in your project. Please know that I think it is a most worthwhile one. I would love to see a final draft.

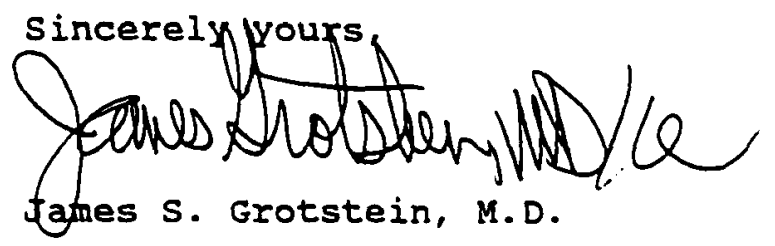

JSG/CC 


\title{
CHERRYL ANNE GALLEY
}

\author{
P. O. Box 785 \\ Reynoldsburg, $\mathrm{OH} 43068$ \\ (614) $863-9558$
}

Dear Pastor

I am grateful for the opportunity I had to talk with you today about my dissertation project. Thank you for ayreeing to provide a mailing list of the intact couples (married couples who are currently living together) from your congregation.

As we discussed, I will call you in a few weeks to coordinate my getting the list from you. I will then mail survey packets to those couples indicated on your list. Once again. responses provided by all participants will be anonymous.

The sample bulletin announcement is attached which I'm asking all churches to print for two weeks. This will allow those couples who do not wish to take part. an opportunity to express those wishes.

I appreciate your willingness to participate in this undertaking. Your cooperation suggests a desire to help today's families become a better place in which to live. I look forward to sharing with you the results of this study at its completion.

Sincerely,

Cherryl A. Galley

cag

Attachment 


\section{SAMPLE BULLETIN ANNOUNCEMENT}

A doctoral student from Andrews University, Berrien Springs, MI, has asked married couples in our church to participate in a research project focused on improving marriage and family life. The church office will provide a mailing list to this student. The student will then mail surveys directly to your homes. Return envelopes will be provided for you to return the completed surveys to the student. If you would prefer not to be contact, please notify the pastor. All responses will be anonymous. Thank you for your help. 


\section{CHERRYL ANNE GALLEY}

P. O. Box 785

Reynoldsburg, OH 43068

Dear Husband and Wife:

Your church pastor has given me permission to send the enclosed materials to you. I am a doctoral student from Andrews University in Berrien Springs, Michigan.

During my course of studies. I have become particularly concerned about not only the large numbers of unhappy families that we see today, but also about ways that families can increase their enjoyment of each other and improve the quality of their family lives. As part of my degree requirements, I am presently involved in conducting dissertation research which focuses on relationships between husbands and wives. This is where I need your help.

Enclosed you will find three questionnaires. I would appreciate it if you would follow the instructions shown at the beginning of each form and fill in the information requested. Each of you should complete your forms separately from your mate. without consulting him or her. Remember that there are no right or wrong answers, only answers that are most accurate for you. Please do not leave any questions unanswered. Allow yourseives 40 to 50 minutes to complete the forms.

I am interested in examining the responses provided by the entire sample, rather than individual couples. Therefore, at least 500 couples will be surveyed. All of your responses will remain anonymous. The numbers that appear in the tope right corners of the forms are necessary in order to keep your responses and your spouses responses together as a team. When the data is analyzed, references will be made to these numbers only, and mailing lists will be destroyed.

This study would be impossible without your participation. Please mail your completed surveys today. A self-addressed, stamped envelope is enclosed for your convenience. Your prompt response will be greatly appreciated.

Results of the study will be provided when the project has been completed. Thank you in advance for your cooperation.

Sincerely,

Cherryl A. Galley

cag 


\title{
CHERRYL ANNE GALLEY
}

\author{
P. O. Box 785 \\ Reynoldsburg, $\mathrm{OH} 43068$
}

Dear Husband:

Thank you for participating in this research project.

In order for your responses to reflect your own thoughts, it is important that you do not discuss the survey questions with your wife until after you both have mailed your completed forms to me in the return envelopes provided. There is a separate return envelope for you in this packet and one for your spouse in her packet.

Do not put your name on the questionnaires. This way, all of your responses will be anonymous. Please remember to answer all questions.

Again. thank you for your help.

Sincerely,

Cherryl A. Galley

cag 


\title{
ChERRYL ANNE GALLEY
}

\author{
P. O. Box 785 \\ Reynoldsburg, $\mathrm{OH} 43068$
}

\section{Dear Wife:}

Thank you for participating in this research project.

In order for your responses to reflect your own thoughts, it is important that you do not discuss the survey questions with your husband until after you both have mailed your completed forms to me in the return envelopes provided. There is a separate return envelope for you in this packet and one for your spouse in his packet.

Do not put your name on the questionnaires. This way, all of your responses will be anonymous. Please rememher to answer all questions.

Again, thank you for your help.

Sincerely,

Cherryl A. Galley

cag 
152

\section{CHERRYL ANNE GALLEY}

P. O.Box 785

Reynoldsburg, $\mathrm{OH} 43068$

Dear Husband and Wife:

Several weeks ago you received a letter from me requesting that each of you complete a set of questionnaires as part of my research project. I am grateful that your pastor allowed me to send these materials to you.

This is just a second request to those individuals who have not yet been able to respond, to please complete and return the questionnaires as promptly as possible.

If you have already returned your materials, please disregard this letter. I certainly appreciate your timely support.

Thank you again for your cooperation and participation. Your church will receive the results of this study at its completion.

Sincerely,

Cherryl A. Galley

cag 
Cherryl Galley

P.O. Box 785

Reynoldsburg, OH 43068

July 11,1995

Dear Ms. Galley:

Thank you for your interest in the Dyadic Adjustment Scale (DAS) by Dr. Graham Spanier.

MHS grants you permission to reprint up to six items of the DAS in the appendix of your dissertation, "An analysis of the relative better nurturing spousal friendship and marital quality". Permission is contingent on your acknowledgment of the items as copyrighted by MHS. The citation should read, "Reproduced by permission of Multi-Health Systems Inc., 908 Niagara Falls Boulevard, North Tonawanda, NY, 14120-2060, (800) 456-3003". MHS further extends this authorization to University Microfilms International for the purposes of reproducing and distributing microfilmed copies of the dissertation.

I trust that this is satisfactory. Should you have any questions or concerns, please do not hesitate to contact me.

Sincerely,

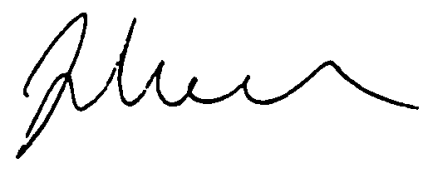

Joanne Morrison

Permissions Officer

In Canada

65 Overlea Blvd., Suite 210

Toronto, Ontario M4H IPI
In the United States

908 Niagara Falls Blvd.

North Tonawanda, NY 14120-2060 
Order Department:

(619) 222-1666

Fax: (619) 226-1666

\section{Cherryl A. Galley}

PO $30 \times 785$

Reynoldsburg, OH 43068

July 12, 1995

Dear Ms. Galley:

Thank you for your recent communication regarding the Caring Relationship Inventory (CRI).

This letter will grant you permission to reproduce five items from the CRI. Appropriate citation must be made and this does not grant permission to bind a copy of the instrument into your thesis,

I look forward to seeing the results of your research and to receiving a copy of your abstract or summary of your results.

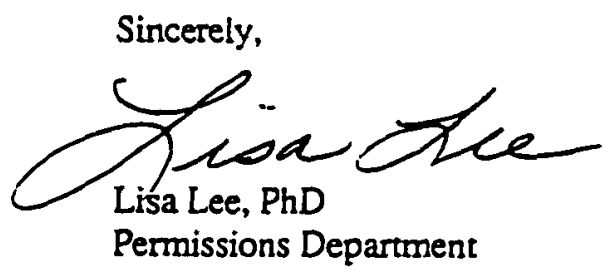



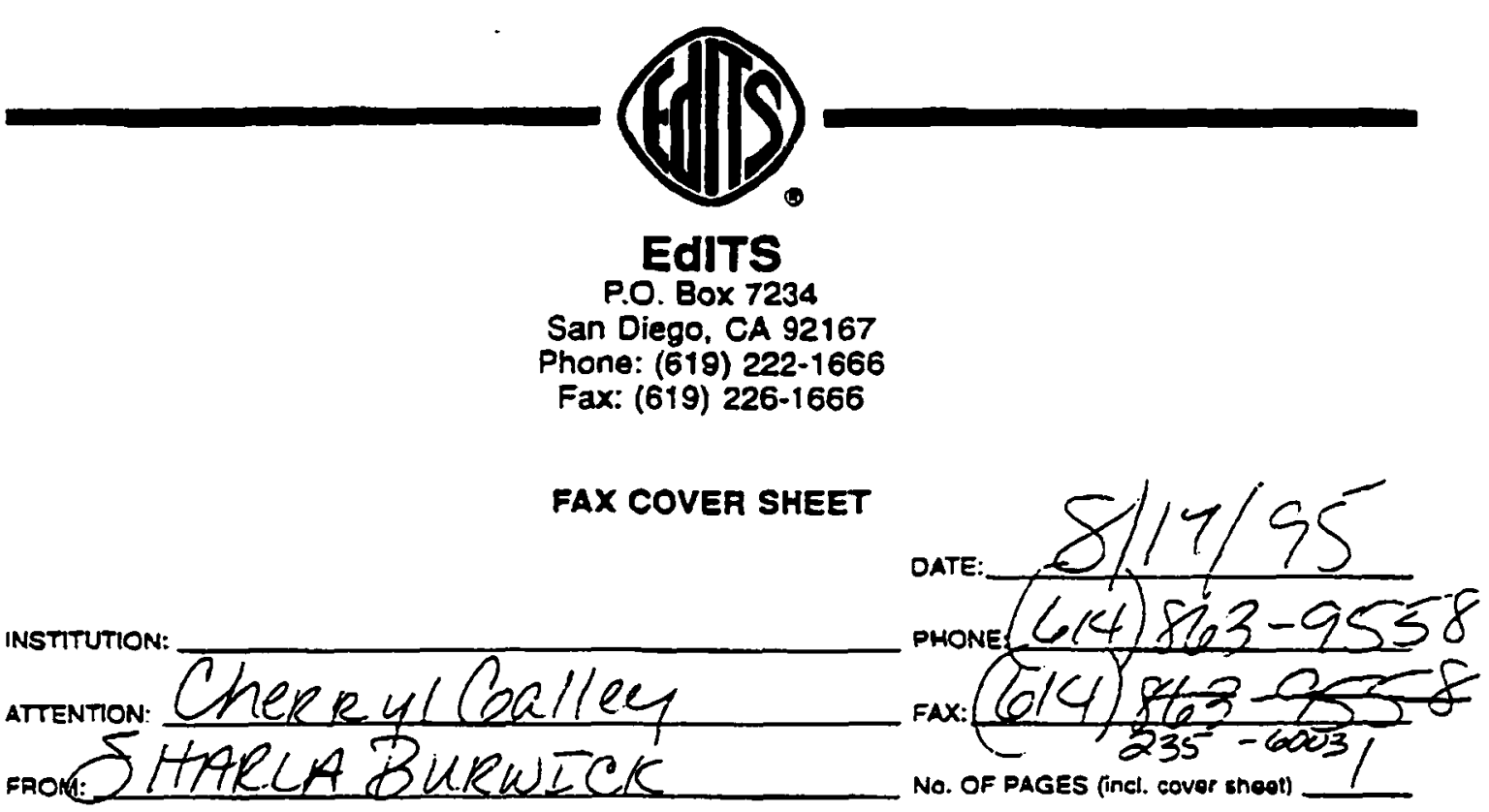

Message

Dear Chergul,

This latter gives you permission to reproduce, in your dissertatzon, a portion of Table 1. "Means,stanciard Deviations and Differences be tween Successqully

Mazriad, Troubled and Divorsed Coupleg," shown on gage 7 of ite Gai ianuai.

As you requested. jis latter gives you permssion to use all of the table

except the "Mean Differences" colunns. Pleasa include the groper jitation

as to source and the pnrase "peproduced lith Permission."

Please feel free to contact me iz you have any questions, or if I can be

of Eurther service.

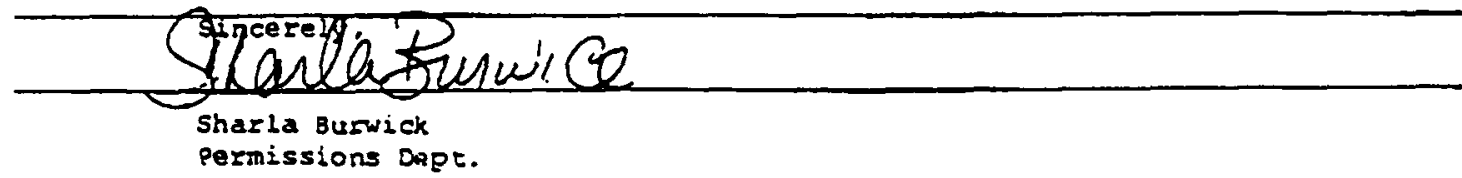

TDTAL P.DI 
APPENDIX B

INSTRUMENTATION

Reproduced with permission of the copyright owner. Further reproduction prohibited without permission. 


\section{DEMOGRAPHIC QUESTIONNAIRE}

Please circle or write in the response that is most appropriate for you.

1. Your sex: Male Female

2. What is your age group?

19 or less $\quad 20-35 \quad 36-50 \quad 51-65 \quad$ Over 65

3. What is your ethnic background?

Asian Black Hispanic White

Other (please specify)

4. How long have you and your present spouse been married?

Less than $1 \mathrm{yr}$. $\quad 1-5 \mathrm{yrs}$.

$11-20$ yrs. Over 20 yrs. over 50 yrs.

5. Which marriage is this for you?

First Second Third Other (please specify)

6. How many children do you have?

7. What are their ages?

8. How many of your children are presently living at home?

9. What are their ages?

10. How long did you know your spouse before the two of you were married?

Less than $1 \mathrm{yr}$. $\quad 1-5 \mathrm{yrs}$ Other (please specify)

11. What is your religious preference?

Catholic

Methodist

Seventh-day Adventist

Lutheran

None

Other (please specify) 


\section{Dyadic Adjustment Scale}

Presented below are six items from the Dyadic Adjustment Scale.

Instructions ask respondents to indicate the approximately extent of agreement or disagreement between themselves and their partner for each item.

1. Handing family finances

3. Religious matters

5. Friends

7. Conventionality (correct or proper behavior)

9. Ways of dealing with parents or in-laws

11. Amount of time spent together

Note: Reproduced by permission of Multi-Health Systems Inc., 908 Niagara Falis Boulevard, North Tanawana, NY, $14120-2060$, (800; 456-3003.

Responses in this section are rated according to the following scale:

Always Agree

Almost Always Agree Occasionally Disagree

Frequently Disagree

Almost Always Disagree

Always Disagree 
Caring Relationship Inventory

The following five items are included in the 16 items that compose the Friendship scale.

All items are "True" or "False" questions.

2. I respect his/her individuality.

11. I have the feeling that we are "buddies" together.

12. I share important common interest with him/her.

48. He/She seems to bring out the best in me.

69. I can be both strong and weak with him/her.

Note: Reproduced with permission. 


\section{APPENDIX C}

DATA

Reproduced with permission of the copyright owner. Further reproduction prohibited without permission. 
DATA FILE FORMAT

\section{Columns}

$1-3$

4

5

11

12

13

14

15

16

17

18

$19-20$

$21-22$

$23-24$

$25-26$

$27-29$

$30-31$

$32-33$

$34-35$

$36-37$

$38-39$

$40-41$

$42-43$

$44-45$

$46-47$

$48-49$

$50-51$

$52-53$

$54-55$

$56-57$
Identification number

Gender

Age group

Ethnic group

Length of marriage

Which marriage

No. of children aged below 6

No. of children aged 6 to 12 (inclusive)

No. of children aged 13 to 21

No. of children aged above 21

No. of children aged below 6 living at home

No. of children aged 6 to 12 living at home

No. of children aged 13 to 21 living at home

No. of children aged above 21 living at home

Time known spouse before marriage

Religious preference

Dyadic Consensus score

Dyadic Satisfaction score

Affectional Expression score

Dyadic Cohesion score

DAS Total score

CRI Affection other score

CRI Friendship Other score

CRI Eros Other score

CRI Empathy Other score

CRI Self Love other score

CRI Deficiency Love Other score

CRI Being Love Other score

CRI Affection Ideal score

CRI Friendship Ideal score

CRI Eros Ideal score

CRI Empathy Ideal score

CRI Self Love Ideal score

CRI Deficiency Love Ideal score

CRI Being Love Ideal score 
101244510002000034463609131041010061207051214151117120618 101144510002000034493810141110911071310041311151116090517 1022345100200020132522041606704140311140608 1032445200020000246247111513514140915130515 103144520002000014553905171161006050807030704070107040007 107234320020000024222303090571003020804020913080713110513 115134510020002024463909161100914101410071110141406151210 117241510004000024473310131031015081210041008140812100508 117141510004000026463407131000811110312100913151116100416 121224321100110024372602050701106111405081013161016130516 122225340000000037413710231111016121614061311161216140713 129234320020001024453506130990712040813031112161111150713 1291443300040000263632040808008090611070411 1311445100020000345147121412410090713060513 131244510002000024574412241371216111610041812161215130518 134124210000000024534310231291414101410041714141017110418 134224210000000024523912221251215111413061713161016120517 136234510002000024454609151151415101610061713151017120717 139134411000100024483607141051311061508031613151414130718 139234411000100024413708110970613031314041310150915130414 143154520000000014574112241341315121109051414151015100616 143244520000000014524108211221212051612041512140617120415 145154510004000024463910171121213111308041612141213130717 147144320103010034383504160941311101512051511130915110316 147234330210021031443204130931206071211031114150913140416 150144510003000134523110231161415171614121614161715141116 150234510003000134514610221291116141312081613161415130717 152124311100110024463906131041215141713091711151417130916 152224312000200034534108131151013111107101613161417130916 1531342202210210245230072211113120515090216141509171303.17 153224220210021024421602130730406021204020911150916120317 154122312000200014584607221330914091412061212140914120314 154224312000200014574405231290915091314051409151014140514 159131510130013024463809141071014091207051613161315130716 159234510130003024383407130920912101209061113161514120916 160134420200020014534112161221116071212031514161115120517 160234420200020014584712231401315101412031614151014120316 167131510020001034473709121051111131311061411151116080318 167231510020001024444210111071313111608041714141017100318 168244510111011014473506181060914011511021213161217100618 179134410000000027474209131111211070911031512131109120316 180124220120002014504109221221515141610071814151016100518 182234510012001124413210100931015101414071613161417110818 187124210000000024453909151081012081511061514141315120916 187220200000000020394108141021015081413041611161112150514 192134313000300024433607070931113071108041412151017140516 1922243130003000244436101210209151214100414 201130400000000000483910181151316111713051713161217130617 216124311100110034524109171191313131612081714151316130717 216224311100110031564209201270915101513051414160917130517 220154510002000024503408081001414101408051614130814090515 223134510000000014494510191231115101313051811151013130618 223234510000000014474611191231316101815071813161017150718 229144510006000124504009141131314081409061507110211050313

Reproduced with permission of the copyright owner. Further reproduction prohibited without permission. 
229254510006000124504208091091216101413031611150816150515 230144420004000024594608181311514111810051814151218090618 230244440004000024554509161250815051311031513161117100418 2321546100030000244938121811712161415100717

2322546100030000245748121713413151316090716 233154510003000014523605141071214081212071610130610090514 246132311210121034454109181131015091411041513151017130417 246232321210121034534611191290713091014051209140710140512 250152610003000017563905231230915111403051608151014030415 271132420110011024504510221271315121612061713151316100717 271232420110011024504112211241014071610061410150915110714 272244430001000024564212191291014081411031510160816120216 2861422300130000245346112113115161016110517

286242220003000034564511211331116121511101511161115120515 2921425100100010245838062312513140314110613

2922425100100010245241092012212151114120616

294122210000000024384203181011013101013071412151016130415 294222210000000024424407211140610101212071210131112100415 298232510030002024564007221251316061513021513161116130516 305242510002000024513910121121112071309051208140714100411 321132210000000024354007170990914121110061214151214110616 321222210000000024504307161161314111310051512141114120415 335154610004000024554312191291416041413041314160414130413 335254610004000024524310211261415101610041614161115110516 336144510002000034473204130960813021108021114161315120716 336244510002000034453507151021114081407041212161314120616 337124210000000024503706171101114071212061114150716100515 337224210000000034534208151181115081208041313160915120615 339134510012001024504010131131115101112061411160914130315 339230500012001020504210171191416101413061514161014140615 3412425100020000243829092009608110411110411

342134420020000014514210201231215111409061513161016100516 342234410000000014513909111101015121103061314151216140617 344124410200020024204306150841215131509061714161017130517 344234410200020024424108161071115121412061612161018130517 357124311100110024423006160941209081008041312161012150515 357224311100110024463107100940812081010041313160916130317 358134510000000024473909191141115111707051614161017120318 358234510000000024504310191221315101611041714151016110318 361154420003000034554212131221116111613061511161016140614 3612544200030000245634121211404130512050316

369143510021001024403207090790911101207071110111411041013 369233510012001024432405080800708071106060811161217120617 370154610003000024473911161130000000000000009150514120117 370254610003000034584512221371215091610041512150914110415 374154610001000027423308100931316151407091707111010091009 374254610001000024503707161101015091412071114150814120315 380154320001000024534310191251114131309071512161416080716 380254320000000024423510110980912131106090910151311040810 381154420002000024564712191341316131510071613161314100716 381243420002000024524412181261216101411051513151016120516 383144510001000013574910231391416101613041614161016130416 383244510001000014655012151421316081713021813160817130218 388132410110011014514107211200000000000000012151115080615 
388234410110011014403307201000911071108051313161316150818 389241510021001034523809141130811091011071212161017080517 393124210000000024474208201171115111306061313161215100615 393224210000000024504410201241415131515081714161516150918 401140500003000020484311111131114131313051713151113110517 401242510003000024603311121161016091514051510160915150515 402144510002000024453108120960611051309061114131215100516 402244510002000024453004160951115111115071014161114140714 403154510004000024383507110911013121404061711091110050612 403254510004000024383303150890609030810020714151116080517 404144510002000024503808121081009111406051312151216120616 405134510020002024524409151201115111412061312151114140615 4052345100200020245245081612110130813120416

422144510003000016383509100921208101209071312080912090712 422244510003000014353607100880914051409021315161014100317 431144420004000014504107161141114081409111613151316110617 4401005000030000305031101810911140611120311

440252520003000034482607060871006131109071212061212060712 4481224101100110245643122113211131011110613

4482224101100110245840101812610130913120414

580222210000000024443805171041415141414091614131316110817 585144510002000024463910151101313091407031714131016080418 585244510002000124484512191241316121511061514161115150616 594132510012001124514209141161315111412051513151115130515 594233510012001124594010141231116081612031412150916140215 5961525100030000244032021408810140511090312

596252510003000024493511171121215071414041512150815160615 597132410010001034454010121070913060909041214141016120416 597232410010001024543509111091216101712051612130814120413 599144510002000034513606111041112011605041413161216120617 599254520002000034433506110950610070809041013140914100415 356234510020001014353108050790904071106041013151115140509 241244510002000025454308161121014071412031511151215130616 464234510002000011504008201181014081313071112150914150712 471234320110011025524410151211116121714061813161317160718 471134310110011025494110131131114091012081613161217130518 472235410400040025564312131241214121615081714161317150817 475134410110011035513610151121216051214041614161015140417 484224312000200025524410171231115081412051712151016140617 516224210000000021484410171191315091315041613150915150517 520154610002000025544111201261012151510081312111214110714 538124210000000025514008151140915071112041213131511111013 538224210000000035494307151141411090911041514151317150817 544134510020002025624611191381315111510051613151015100416 544234510020002025594308191291013091212041611161014130416 552134410020002025474009171131216111411051614161115110417 5522344100200020254843071711511150811060414

554224211000100025524707201261216081613031613161016130416 555144510003000035504109151151214111411061411141014100614 5552445100030000255337071611313141514081116 5652243100000000256446111914014151412130817 473124311000100025503907131091415131507061814161316150718 476234420203020025493504141020712081512041212151515150816 5011305000020000206247111313314161214100616 
501234510002000025594612191361014091512031411160915130415 520254610002000025474010161130914101607061111121114070613 458134410300030025594510211351216121612051713161216120517 460144510002000225564409161251414081412041613150814130516 464132510011000025423906131000812091108071212141016130717 465244510002000025524109161181215051309041413161114100616 476144420203020025463306140991211141108091309150814110414 493134410120012035413307130941112081107041313141214130615 500234510012001025503910211201113131113091311141211120814 508134510021002025342705090750610040907031114161316130717 508234510030002025504008141121114041509021313130714120414 556144220004000035424809211201215081312061512150814120615 556244220002000035494308141141214051313051412150713110614 570234410120012025584511171311314091612041713140916110417 
REFERENCE LIST

Reproduced with permission of the copyright owner. Further reproduction prohibited without permission. 
Ameritech. (1994). Pages plus yellow pages: Columbus and vicinity. Independence, OH: Author.

Adams, J., \& Sprenkle, D. H. (1990). Premarital cohabitation and subsequent marital stability in the United States: A reassessment. Journal of Marriage and the Family, 54, 178-190.

Adler, A. (1946). Understanding human nature. New York: Greenberg.

Aida, Y., \& Falbo, T. (1991). Relationships between marital satisfaction, resources, and power strategies. Sex Roles, 24, 43-56.

Antill, J. K., \& Cotton, S. (1987). Self disclosure between husbands and wives: Its relationship to sex roles and marital happiness. Australian Journal of Psycholooy, 39(1), 11-24.

Barnes, G. M., \& Farrell, M. P. (1992). Parental support and control as predictors of adolescent drinking, delinquency, and related problem behaviors. Journal of Marriage and the Family, 54, 763-776.

Bell, R. A., Daly, J. A., \& Gonzalez, M. C. (1987). Affinity-maintenance in marriage and its relatiurship to women's marital satisfaction. Journal of Marriage and the Family, 49, 445-454.

Berndt, T. J. (1989). Obtaining support from friends during childhood and adolescence. In D. Bell (Ed.), Children's social networks and social supports (pp. 308-331). New York: John Wiley \& Sons.

Broom, B. L. (1994). Impact of marital quality and psychological well-being on parentai sensitivity. Nursing Research, $43(3), 138-143$.

Bullock, J.R. (1992). Children without friends: Who are they and how can teachers help? Childhood Education, $\underline{69}(2), 92-96$. 
Bunch, T. G. (1958). Secrets of a happy marriage. Washington, DC: Review and Herald.

Bustanoby, A. (1993). Can men and women be iust friends? Grand Rapids, MI: Zondervan.

Chassin, L., Pillow, D. R., Curran, P. J., Molina, G. S. G., \& Barrera, M., Jr. (1993). Relation of parental alcoholism to early adolescent substance use: A test of three mediating mechanisms. Journal of Abnormal Psychology, 102, 3-19.

Claes, M., \& Simard, R. (1992). Friendship characteristics of delinquent adolescents. International Journal of Adolescence and Youth, 3, 287-301.

Dailey, D. M. (1979). Adjustment of heterosexual and homosexual couples in pairing relationships: An exploratory study. The Journal of Sex Research, $15(2), 143-157$.

Davis, K. E. (1988). Interparental violence: The children as victims. Issues in Comprehensive Pediatric Nursing, 11, 291-302.

Duck, S., \& Wright, P. H. (1993). Reexamining gender differences in same-gender friendships: A close look at two kinds of data. Sex Roles, 28, 709-727.

Elkins, L. E., \& Peterson, C. (1993). Gender differences in best friendships. Sex Roles, 29(7-8), 497-508.

Erdahl, L., \& Erdahl, C. (1981). Be good to each other: An open letter on marriage. San Francisco: Harper \& Row.

Fenell, D. L. (1993). Characteristics of long-term marriages. Journal of Mental Health Counseling, 15, 446-460.

Fiebert, M. S., \& Wright, K. S. (1989). Midlife Eriendships in an American faculty sample. psychological Reports, 64(3, Pt. 2), 1127-1130.

Fields, D. (1993). Date your mate. In M. Yorkey (Ed.), Growing a healthy marriage (pp. 47-54). Colorado Springs, CO: Focus on the Family.

Fincham, F. D., Garnier, P. C., Gano-Phillips, S. \& \& Osborne, L. N. (1995). Preinteraction expectations, marital satisfaction, and accessibility: A new look at sentiment override. Journal of Family Psychology, g(1), 3-14. 
Fisiloglu, H., \& Lorenzetti, A. F. (1994). The relation of family cohesion to marital adjustment.

Contemporary Family Therapy, 16 (6), 539-552.

Fowers, G. J., \& Olson, D. H. (1993). ENRICH marital satisfaction scale: A brief research and clinical tool. Journal of Family Psychology, I(2), 176-185.

Gaines, S. O. (1994). Exchange of respect-denying behaviors among male-female Eriendships. Journal of Social and Personal Relationships, 11(1), 5-24.

Gettinger, M., Doll, B., \& Salmon, D. (1994). Effects of social problem solving and goal setting, and parent training on children's peer relations. Journal of Applied Developmental Psychology, 15(2), 141-163.

Goldenberg, I., \& Goldenberg, H. (1991). Family therapy: An overview (3rd ed.). Pacific Grove, CA: Brooks/Cole.

Gottman, J. M. (1982). Emotional responsiveness in marital conversations. Journal of Communication, $\underline{32}(3), 108-120$.

Grotstein, J. S. (1989). Of human bonding and of human bondage: The role of friendship in intimacy. Contemporary Psychotherapy Review, 5(1), 5-32.

Hansen, G. L. (1987). The effect of religiosity on factors predicting marital adjustment. Social Psychology Quarterly, 50, 264-269.

Hartshorne, T.S. (1991). The Exiendship life task and family-life satisfaction. Individual Psychology, $\underline{47}(4), 477-481$.

Heaton, T. B., \& Pratt, E. I. (1990). The effects of religious homogamy on marital satisfaction and stability. Journal of Family Issues, 11, 191-207.

Hendrick, C., \& Hendrick, S. (1983). Liking, loving, \& relating. Monterey Park, CA: Brooks/Cole.

Hoffman, R. G. (1991). Companion animals: A therapeutic measure for elderly patients. Journal of Gerontological social work, 18, 195-205.

Honeycutt, J. M. (1993). Marital happiness, divorce status and partner differences in attributions about communication behaviors. Journal of Divorce and Remarriage, 21(1-2), 177-205. 
Hudson, R. L. (1971). Love yourself. In J. A. Petersen (Ed.), The marriage affair: The family counselor (pp. 47-49). Wheaton, IL: Tyndale House.

Johnson, C. L., \& Troll, L. E. (1994). Constraints and facilitators to friendships in late life. Gerontologist, 34(1), 79-87.

Kalter. N. (1987). Long-term effects of divorce on children: A developmental vulnerability model. American Journal of Orthopsychiatry, 57, 587-600.

Kenny, D. A., \& Acitelli, L. K. (1994). Measuring similarity in couples. Journal of Family Psychology, 8 $(4), 417-431$.

Kosch, S. G., \& Reiner, C. A. (1984). The co-therapy relationship: Mutuality, agreement and client outcome. Journal of Contemporary Psychology, 14 (2), 145-157.

Kurdeck, L. A. (1993). Nature and prediction of changes in marital quality for first-time parents and nonparent husbands and wives. Journal of Eamily Psychology, $6(3), 255-265$.

Langis, J., Sabourin, S., Lussier, Y., \& Mathieu, M. (1994). Masculinity, femininity, and marital satisfaction: An examination of theoretical models. Journal of Personality, 62(3), 393-414.

Lauer, J. C., \& Lauer, R. H. (1986). 'Til death do us part: A study and quide to long-term marriage. New York: Harrington Park Press.

Lauer, R. H., Lauer, J. C., \& Kerr, S. T. (1990). The long-term marriage: Perceptions of stability and satisfaction. International Journal of Aging and Human Development, 31(3), 189-195.

Lavee, Y. (1987). Partner understanding and marital happiness: Reestimation of Honeycutt's model. Journal of Marriage and the Family, 49, 939-944.

Lewis, C. S. (1988). The four loves. San Diego: Harcourt Brace.

Malcolm, K. D. (1992). Personal growth in marriage: An Adlerian unilateral marriage enrichment program. Individual Psychology, 48(4), 488-492.

Maslow, A. H. (1954). Motivation and personality. New York: Harper \& Brothers. 
Maslow, A. H. (1968). Toward a psychology of being (2nd ed.). Princeton, NJ: D. Van Nostrand Co.

McGinnis, A. L. (1979). The Eriendship factor: How to get closer to the people you care for. Minneapolis, MN : Augsburg.

Moxley, V., Eggeman, K., \& Schumm, W. R. (1987). An evaluation of the "Recovery of Hope" program. Journal of Divorce, 10, 241-261.

Nelson-Jones, R. (1990). Human relationships: A skilis approach. Pacific Grove, CA: Brooks/Cole.

Newcomb, M. D., \& Rickards, S. (1995). Parent drug-use problems and adult intimate relations: Associations among community samples of young adult women and men. Journal of Counseling Psychology, 42, 141-154.

Olson, D. H. (1983). How effective is marriage preparation? In D. R. Mace (Ed.), prevention in Eamily services: Approaches to Eamily wellness (pp. 65-75). Beverly Hilis: Sage.

Parker, S., \& de Vries, B. (1993). Patterns of Eriendship for women and men in same and cross-sex relationships. Journal of Social and Personal Relationships, $10(4)$, 617-626.

Patterson, B. R., \& Bettini, L.M. (1993). Age, depression, and Eriendship: Development of a general Eriendship inventory. Communication Research Reports, $10(2), 161-170$.

Paul, J., \& Paul, M. (1983). Do I have to give up me to be loved by you? Minneapolis, MN: CompCare.

Pulakos, J. (1989). Young adult relationships: siblings and friends. The Journal of Psychology, 123, 237-244.

Rangell, L. (1963). On friendship. Journal of the American Psychoanalytic Association, 11, 3-54.

Reisman, J. M. (1985). Friendship and its implications for mental health or social competence. Journal of Early Adolescence, $\underline{5}(3), 383-391$.

Renshaw, P. D. \& Brown, P. J. (1993). Loneliness in middle childhood: Concurrent and longitudinal predictors. Child Development, 64, 1271-1284. 
Rhyme, D. (1981). Bases of marital satisfaction among men and women. Journal of Marriage and the Family, $43(4)$, 94I-955.

Rosenthal, H. (1993). Friendship groups: An approach to helping friendless children. Educational psychology in Practice, $9(2), 112-120$.

Russell, R. J. H., \& Wells, P. A. (1994). Personality and quality of marriage. British Journal of Psychology, 85, 161-168.

Satir, V. (1976). Making contact. Millbrae, CA: Celestial Arts.

Schultz, D., \& Schultz, S. E. (1994). Theories of personality (5th ed.). Pacific Grove, CA: Brooks/Cole.

Selman, R. L., \& Selman, A. P. (1979, October). Children's ideas about friendship: A new theory. Psycholooy Today, pp. 71-80, 114 .

Shain, M. (1978). When lovers are Exiends. New York: Bantam Books.

Sharpley, C. F., \& Cross, D. G. (1982). A psychometric evaluation of the Spanier Dyadic Adjustment Scale. Journal of Marriage and the Family, 44, 739-741.

Shostrom, E. L. (1975). Caring relationship inventory manual. San Diego: EdITS.

Shostrom, E. L., Knapp, L. F. , \& Knapp, R. R. (1976). Actualizing therapy: Foundations for a scientific ethic. San Diego, CA: EdITS.

Shulman, S., Seiffge-Krenke, I., \& Dimitrovsky, I. (1994). The functions of pen pals for adolescents. Journal of Psychology, 128(1), 89-100.

Siegel, B. S. (1986). Love, medicine \& miracles: Lessons learned bout self-healing from a surgeon's experience with exceptional patients. New York: Harper \& Row.

Silverman, M. S., \& Urbaniak, L. (1983). Marriage encounter: Characteristics of participants. Counseling and Values, 28(1), 42-51.

Southard, S. (1974). Like the one you love: Intimacy and equality in modern marriage. Philadelphia: Westminster Press. 
Spanier, G. B. (1976). Measuring dyadic adjustment: New scales for assessing the quality of marriage and similar dyads. Journal of Marriage and the Family, 38, 15-28.

Spanier, G. B. (1979). The measurement of marital quality. Journal of Sex \& Marital Therapy, 5 (3), 288300 .

Spanier, G. B. (1989). Dyadic adjustment scale manual. Toronto: Multi-Health systems.

Sprecher, S., \& Duck, S. (1994). Sweet talk: The importance of perceived communication for romantic and friendship attraction experienced during a getacquainted date. Personality and Social Psycholoay Bulletin, 20(4), 391-400.

Tannen, D. $(1990)$. You just don't understand: Women and men in conversation. New York: Ballantine Books.

Terry, D. J., McHugh, T. A., \& Noller, P. (1991). Role dissatisfaction and the decline in marital quality across the transition to parenthood. Australian Journal of Psychology, 43(3), 129-132.

Tesch, S. A. (1983). Review of friendship development across the life span. Human Development, 26, 266-276.

Travis, R. P., \& Travis, P. Y. (1975). The pairing enrichment program: Actualizing the marriage. The Family Coordinator, 24(2), 161-165.

Truant, G. S. (1994). Personality diagnosis and childhood care associated with adult marital quality. Canadian Journal of Psychiatry, 39(5), 269-276.

Tsoi-Hoshmand, L. (1976). Marital therapy: An integrative behavioral-learning model. Journal of Marriage and Family Counseling, $\underline{2}(2), 179-191$.

Tucker, P., \& Aron, A. (1993). Passionate love and marital satisfaction at key transition points in the family life cycle. Journal of Social and Clinical psychology, 12(2), 135-147.

U. S. Bureau of the Census. (1992). Statistical abstracts of the United States: 1992. Washington, DC: Author.

Walker, K. (1994). Men, women, and friendship: what they say, what they do. Gender and Society, 8 (2), 246-265. 
Wallerstein, J. S., \& Blakeslee, S. (1989). Second chances: Men, women, children a decade after divorce. New York: Ticknor \& Fields.

Webster's ninth new collegiate dictionary. (1990). Springfield, MA: Merriam-Webster.

Weiner-Davis, M. (1992). Divorce busting. New York: Fireside.

Willetts-Bloom, M. C., \& Nock, S. I. (1992). The effects of childhood family structure and perceptions of parents' marital happiness on familial aspirations. Journal of Divorce and Remarriage, $18(3-4), 3-23$.

Witmer, J. M., \& Sweeney, T. J. (1992). A holistic model for wellness and prevention over the life span. Journal of Counseling \& Development, 71, 140-148.

Woititz, J. G. (1985). Struggle for intimacy. Pompano Beach, FL: Health Communications.

Wright, H. N. (1994). Marital counseling. Journal of Psychology and Christianity, 13(2), 174-181.

Wright, P. H., Scanlon, M. B. (1991). Gender role orientations and friendship: Some attenuation, but gender differences abound. Sex Roles, 24 $(9,10), 551-$ 566 . 
VITA

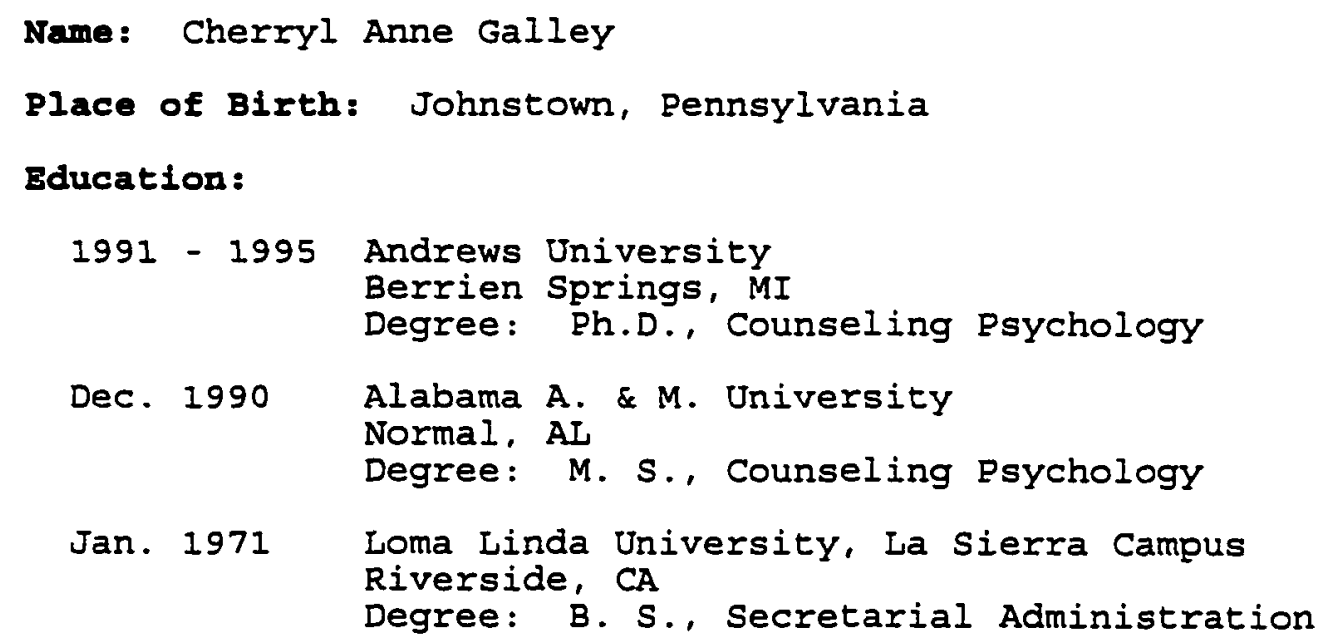

Supervised Clinical Experience:

1994 - Pr. Predoctoral Psychology Intern

INTERACT Behavioral Healthcare Services Inc.

Columbus, $\mathrm{OH}$

1991 - 1994 Practicum student

- Counseling \& Psychological Services Center Andrews University, Berrien Springs, MI

- Jordan/Andrews Counseling Center Jordan College, Benton Harbor, MI

Summer 1990 Practicum student

Huntsville/Madison County Mental Health

Center, Huntsville, AL

\section{Professional Experience:}

1991 - 1994 Graduate Assistant to Elsie Jackson, Ph.D. Assistant Dept. Chair, Andrews University Dept. of Educational \& Counseling Psychology 


\begin{abstract}
1990 - 1991 Counselor
Southeast Adolescent Program

Owens Cross Road, AL

Presentations:

1991

Presentation of Master's Thesis at Annual Conference of the Assn. of Social and

Behavioral Scientists, Nashville, TN

Topic: "An Analysis of Parental Divorce on Self-Esteem, Male-Female Relationships, and Causal Explanations Among Black College students"

1993

Group presentation at East Chapter of the Christian Assoc. for Psychological studies, Inc. (CAPS), Ligonier, PA

Topic: "The Odd Couple: Rural Christian University Sponsors Community College Counseling center"

1994

Group presentation of previous topic at the American Counseling Assoc. Convention, Minneapolis, MN

\section{Professional Membershipa:}

American Counseling Association

American Psychological Association

The Assoc. of Black Psychologists, Central Ohio Chapter The Association of Social and Behavioral Scientists, Inc. Ohio Psychological Association

Pi Lambda Theta
\end{abstract}

